U.S. Department

of Transportation

Nefional nighmoy

Trenfic Safoly

Administration

DOT HS 809021

October 1999

Final Report

\title{
Literature Review on Vehicle Travel Speeds and Pedestrian Injuries
}

This document is available to the public from the National Technical Information Service. Springfield, Virginia 22161. 
This publication is distributed by the U.S. Department of Transportation, National Highway Traffic Safety Administration, in the interest of information exchange. The opinions, findings, and conclusions expressed in this publication are those of the authors and not necessarily those of the Department of Transportation or the National Highway Traffic Safety Administration. The United States Government assumes no liability for its contents or use thereof. If trade or manufacturers' names or products are mentioned, it is because they are considered essential to the object of the publication and should not be construed as an endorsement. The United States Government does not endorse products or manufacturers. 


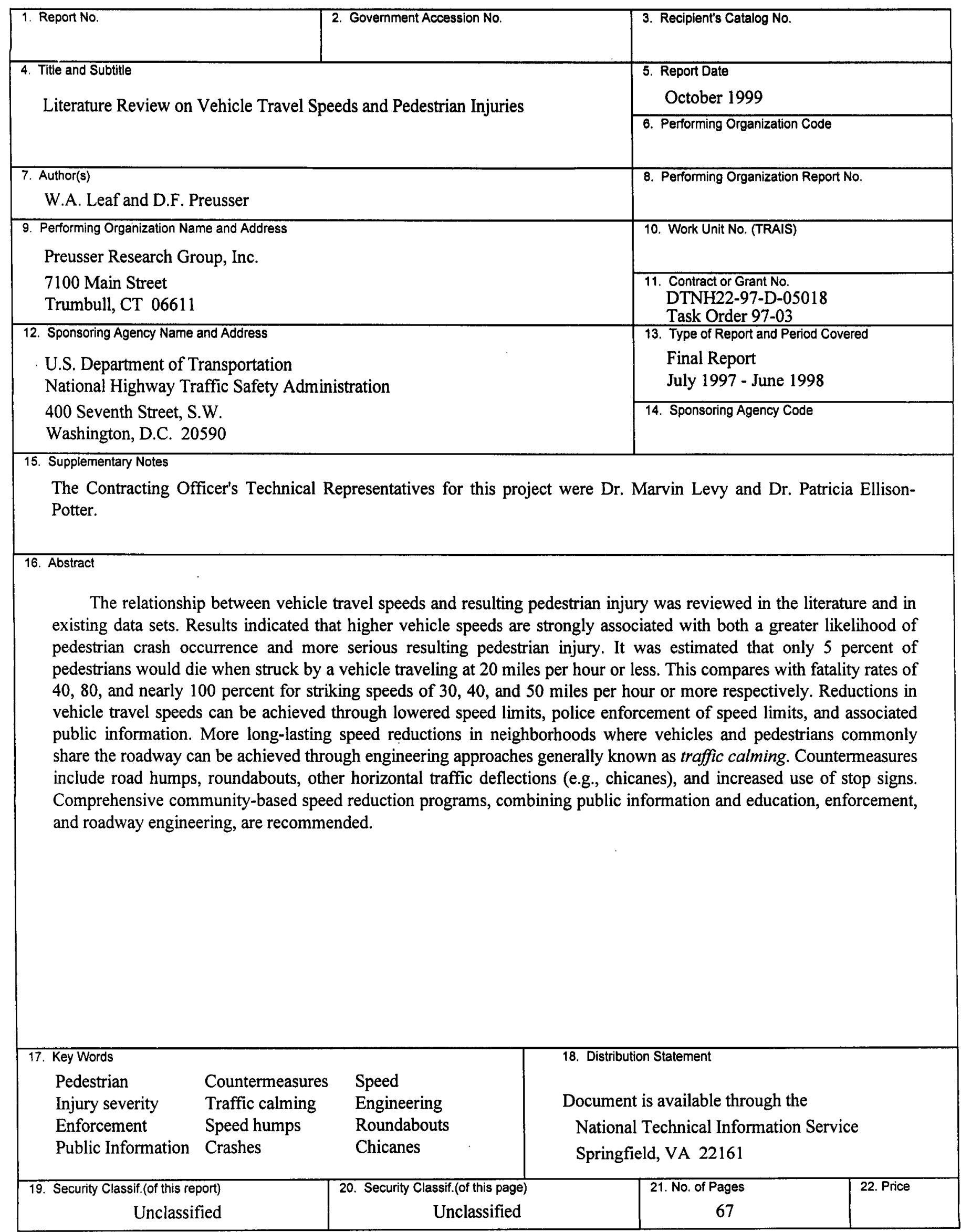


This page intentionally left blank. 
TECHNICAL SUMMARY

\begin{tabular}{l|l}
\hline \hline $\begin{array}{l}\text { CONTRACTOR } \\
\text { Preusser Research Group, Inc. }\end{array}$ & $\begin{array}{l}\text { CONTRACT NUMBER } \\
\text { DTNH22-97-D-05018 } \\
\text { Task Order 97-03 }\end{array}$ \\
\hline $\begin{array}{l}\text { REPORT TITLE } \\
\text { Literature Review on Vehicle Travel Speeds and Pedestrian Injuries }\end{array}$ & REPORT DATE \\
October 1999 \\
\hline REPORT AUTHOR(S) \\
W. A. Leaf and D. F. Preusser
\end{tabular}

\section{Background}

In the U.S. during 1995 , there were about 84,000 pedestrian injuries and 5,585 pedestrian fatalities (NHTSA, 1996), for an overall ratio of 15.0 injured pedestrians for every fatality. This ratio varied substantially as a function of posted speed limits, from 57.1 injuries per fatality on roadways with posted limits of 25 miles per hour or less to just 0.3 injuries per fatality for posted speed limits of $60 \mathrm{mph}$ or higher.

While posted speeds are not necessarily the same as travel speeds or impact speeds, the data clearly suggest a strong relationship between higher vehicle speed and the greater severity of resulting personal injury.

\section{Objectives}

This project had three objectives. First, to reaffirm and quantify the relationship between vehicle speeds and pedestrian crash severities through literature review and data analysis. Second, to describe techniques that have been used for reducing vehicle speeds and review their effectiveness. Third, to synthesize these results into recommendations for countermeasure programs to be tested in this country.

\section{Methods}

American and international literature related to vehicle speeds and crash results and to speed reduction and control strategies was reviewed. Over 600 potentially relevant references were identified. Articles were sought from libraries, authors, and publishers. Sources contacted in the U.S. included the Transportation Research Board (TRB), the Institute of Transportation Engineers (ITE), the Federal Highway Administration (FHWA), and researchers and traffic engineering practitioners. Foreign sources included individual authors and research organizations in Canada, Great Britain, France, Denmark, Austria, Finland, and South Africa. Additional countries represented in the research articles included Australia, Germany, The Netherlands, Greece, Norway, Sweden, Japan, Jordan, and Kuwait. Discussions were held with researchers and practitioners in the U.S. and abroad.

Also, analyses were conducted of existing crash record datasets. Three datasets were studied: NHTSA's General Estimates System (GES), a nationwide probability sample of police-reported crashes,

(Continue on additional pages)

"PREPARED FOR THE DEPARTMENT OF TRANSPORTATION, NATIONAL HIGHWAY TRAFFIC SAFETY ADMINISTRATION UNDER CONTRACT NO. THE OPINIONS FINDINGS, AND CONCLUSIONS EXPRESSED IN THIS PUBLICATION ARE THOSE OF THE AUTHORS AND NOT NECESSARILY THOSE OF THE NATIONAL HIGHWAY TRAFFIC SAFE TY ADMINISTRATION." 
for 1994 - 1996; State of Florida pedestrian crash data for the years 1993 - 1996; and NHTSA's Fatality Analysis Reporting System (FARS) crashes resulting in pedestrian fatalities for the years $1989-1997$. GES and Florida data were analyzed to relate posted speed limits and vehicle travel speeds to injury severities. FARS data were analyzed to identify characteristics of these most serious pedestrian crashes.

\section{Vehicle Speed and Pedestrian Injuries}

\section{Published Studies}

The idea that the faster a striking vehicle is traveling, the more damage is done to a struck pedestrian, has been documented in a number of studies. Pasanen (1992), for example, concluded from three studies relating collision speeds and pedestrian injury severity that about 5 percent of pedestrians would die when struck by a vehicle traveling $20 \mathrm{mph}$, about 40 percent for vehicles traveling $30 \mathrm{mph}$, about 80 percent for vehicles traveling $40 \mathrm{mph}$, and nearly 100 percent for speeds over $50 \mathrm{mph}$.

Pasanen (1993) and Anderson et al. (1997) examined specific crashes and both determined that reducing vehicle speeds would have reduced pedestrian injuries in two ways: by eliminating some crashes altogether, and by reducing injury severities in the others. Wazana et al. (1997), in a metaanalysis, found that higher speed limits were associated with higher risk of injury to child pedestrians in studies in New Zealand and Seattle, Washington. Pitt et al. (1990) examined about 1,000 urban crashes with pedestrians younger than 20 years of age taken from NHTSA's Pedestrian Injury Causation Study (PICS) data. They found that, compared to crashes with vehicle travel speeds of $10-19 \mathrm{mph}$, the risk of serious injury (or death) was 2.1 for speeds of $20-29 \mathrm{mph}, 7.2$ for speeds of $30-39 \mathrm{mph}$, and 30.7 for speeds of $40 \mathrm{mph}$ or more.

In Denmark, national speed limits were lowered several times beginning with the introduction of general speed limits in 1974. Jensen (1998) summarized several studies showing that actual travel speeds came down with each speed limit reduction, and each time pedestrian injuries were reduced in frequency and severity. Numerous additional European studies document the effects of "traffic calming" changes on crash reductions and pedestrian safety.

\section{Empirical Results: Three U.S. Databases}

GES + FARS. The General Estimates System (GES) database is a probability sample of police-reported crashes with all levels of severity. From 1994 through 1996, there were 5,921 pedestrian crashes in the database which involved a total of 6,171 pedestrians. Weighted, this sample projected to a national estimate of 283,828 pedestrians for the three years. GES is the best national estimate of crashes with less-than-fatal injury levels. The Fatality Analysis Reporting System (FARS) is an enumeration of all fatal motor vehicle crashes on public roads in the U.S.; its data on fatal crashes were combined with GES data on non-fatal crashes.

Speed limits were recorded for nearly all of the GES crashes and for 97 percent of the FARS crashes. The distribution of injuries for pedestrians with known injury severity as a function of speed limit is shown in Table 1. Fatalities rose from under two percent of struck pedestrians in crashes where the speed limits were below $25 \mathrm{mph}$ to over 22 percent in crashes with speed limits of $50 \mathrm{mph}$ or more. 
Table 1. Pedestrian injury severity as a function of speed limit.

(FARS (fatals) and GES, 1994-1996; all pedestrians with known injury severity)

\begin{tabular}{|c|c|c|c|c|c|c|c|}
\hline \multirow{2}{*}{$\begin{array}{l}\text { Pedestrian } \\
\text { Injury Severity }\end{array}$} & \multicolumn{6}{|c|}{ Posted Speed Limit } & \multirow[b]{2}{*}{ Total } \\
\hline & $<=20 \mathrm{mph}$ & $25 \mathrm{mph}$ & $30 \mathrm{mph}$ & $35 \mathrm{mph}$ & $40-45 \mathrm{mph}$ & $50+\mathrm{mph}$ & \\
\hline Fatal (K) injury & $1.2 \%$ & $1.8 \%$ & $5.4 \%$ & $4.1 \%$ & $8.6 \%$ & $22.2 \%$ & $5.7^{\circ}$ \\
\hline (A) & $14.6 \%$ & $18.2 \%$ & $23.4 \%$ & $23.4 \%$ & $30.8 \%$ & $26.0 \%$ & \\
\hline tating (B) & $39.9 \%$ & $34.5 \%$ & $32.4 \%$ & $33.7 \%$ & $26.5 \%$ & $19.9 \%$ & $31.7 \%$ \\
\hline Minor $(C)$ or none & $44.3 \%$ & $45.5 \%$ & $38.7 \%$ & $38.8 \%$ & $34.1 \%$ & $31.9 \%$ & $39.7 \%$ \\
\hline Total frequency & 11,564 & 84,948 & 45,672 & 70,810 & 42,521 & 24,013 & 279.528 \\
\hline
\end{tabular}

State of Florida. In Florida in 1993 - 1996, 32,651 of the pedestrians in crashes were in single-vehicle crashes ( 91 percent). For 23,831 of those pedestrians ( 74 percent), estimated travel speeds were provided for the striking vehicles. For those pedestrians, there were 1,550 ( 6 percent) fatalities, 6,414 ( 27 percent) with A (incapacitating) injuries, 9,206 (39 percent) with B (non-incapacitating) injuries, and 6,583 (28 percent) with $\mathrm{C}$ (possible) or no injuries. The proportion of serious injuries and fatalities increased steadily with increasing vehicle speeds (as estimated by the investigating police officer). The distribution is shown in Table 2.

Table 2. Vehicle travel speed and pedestrian injury severity.

(Florida, 1993-1996; pedestrians in single-vehicle crashes)

\begin{tabular}{||l|r|r|r|r|r|r|r||}
\hline & \multicolumn{6}{|c|}{ Travel Speed (Officer Estimates) } & \multirow{2}{*}{ Total } \\
\cline { 2 - 7 } Injury Severity & $1-20 \mathrm{mph}$ & $21-25 \mathrm{mph}$ & $26-30 \mathrm{mph}$ & $31-35 \mathrm{mph}$ & $36-45 \mathrm{mph}$ & $46+\mathrm{mph}$ & \multicolumn{1}{|c|}{ Th } \\
\hline Fatal (K) injury & $1.1 \%$ & $3.7 \%$ & $6.1 \%$ & $12.5 \%$ & $22.4 \%$ & $36.1 \%$ & $6.5 \%$ \\
Incapacitating (A) & $19.4 \%$ & $32.0 \%$ & $35.9 \%$ & $39.3 \%$ & $40.2 \%$ & $33.7 \%$ & $27.0 \%$ \\
Nonincapacitating (B) & $43.8 \%$ & $41.2 \%$ & $36.8 \%$ & $31.6 \%$ & $24.7 \%$ & $20.5 \%$ & $38.8 \%$ \\
Possible inj (C) or none & $35.6 \%$ & $23.0 \%$ & $21.2 \%$ & $16.6 \%$ & $12.7 \%$ & $9.7 \%$ & $27.7 \%$ \\
\hline Total frequency & 13,368 & 1,925 & 2,873 & 2,188 & 2,493 & 906 & 23,753 \\
\hline
\end{tabular}

Younger pedestrians are generally more able to resist serious injury and death, while elderly pedestrians are much more susceptible to more serious consequences as crash victims. Within age groups, fatality rate increases sharply with increasing vehicle speed, as is illustrated in Figure 1. Overall, pedestrians age 65 and older are more than 5 times as likely to die in crashes than pedestrians age 14 or less, and the likelihood of death increases steadily for ages in between. For vehicle travel speeds above $45 \mathrm{mph}$, pedestrians above age 65 die in about 5 of 8 crashes. 
Figure 1. Fatal Injury Rates by Vehicle Speed, by Pedestrian Ages

(Florida, 1993-1996; pedestrians in single-vehicle crashes)

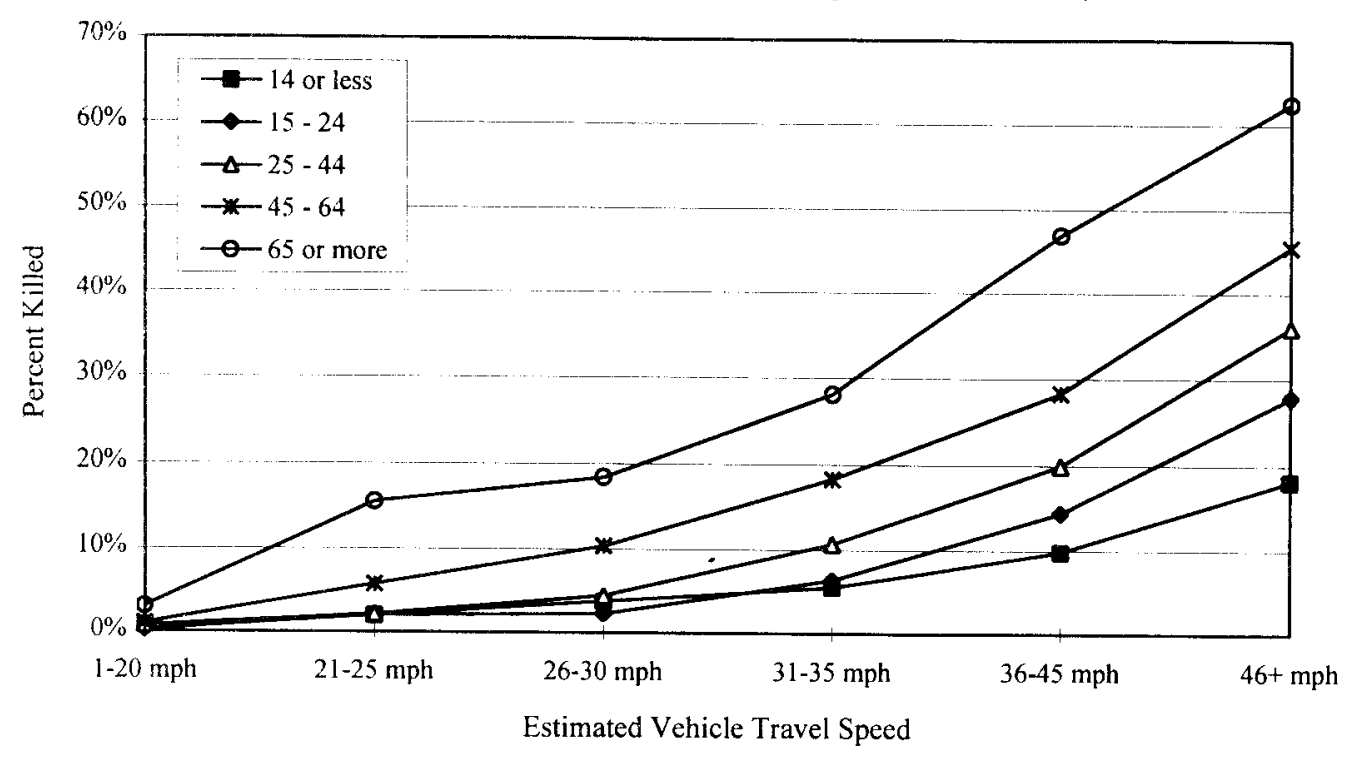

FARS. Pedestrian crashes from the Fatality Analysis Reporting System (FARS) database were examined for crash characteristics as they related to vehicle speeds and speed limits. FARS data for the years 1989 - 1997, including 51,866 pedestrian fatalities in 50,985 crashes, were examined. Conditions associated with significantly more high-speed crashes included: Males; ages 15 - 44; late night; and alcohol.

\section{Speed Control Literature}

In the U.S., speed control has traditionally emphasized reduced speed limits and enforcement on continuous segments of roadway and the installation of stop signs or traffic signals at intersections. Education, in the sense of informing the public of the dangers of excessive speed and the likely presence of police enforcement, has also been used. Increasingly in the U.S., and commonly in Europe, Australia, and Canada, roadways and intersections have seen engineering changes designed to encourage or require drivers to reduce their speeds. Engineering approaches are often given the general title of "traffic calming."

\section{Speed Limits, Enforcement, and Speed}

Lowering speed limits has been used almost universally as the first approach to speed reduction. Many studies (e.g., Jensen, 1998) have observed that reducing speed limits reduces speeds by, at best, about one quarter of the speed limit reduction. Several European studies, which examined the broad implementation of lower urban speed limits, showed that reduced limits could be well accepted by all road users and that modest speed reductions were associated with reduced crashes and injuries. (See Johansson, 1996; Page and Lassarre, 1994; Sammer, 1997; and Pischinger et al., 1995.) 
Police enforcement of speed limits has been a primary tool to reduce speeds, but it is a technique with long-recognized limitations. In general, speed enforcement will have the greatest effects on drivers if it is: 1) believed likely to occur, 2) meaningfully costly to the offenders, 3) associated with driving in general rather than any specific time of day or roadways, and 4) not associated with any specific cues (that show when enforcement is occurring and, by their absence, when enforcement is absent). Most actual enforcement patterns seem transient and localized, and drivers respond by slowing at the point of enforcement during times of enforcement. A summary and recommendations on speed enforcement was published by the National Highway Traffic Safety Administration (Beyond the limits: A law enforcement guide to speed enforcement, 1992).

Overall, speed control by reducing speed limits and providing a mix of enforcement and public information has proven to have modest but real effectiveness. The approach operates through education, to inform and educate drivers that slower speeds are appropriate and reasonable and, through enforcement, to increase the perceived negative consequences of driving fast. One reason that these approaches have only limited success, however, is context: The roadways on which the limits are desired are typically engineered to support higher speeds. Engineering approaches can produce roadways that "naturally" support the desired lower speeds.

\section{Engineering Approaches to Speed Management}

Speed management approaches that include traffic engineering components are often called traffic calming. One definition that is particularly appropriate to the focus of this report was offered by the ITE: "Traffic calming is the combination of mainly physical measures that reduce the negative effects of motor vehicle use, alter driver behavior, and improve conditions for non-motorized street users" (cited in Lockwood, 1997). Perhaps because engineering changes produce visible and often drastic alterations to the driving environment, their success requires the public's understanding, involvement in planning, and approval.

The history of roadway engineering to control vehicle speeds is most extensive with the development of traffic calming in Europe and a few other countries. In the U.S. areas like Seattle, Washington, and Portland, Oregon, have been implementing speed control measures on their roads and at their intersections for nearly 20 years. There, measures have been successful, both in terms of public acceptance and crash and injury reduction. The programs have proceeded slowly, starting at a few sites with well-known crash problems and, with initial success, expanding to more and more sites. Public acceptance has kept up, and new installations can almost always be placed where the public has requested them.

Engineering measures are most practical on moderate and low speed roadways. They are useful at specific high-crash sites, but they also have characteristics that make them suitable for moderatetraffic, moderate-crash sites. Foremost is that, once implemented, they are effective without constant attention (such as enforcement), and they can be placed in areas where regular enforcement could never be afforded. Also, they require little maintenance, so engineering changes can be implemented as funding is available without placing burdens on future budgets.

The kinds of engineering measures used include road humps, horizontal traffic deflections ("chicanes"), roundabouts, and neighborhood and town gateways and entry treatments. Extensive 
research has been accumulated on the design, implementation, and effectiveness of specific measures and area-wide projects, and the research is described in this report.

\section{Recommendations}

Reductions in vehicle speeds can have a very significant influence on pedestrian crashes and injuries. Pedestrians suffer much more serious injuries when struck by high-speed vehicles than when struck by vehicles going more slowly. Also, many pedestrian crashes would be prevented entirely had the vehicles been traveling more slowly, since driver and pedestrian would have had more time to perceive the risk and react.

Programs can be developed to lower overall vehicle speeds in areas where pedestrians and vehicles commonly share the roadway. Key elements to such programs can include regulation (speed limits), signage, public information and education, enforcement, and engineering modifications. A list of possible steps that should be included in these programs includes:

1. Enlisting the involvement of community leaders.

2. Performing problem identification and evaluation, including identifying the boundaries of the dangerous areas, assessing traffic speed characteristics, and quantifying the pedestrian crash and injury problems.

3. With full community participation, recommending specific countermeasures and deployment patterns. Include public information and education, enforcement, and engineering components. Estimate the effects of the changes, not only in terms of pedestrian safety but also in terms of traffic distribution, traffic delays, and changes in the affected neighborhoods. These kinds of projections are important for communities to decide whether to make the changes and to defend their choices.

4. Developing an implementation plan. The full plan should include the PI\&E, enforcement, and engineering components and should include a timetable for coordinating all of the components. The plan should identify public information and education needs to support the project, for the community at large as well as for pedestrians, motorists, and other road users, as well as education and enforcement roles for police departments.

5. Implementing the program.

6. Evaluating the program. Impact measures can include: Changes in speed distributions; diversion of traffic to adjoining areas; delays to motorists; safety effects in affected areas; general public, pedestrian, and motorist knowledge of and reactions to the project; nontraffic benefits such as improved quality of life; and cost-benefit calculations.

Sufficient knowledge and experience is available to begin pilot programs across the country. Pilot sites should be ones with public concerns about speed-related crashes and significant pedestrian injuries. The results of the pilot programs should emphasize how to successfully design and implement the countermeasures, how to raise and maintain informed public support, and what improvements were achieved in public opinions, speed management, and crash and injury reductions. 


\title{
ACKNOWLEDGMENTS
}

During the literature review section of this project, traffic safety professionals from around the world gladly provided copies of their publications, preprints of work in progress, and leads to others resources in the field. Discussions with these people were invariably pleasant and fruitful. Their inputs significantly expanded the scope of materials that could be included in this review. Specific individuals who contributed included:

\author{
Ms. Crysttal Atkins (Oregon) \\ Dr. John Braaksma (Canada) \\ Mr. Ray Brindle (Australia) \\ Mr. Dan Burden (Florida) \\ Dr. Forrest Council (North Carolina) \\ Dr. Andrew Clayton (United Kingdom) \\ Mr. Michael Cynecki (Arizona) \\ Dr. W. Jeffrey Davis (South Carolina) \\ Mr. Mac Elliott (California) \\ Dr. Reid Ewing (Florida) \\ Dr. Hélène Fontaine (France) \\ Dr. Charles Goldenbeld (The Netherlands) \\ Dr. Lene Herrstedt (Denmark) \\ Mr. Ralph Hirsch (Pennsylvania and Germany) \\ Dr. Veli-Pekka Kallberg (Finland) \\ Mr. Todd Litman (Canada) \\ Mr. Archie Mackie (United Kingdom) \\ Mr. Ellis McCoy (Oregon) \\ Mr. James Mundell (Washington) \\ Mr. Fred Offen (United Kingdom) \\ Mr. Rick Pain (District of Columbia) \\ Dr. Eero Pasanen (Finland) \\ Dr. Margaret Peden (South Africa) \\ Mr. Steve Proctor (United Kingdom) \\ Mr. Richard Retting (Virginia) \\ Prof. Gerd Sammer (Austria) \\ Dr. Sheila Sarkar (California) \\ Mr. David Silcock (United Kingdom) \\ Dr. Jane Stutts (North Carolina) \\ Dr. Carol Tan-Esse (Virginia) \\ Dr. Johan van der Spuy (South Africa) \\ Mr. Wim A.J.M van Loosbroek (The Netherlands) \\ Mr. Michael Wallwork (Florida) \\ Mr. Davey Warren (Virginia) \\ Prof. Barry Wellar (Canada) \\ Dr. Charles Zegeer (Virginia) \\ Mr. Sany Zein (Canada)
}




\section{TABLE OF CONTENTS}

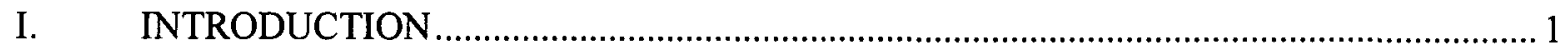

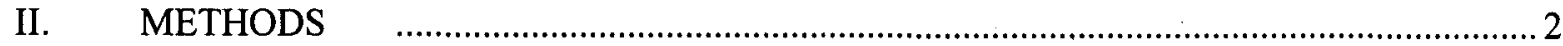

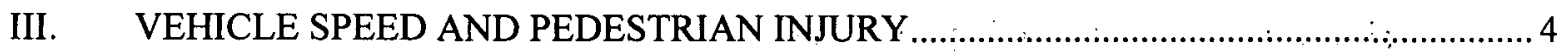

Review of Published Studies .................................................................................. 4

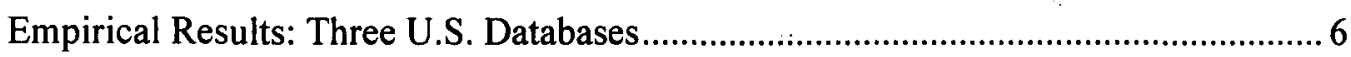

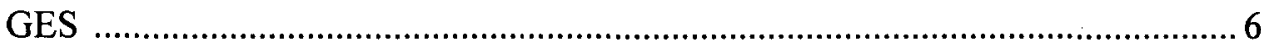

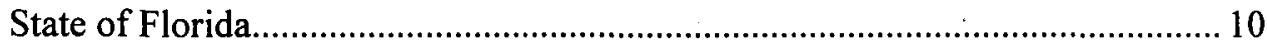

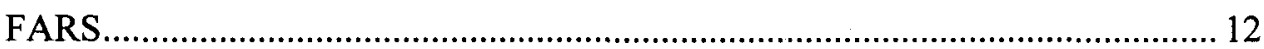

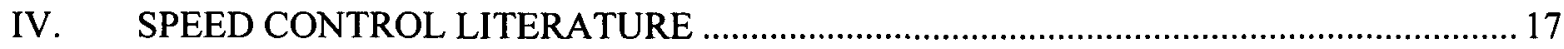

Speed Limits, Enforcement, and Speed.......................................................... 17

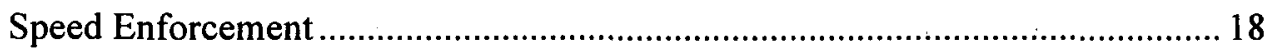

Radar and Laser Detectors ......................................................................... 21

Automated Speed Enforcement (ASE) ........................................................... 22

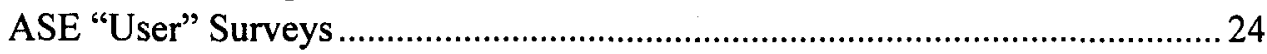

Other Speed Management Approaches............................................................. 24

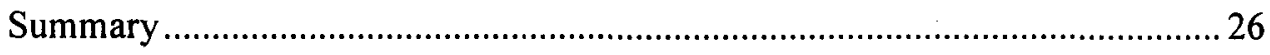

Engineering Approaches to Speed Management................................................. 27

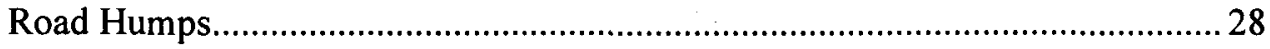

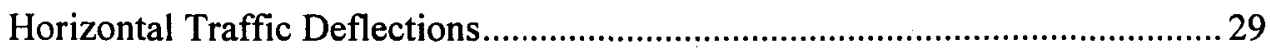

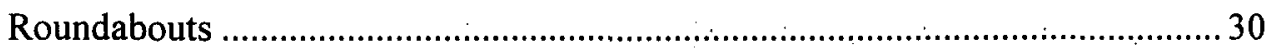

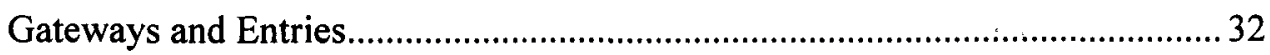

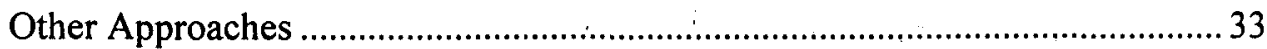

Wide Area Traffic Management........................................................................... 33

Traffic Calming Review Articles................................................................. 34

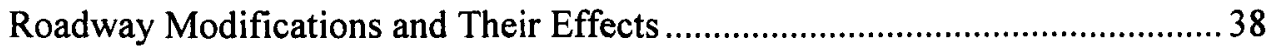

Traffic Management Guidelines .................................................................. 39

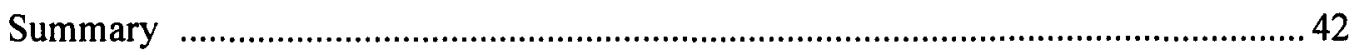

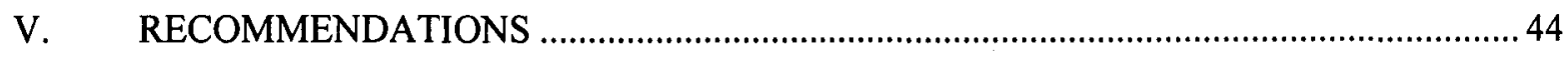

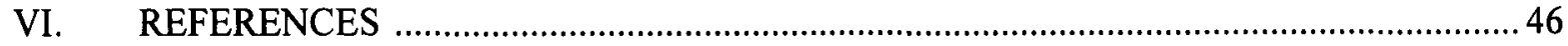




\section{List of Tables}

Table Number $\quad \underline{\text { Page }}$

1. Pedestrian injury severity as a function of pre-crash vehicle travel speed

(GES, 1994-1996; all crashes with known injury severity) .................................... 7

2. Pedestrian injury severity as a function of speed limit (GES, 1994-1996;

all crashes with known injury severity) 7

3. Pedestrian injury severity as a function of speed limit, for vehicles going straight (GES, 1994-1996; all crashes with known injury severity) .................................... 8

4. Distribution of pedestrian crash "covariates" by speed limits (GES, 1994-1996) ............9

5. Vehicle travel speed and pedestrian injury severity (Florida, 1993-1996; pedestrians in single-vehicle crashes) ................................................................................ 10

6. Fatality rates by estimated vehicle travel speeds, by pedestrian age (Florida, 1993-1996; pedestrians in single-vehicle crashes)

7. (Fatality + serious injury) rates by estimated vehicle travel speeds, by pedestrian age (Florida, 1993-1996; pedestrians in single-vehicle crashes)

8. Speed limit and pedestrian injury severity (Florida, 1993-1996; pedestrians in single-vehicle crashes)

9. (Fatality + serious injury) rates by posted speed limits, by pedestrian age (Florida, 1993-1996; pedestrians in single-vehicle crashes)

10. Pedestrian fatalities by vehicle travel speed: By pedestrian age (FARS, 1989-1997; crashes with known striking vehicle speed)

11. Pedestrian fatalities by posted speed limits: By pedestrian age (FARS, 1989-1997; crashes with known speed limits)

12. Distribution of pedestrian crash "covariates" by striking vehicle speed (FARS, 1989-1997; crashes with known striking vehicle speed) 15

13. Distribution of pedestrian crash "covariates" by posted speed limit (FARS, 1989-1997; crashes with known speed limits) 16

\section{List of Figures}

Figure Number

Page

1. Vehicle Impact Speed and Pedestrian Injury Severity (from UK's DoT, e.g., 1993)....... 4

2. Fatal Injury Rates by Vehicle Speed, by Pedestrian Ages (Florida, 1993-1996; pedestrians in single-vehicle crashes) 


\section{INTRODUCTION}

In the U.S. during 1995 , there were about 84,000 pedestrian injuries and 5,585 pedestrian fatalities (NHTSA, 1996), for an overall ratio of 15.0 injured pedestrians for every fatality. This ratio varied substantially as a function of posted speed limits. On roadways with posted limits of 25 miles per hour or less, there were 57.1 injuries for every fatality. The number of injuries per fatality dropped sharply as speed limits rose, showing an increase in typical crash severities. For posted limits of 30 - 35 $\mathrm{mph}$, there were 19.3 injuries per fatality; for posted limits of $40-45 \mathrm{mph}$, there were 10.1 injuries per fatality; the ratio dropped to 3.0 injuries per fatality for posted limits of $50-55 \mathrm{mph}$ and to just 0.3 injuries per fatality for posted speed limits of $60 \mathrm{mph}$ or higher.

While posted speeds are not necessarily the same as travel speeds or impact speeds, the data clearly suggest a strong relationship between speed and the severity of resulting personal injury. Several foreign studies suggest that lowered speeds result in less severe pedestrian injuries and fewer injuries and fatalities - both through reduced collision intensity and through reduced numbers of collisions (slowermoving motorists can avoid entirely crashes that would have occurred if they were driving faster).

Although there is some U.S. literature available, most of the available literature on the relationship between speed, pedestrian crashes, and resulting injuries is from other countries. The foreign literature has not been organized into one data set, nor has it been reviewed from the point of view of applicability to the U.S.

Moreover, there remain the questions of how to reduce speeds and how to do it cost effectively. Techniques include reducing speed limits, increasing police enforcement, and re-engineering streets to make traffic move more slowly. The measures can be taken city-wide, in selected neighborhoods, or at selected times of the day.

This project had three objectives. First, to reaffirm and quantify the relationship between vehicle speeds and pedestrian crash severities through literature review and data analysis. Second, to describe techniques that have been used for reducing vehicle speeds and review their effectiveness. Third, to synthesize these results into recommendations for countermeasure programs to be tested in this country.

The results of the project are presented in the following four sections:

II. Methods used in the crash data analyses and in the literature acquisition and review.

III. Vehicle Speed and Pedestrian Injury, a brief review of the literature relating vehicle speeds to injury severity and a review of U.S. crash data from the General Estimates System (GES) and from the Fatality Analysis Reporting System (FARS), as well as data from the state of Florida, which records vehicle travel speeds on their crash reports.

IV. Speed Control Literature, divided into three broad topics: speed management including legislation, enforcement, and education; specific engineering techniques used to control speed, and general engineering approaches including traffic calming and other wide-area approaches.

V. Recommendations, for countermeasure approaches likely to be effective in this country. 


\section{METHODS}

The work on this project consisted of two distinct efforts, each with its own methodology.

First, analyses were conducted of existing crash record datasets. Three datasets were studied:

1. The General Estimates System (GES) is a nationwide probability sample of police-reported crashes on trafficways with all levels of severity (fatalities, injuries, and property damage only). GES is part of NHTSA's National Automotive Sampling System (NASS). Each crash in the GES database is weighted based on its probability of having been sampled, and the combined weighted crash data form estimates of national crash figures.

For these analyses, data from the years 1994 - 1996 were included. In those years, there were 6,171 pedestrians in 5,921 sampled crashes which, when weighted to account for sampling probability, represented an estimated 283,828 crash-involved pedestrians - nearly 95,000 per year - from 273,440 crashes.

2. State of Florida pedestrian crash data for the years 1993 - 1996 were obtained and analyzed. Florida data were selected because they included vehicle travel speeds for a large proportion of the crashes and because Florida has a relatively large population and, therefore, a large number of crashes. Statewide data are collected from police crash reports, which are filed whenever there is a personal injury or when alcohol use is suspected or an involved vehicle must be towed from the scene. There were 36,016 pedestrians involved in reported crashes for those years. In order to make the connection between vehicle speed and injury as directly as possible, only crashes involving one vehicle were retained for analysis. These included 32,651 pedestrians, nearly 91 percent of the total.

3. Data from NHTSA's Fatality Analysis Reporting System (FARS) were examined for the years 1992 - 1996. The FARS database is an enumeration of all crashes on roads open to the public that result in the death of a vehicle occupant or a nonmotorist within 30 days of the crash. In those years, there were 27,934 pedestrian fatalities resulting from 27,450 crashes.

The purposes of these analyses were to relate pedestrian injury levels to striking vehicle speeds and to identify risk factors associated with higher-speed crashes. Two measures of striking vehicle speeds were used. The first, speeds estimated by the investigating officers, would be expected to be generally accurate, but they were present for relatively few crashes. The second, posted speed limits, were almost universally available, but they would likely be only general indications of actual speeds. These limitations allow valid general conclusions about the relationship of speed to injuries and crash conditions, but they prohibit deriving precise relationships.

While pre-crash vehicle speeds are very relevant to the conditions under which crashes occur, they are one step removed from the injury-causing event. Prior to the crash itself, the striking vehicle often, or usually, reduces its speed somewhat from its travel speed, either to perform a maneuver such as a turn or in an attempt to avoid or minimize the crash itself. Thus it was not possible to derive precise relationships between impact speeds and injury levels.

The primary method of analysis was based on crosstabulations, relating posted speed limits or, where available, vehicle travel speeds to injury severities. Because the likelihood of injury depends on the pedestrian's age - most dramatically, older pedestrians are much more likely to be fatally injured analyses were repeated for different pedestrian age groups. 
It was also of interest to examine the relationship of other variables to the distribution of pedestrian injury severities. For the GES data, injury severity distributions were tabulated for pedestrian, crash, and vehicle characteristics. Also, general tabulations of the distribution of FARS fatalities across levels of pedestrian, crash, and vehicle characteristics were made.

The second major effort reported here was the review of literature related to vehicle speeds and crash results and to speed reduction and control strategies. There were three major steps involved.

First, searches of automated transportation reference databases available through the Transportation Research Board (TRB) were performed. The purpose was to identify relevant references articles, books, and research papers - from around the world. Searches were made in three databases: TRIS (Transportation Research Information Services), with 310,000 records covering transportationrelated publications from the U.S.; TRANSDOC, with 40,000 records on the social sciences of transportation published in European and associated countries; and IRRD (International Road Research Documentation), with 285,000 records covering all aspects of road research internationally. Two main searches were conducted: Articles on pedestrian fatalities in general, from 1992 on, and articles referencing pedestrian fatalities and vehicle rates of speed for all years. The first search yielded 271 possible "hits," and the second yielded 384. Other, more specialized, searches yielded another 20 or so references. Search results included article abstracts or summaries and names and addresses of publishers. The search results were combined with books, articles, and reports already in our possession.

Second, numerous articles were sought, from libraries, authors, and publishers. Contacts were initiated to acquire specific documents identified from the database search, and we also used the contacts to request other reports related to pedestrian safety and vehicle speed control. Sources contacted included, in the U.S., TRB, the Institute of Transportation Engineers (ITE), the Federal Highway Administration (FHWA), and researchers and traffic engineering practitioners. Foreign sources included individual authors and research organizations in Canada, Great Britain, France, Denmark, Austria, Finland, and South Africa. Additional countries represented in the research articles included Australia, Germany, The Netherlands, Greece, Norway, Sweden, Japan, Jordan, and Kuwait.

Third, discussions were held with researchers and practitioners in the U.S. and abroad. The discussions provided insights into research and applications programs, and in many cases the sources provided otherwise unpublished or interim materials. 


\section{VEHICLE SPEED AND PEDESTRIAN INJURY}

The first part of this chapter reviews published studies relating vehicle speed to pedestrian injury severity. The second part presents analyses of three databases for the empirical relationship between speed limits and vehicle speeds and pedestrian injuries. The analyses also review other characteristics of the crashes and their relationship to vehicle speeds and pedestrian injury severities.

\section{Review of Published Studies}

The idea that the faster a striking vehicle is traveling, the more damage is done to a struck pedestrian, is almost too obvious to require proof. Yet the relationship has been documented in a number of studies. Pasanen (1992) reviewed three studies relating collision speeds and pedestrian injury severity, finding their results quite consistent and that the probability of pedestrian death reached nearly $100 \%$ for speeds over $80 \mathrm{~km} / \mathrm{h}(50 \mathrm{mph})$. Modeling the data from Ashton (1982), Pasanen estimated that about 5 percent of pedestrians would die when struck by a vehicle traveling $20 \mathrm{mph}$. The pedestrian fatality percentage would rise to about 40 percent for vehicles traveling $30 \mathrm{mph}$, about 80 percent for vehicles traveling $40 \mathrm{mph}$, and nearly 100 percent for speeds over $50 \mathrm{mph}$.

Numbers comparable to these are cited in a number of other references. For example, in the UK Department of Transport ${ }^{1}$ Traffic Advisory Leaflet $7 / 93$ (TAU, 1993), figures quoted are, for $20 \mathrm{mph}$ impact speeds: 5 percent death, 65 percent injured, and 30 percent uninjured; for $30 \mathrm{mph}$ impact speeds: 45 percent death, 50 percent injured, and 5 percent uninjured; for $40 \mathrm{mph}$ impact speeds: 85 percent death and 15 percent injured. The UK DoT values are illustrated in Figure 1.

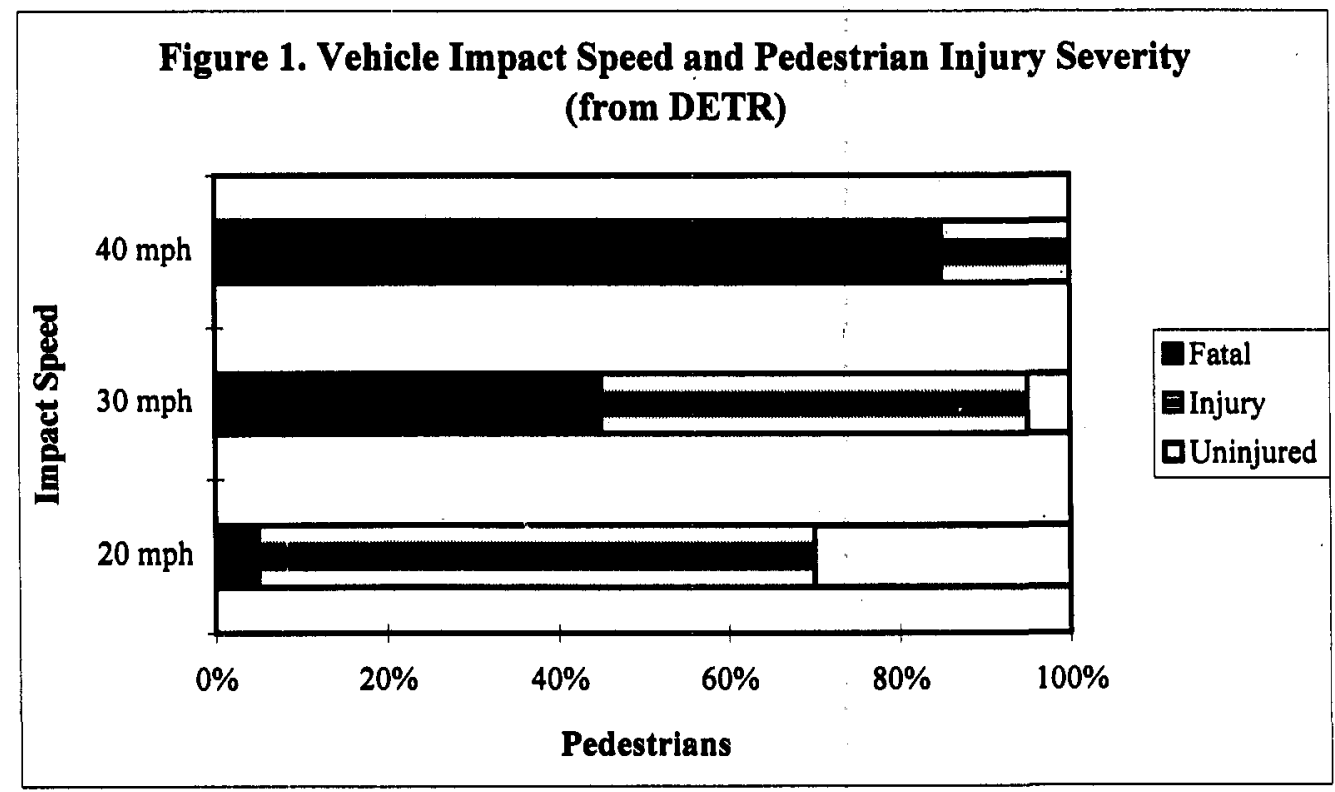

${ }^{1}$ In the UK, the Department of Transport (DoT) became part of the Department of Environment, Transport, and the Regions (DETR) in mid-1997. 
In a separate effort, Pasanen (1993) took advantage of an intersection videotape surveillance system to examine ten pedestrian accidents in Helsinki. The speed of approaching vehicles ranged from $18 \mathrm{~km} / \mathrm{h}(11 \mathrm{mph})$ to $62 \mathrm{~km} / \mathrm{h}(39 \mathrm{mph})$, and Pasanen calculated the average probability of death as 0.16 . Pasanen estimated that reducing approach speeds to a maximum of $40 \mathrm{~km} / \mathrm{h}(25 \mathrm{mph})$, which would have slowed the vehicles in six of the crashes, would have eliminated two of the crashes entirely and reduced the estimated average probability of death to only 0.055 . Pasanen also noted that all of the crashes occurred between pedestrians and free-moving vehicles, i.e., ones not part of and constrained by a queue of vehicles.

Anderson et al. (1997) projected the effects of lowered vehicle travel speeds in 176 fatal pedestrian crashes occurring in $60 \mathrm{~km} / \mathrm{h}(37 \mathrm{mph})$ zones in Adelaide, Australia. In the actual crashes, impact speeds ranged from less than $10 \mathrm{~km} / \mathrm{h}(6 \mathrm{mph})$ to about $100 \mathrm{~km} / \mathrm{h}(62 \mathrm{mph})$, with a median of about $55 \mathrm{~km} / \mathrm{h}$ ( $34 \mathrm{mph}$ ). Projected savings in fatalities ranged from 13 percent, assuming that all drivers obeyed the existing speed limit, to 48 percent, assuming all drivers traveled $10 \mathrm{~km} / \mathrm{h}(6 \mathrm{mph})$ slower. Anderson et al. also developed curves relating probability of fatal injury with vehicle impact speed, based on data from the Interdisciplinary Working Group for Accident Mechanics (1986) and Walz et al. (1983). Anderson's curve showed about 5 percent of pedestrians would die if struck by a vehicle at 25 $\mathrm{km} / \mathrm{h}(16 \mathrm{mph})$, about 25 percent if struck at $40 \mathrm{~km} / \mathrm{h}(25 \mathrm{mph})$, and about 80 percent if struck at $50 \mathrm{~km} / \mathrm{h}$ (31 mph). Although the curve is a bit higher at lower speeds than Pasanen's estimates, the general patterns are in quite good agreement.

Wazana et al. (1997) reviewed articles identifying risk factors for child pedestrian injuries. Two studies showed that higher speed limits were associated with higher risk of injury to child pedestrians. In New Zealand, Roberts et al. (1995) found an odds ratio of 3.22 for injuries on $40-49 \mathrm{~km} / \mathrm{h}$ (25-30 mph) roads vs. roads with lower limits, and in the Seattle area Mueller et al. (1990) found odds ratios of 3.2 for child pedestrian injuries in $45-55 \mathrm{~km} / \mathrm{h}(28-34 \mathrm{mph})$ zones and 6.0 for roads with limits above $64 \mathrm{~km} / \mathrm{h}$ (40 mph) (vs. roads with speed limits below $40 \mathrm{~km} / \mathrm{h}(25 \mathrm{mph})$ ).

Pitt et al. (1990) found a strong relationship between vehicle speed and pedestrian injury when they reexamined NHTSA's Pedestrian Injury Causation Study (PICS) data, which was developed by investigative teams in five U.S. cities that examined police-reported pedestrian crashes between September 1977 and March 1980. Looking only at about 1,000 urban crashes with pedestrians younger than 20 years of age, Pitt examined cases based on fatality or Injury Severity Scores (ISS) of 16 or higher ("serious" injuries). Compared to vehicle travel speeds of 10-19 mph, the risk of serious injury (or death) was 2.1 for speeds of $20-29 \mathrm{mph}, 7.2$ for speeds of $30-39 \mathrm{mph}$, and 30.7 for speeds of $40 \mathrm{mph}$ or more. A similar positive relationship was seen when injury severity was compared with posted speed limits, though it was weaker.

Harruff et al. (1997), by contrast, found no relationship between severity of injury and vehicle speed. However, they were looking only at fatalities in an urban area, and their indicators of speed were posted speed limit, which were not related with injury patterns, and roadway type. For the latter, pedestrians killed on thoroughfares (major roads) showed somewhat more serious injuries. Without a full range of injury levels, though, and with only indirect indicators of vehicle speed, the negative finding is not surprising and does not necessarily contradict the other findings.

In Denmark, general speed limits were introduced in 1974. They resulted in reductions of average vehicle speeds of $6 \mathrm{~km} / \mathrm{h}(4 \mathrm{mph})$ and speed standard deviations by $3 \mathrm{~km} / \mathrm{h}(1.9 \mathrm{mph})$, and pedestrian crashes (of all severities) dropped by 25 percent. In 1985, the urban speed limit was lowered from $60 \mathrm{~km} / \mathrm{h}(37 \mathrm{mph})$ to $50 \mathrm{~km} / \mathrm{h}(31 \mathrm{mph})$, and average speeds dropped by about $2-3 \mathrm{~km} / \mathrm{h}(1.2-1.9$ $\mathrm{mph}$ ). At the same time, pedestrian fatalities dropped by 31 percent, serious injuries by 4 percent, and 
slight injuries by 9 percent. For all reported pedestrian crashes between 1986 and 1995, pedestrian injury severity distributions were plotted by speed limits. Results ranged from no fatalities $(20 \mathrm{~km} / \mathrm{h}(12 \mathrm{mph})$ or less) to 5 percent fatalities $(50 \mathrm{~km} / \mathrm{h}(31 \mathrm{mph})), 20$ percent fatalities $(80 \mathrm{~km} / \mathrm{h}(50 \mathrm{mph}))$, and 35 percent fatalities $(110 \mathrm{~km} / \mathrm{h}(68 \mathrm{mph}))$. The probability of a fatality as a function of speed limit showed much less variability than the probabilities cited above as functions of actual vehicle speed. This suggests that, even for high vehicle travel speeds, enough speed can be reduced to bring most collisions into survivable-speed areas. It may also be that the impacts are often less than full head-on, which would reduce the severity of the impact and thus the injury. (All results cited in Jensen, 1998.)

Numerous additional European studies exist on the effects of "traffic calming" changes on crash reductions and pedestrian safety. They are reviewed in Chapter IV.

\section{Empirical Results: Three U.S. Databases}

\section{GES}

The General Estimates System (GES) database is a probability sample of police-reported crashes with all levels of severity ( $\mathrm{K}$ (fatal), A (incapacitating), B (non-incapacitating), and $\mathrm{C}$ (minor) injuries as well as property damage only). Each crash in the GES database is weighted based on its probability of having been sampled, with these weights used to make national crash estimates. In the years 1994 through 1996, there were 5,921 pedestrian crashes in the database which involved a total of 6,171 pedestrians. Weighted, the crashes represent projected national figures of 273,440 crashes involving 283,828 pedestrians (across all three years). The projected totals include 9,546 fatalities $^{2}, 64,076 \mathrm{~A}$-level injuries, 88,700 B-level injuries, 96,162 C-level injuries, 14,935 uninjured, and 10,409 (3.7 percent) injuries of unknown severity.

GES results are reported without statistical significance testing. Although most of the results are based on crosstabulation distributions, the values in the cells are not raw frequencies but are projected frequencies based on a small number of actual cases and case-by-case weights. Tests of statistical significance require techniques such as those in the SUDAAN@ software programs (Shah et al., 1995), which were not available for this analysis.

The GES database includes the variable of vehicle speed, which provides the strongest evidence of the relationship between injury severity and speed. The results are shown in Table 1. Relatively few of the struck pedestrians were killed when the vehicle's pre-crash travel speed was $35 \mathrm{mph}$ or lower, but vehicles traveling at $36-45 \mathrm{mph}$ killed about 16 percent of the pedestrians and vehicles traveling at 46 mph or above killed about 35 percent of the pedestrians.

Note that the speed value is for pre-crash motion, which will only be a rough estimate of the true impact speed. In most cases, the reported speed refers to the vehicle's speed on approach to the crash. If the driver was able to attempt evasive or stopping maneuvers, the actual impact speed could have been considerably slower.

Although actual vehicle speeds are the most important values for relating injuries to speeds, they are missing for more than three-fourths ( 77 percent) of all the crashes in GES. (Travel speeds were more

\footnotetext{
${ }^{2}$ Values for fatalities are estimates reflective of GES methodology and sampling and are not intended to match actual counts of fatalities as reported in the Fatality Analysis Reporting System (FARS) enumeration.
} 
likely to have been recorded for fatality or A-injury crashes.) Additional analyses based on posted speed limits, which were known for nearly all reported crashes, were conducted. Posted speed limits are less accurate indicators of the travel speeds of vehicles in pedestrian crashes, but knowing them for nearly all crashes makes such analyses a useful complement to analyses based on estimated travel speeds.

Table 1. Pedestrian injury severity as a function of pre-crash vehicle travel speed.

(GES, 1994-1996; all crashes with known injury severity)

\begin{tabular}{|l|r|r|r|r|r|r|r||}
\hline Pedestrian & \multicolumn{5}{|c|}{ Pre-Crash Vehicle Travel Speed } & \multirow{2}{*}{ Total } \\
\cline { 2 - 7 } Injury Severity & $<=20 \mathrm{mph}$ & $21-25 \mathrm{mph}$ & $26-30 \mathrm{mph}$ & $31-35 \mathrm{mph}$ & $36-45 \mathrm{mph}$ & $46+\mathrm{mph}$ & T6ra. \\
\hline \hline Fatal (K) injury & $1.0 \%$ & $2.9 \%$ & $2.8 \%$ & $4.9 \%$ & $16.2 \%$ & $35.2 \%$ & $6.0 \%$ \\
Incapacitating (A) & $32.5 \%$ & $40.9 \%$ & $47.1 \%$ & $47.3 \%$ & $44.9 \%$ & $38.2 \%$ & $38.9 \%$ \\
Nonincapacitating (B) & $36.2 \%$ & $34.5 \%$ & $27.3 \%$ & $29.2 \%$ & $18.1 \%$ & $18.2 \%$ & $30.6 \%$ \\
Minor (C) or none & $30.3 \%$ & $21.7 \%$ & $22.8 \%$ & $18.6 \%$ & $20.7 \%$ & $8.4 \%$ & $24.5 \%$ \\
\hline Total frequency & 28,699 & 7,000 & 7,566 & 7,126 & 8,413 & 3,791 & 62,595 \\
\hline
\end{tabular}

For tabulations based on posted speed limits, data were combined from GES, for all injury levels below fatality, and FARS, for fatalities. In GES, posted speed limits were known for 99.9 percent of the cases, and in FARS, posted speed limits were known for 97 percent of the cases. While GES is the best national estimate of numbers of crashes producing non-fatal results, FARS is a direct count of all crashes producing fatalities.

Table 2 shows the distribution of injuries for pedestrians with known injury severity as a function of speed limit. The relationships are similar to those seen for actual travel speeds, but they show less drastic swings. For the lowest speed limits, just over one percent of struck pedestrians were killed. At speed limits of $50 \mathrm{mph}$ or higher, 22.2 percent of the pedestrians struck were killed. In addition, the percentage of seriously injured pedestrians rose, from 15 percent (for speed limits up to $20 \mathrm{mph}$ ) to 31 percent and 26 percent (for speed limits of $40-45 \mathrm{mph}$ and $50+\mathrm{mph}$, respectively).

Table 2. Pedestrian injury severity as a function of speed limit.

(FARS (fatals) and GES, 1994-1996; all pedestrians with known injury severity)

\begin{tabular}{||l|r|r|r|r|r|r|r||}
\hline Pedestrian & \multicolumn{6}{|c|}{ Posted Speed Limit } & \multirow{2}{*}{ Total } \\
\cline { 2 - 8 } Injury Severity & $<=20 \mathrm{mph}$ & $25 \mathrm{mph}$ & $30 \mathrm{mph}$ & $35 \mathrm{mph}$ & $40-45 \mathrm{mph}$ & $50+\mathrm{mph}$ & \multicolumn{1}{|c|}{ Tot } \\
\hline Fatal (K) injury & $1.2 \%$ & $1.8 \%$ & $5.4 \%$ & $4.1 \%$ & $8.6 \%$ & $22.2 \%$ & $5.7 \%$ \\
Incapacitating (A) & $14.6 \%$ & $18.2 \%$ & $23.4 \%$ & $23.4 \%$ & $30.8 \%$ & $26.0 \%$ & $22.8 \%$ \\
Nonincapacitating (B) & $39.9 \%$ & $34.5 \%$ & $32.4 \%$ & $33.7 \%$ & $26.5 \%$ & $19.9 \%$ & $31.7 \%$ \\
Minor (C) or none & $44.3 \%$ & $45.5 \%$ & $38.7 \%$ & $38.8 \%$ & $34.1 \%$ & $31.9 \%$ & $39.7 \%$ \\
\hline Total frequency & 11,564 & 84,948 & 45,672 & $70 ; 810$ & 42,521 & 24,013 & 279,528 \\
\hline
\end{tabular}

One problem with simply using speed limit as an indication of true speed is that it doesn't take into account the vehicle's action. Vehicles that are turning, or backing, or already slowing in traffic, would have their speed controlled more by the maneuver than the speed limit. For all GES crashes, only 74 percent of drivers were going straight; nearly 15 percent were turning, 3 percent were backing, 3 percent were slowing in their lanes, and about 5 percent were performing some other action. Drivers going straight ranged from 69 percent at speed limits of $20 \mathrm{mph}$ or less to nearly 80 percent for speed limits of $40 \mathrm{mph}$ or more.

Table 3 examines the relationship between pedestrian injury and speed limits for crashes in which the vehicle was coded as going straight ahead. Overall, the proportion of fatally or seriously injured pedestrians was slightly higher than in Table 2. Also, the distribution of injury levels was somewhat more varied over speed limit. Fatalities increased from less than 2 percent for speed limits of $25 \mathrm{mph}$ or less to $5-6$ percent at speed limits of $30-35 \mathrm{mph}$, nearly 10 percent at $40-45 \mathrm{mph}$ and to 24 
percent at $50 \mathrm{mph}$ or higher. The proportion of non-incapacitating injuries, minor injuries, and no injuries decreased steadily with increasing speed limits.

Table 3. Pedestrian injury severity as a function of speed limit.

(FARS (fatals) + GES, 1994-1996; crashes with vehicles going straight and known injury severity)

\begin{tabular}{|l|r|r|r|r|r|r|r||}
\hline Pedestrian & \multicolumn{6}{|c|}{ Posted Speed Limit } & \multirow{2}{*}{ Total } \\
\cline { 2 - 8 } Injury Severity & $<=20 \mathrm{mph}$ & $25 \mathrm{mph}$ & $30 \mathrm{mph}$ & $35 \mathrm{mph}$ & $40-45 \mathrm{mph}$ & $50+\mathrm{mph}$ & T. \\
\hline Fatal (K) injury & $1.0 \%$ & $1.9 \%$ & $6.2 \%$ & $4.9 \%$ & $9.8 \%$ & $24.1 \%$ & $6.6 \%$ \\
Incapacitating (A) & $17.3 \%$ & $20.2 \%$ & $25.9 \%$ & $27.2 \%$ & $34.6 \%$ & $27.0 \%$ & $25.7 \%$ \\
Nonincapacitating (B) & $39.1 \%$ & $37.7 \%$ & $32.9 \%$ & $33.2 \%$ & $25.9 \%$ & $20.1 \%$ & $32.3 \%$ \\
Minor (C) or none & $42.6 \%$ & $40.2 \%$ & $35.0 \%$ & $34.8 \%$ & $29.7 \%$ & $28.7 \%$ & $35.3 \%$ \\
\hline Total frequency & 7,934 & 60,374 & 31,807 & 52,411 & 33,625 & 18,811 & 204,962 \\
\hline
\end{tabular}

\section{Related Crash Descriptors}

Roads with different speed limits occur in different kinds of areas and attract different mixes of pedestrians and vehicles. To explore the way in which other crash descriptors might be related to pedestrian injury severity and speed limits, the distribution of different variables across speed limits was examined. The results are summarized in Table 4. Moderate differences are seen for most variables. (For example, males were struck somewhat more often on higher speed roads, and weekend crashes also occurred somewhat more often on higher speed roads.) Larger differences included:

- Young pedestrians ( 0 - 14 years old) were much more likely to be struck on roads with speed limits up to $25 \mathrm{mph}$, much less likely to be struck on roads with speed limits of $40 \mathrm{mph}$ or more.

- High speed roads $(50+\mathrm{mph})$ were most often the site of late night (midnight and later) crashes; 40 - 45 mph roads saw more late evening crashes ( 8 p.m. - midnight) than ones at other times; and the lowest-speed roads were more likely to be the sites of midday crashes.

- Not-in-road crashes (ones on shoulders, medians, roadsides, etc.) were much more likely on roads with the highest speed limits.

- Smaller roadways (including two-lane halves of divided highways) more often had very low or very high speed limits.

- Intersections with traffic signals most often had moderate speed limits (25-45 mph); most of the high-speed-limit crashes were not at intersections.

- About twice the proportion of bad-weather crashes occurred on roads with speed limits of 50 mph or more, as compared to good-weather crashes.

- The most rural areas had more of the roads with highest and the lowest speed limits.

- Large striking vehicles, including buses and tractor-trailers, were more often found on the highest speed roads and less often on the roads with very low speed limits.

- Few turning vehicles were on roadways with speed limits of $50 \mathrm{mph}$ or more, but a very large number of backing vehicles were on such roads. 
Table 4. Distribution of pedestrian crash "covariates" by speed limits (GES, 1994-1996).

\begin{tabular}{|c|c|c|c|c|c|c|c|c|}
\hline & \multicolumn{6}{|c|}{ Sneed Limit } & \multirow{2}{*}{$\begin{array}{c}\begin{array}{c}\text { Row } \\
\text { Total } \\
\mathrm{N}=283,413\end{array} \\
\end{array}$} \\
\hline & & $\begin{array}{c}<=20 \mathrm{mph} \\
\mathrm{N}=11.484)\end{array}$ & $\begin{array}{c}25 \mathrm{mph} \\
(\mathrm{N}=89.794)\end{array}$ & $\begin{array}{c}30 \mathrm{mph} \\
\mathrm{N}=45.202)\end{array}$ & $\begin{array}{c}35 \mathrm{mph} \\
N=72.265)\end{array}$ & $\begin{array}{l}40-45 \mathrm{mph} \\
\mathrm{N}=42.522)\end{array}$ & $\begin{array}{c}50+\mathrm{mph} \\
\mathrm{N}=22.146)\end{array}$ & \\
\hline Sex & & $\begin{array}{r}4.3 \% \\
3.7 \% \\
\end{array}$ & $\begin{array}{r}29.9 \% \\
34.2 \% \\
\end{array}$ & $\begin{array}{l}15.4 \% \\
16.7 \% \\
\end{array}$ & $\begin{array}{r}25.5 \% \\
25.5 \% \\
\end{array}$ & $\begin{array}{l}16.2 \% \\
13.3 \% \\
\end{array}$ & $\begin{array}{r}8.7 \% \\
6.6 \% \\
\end{array}$ & $\begin{array}{l}58.3 \% \\
41.7 \% \\
\end{array}$ \\
\hline Age & $\begin{array}{l}0-14 \\
15-24 \\
25-44 \\
45-64 \\
65 \text { or older } \ldots . . .- \\
\text { Unknown }\end{array}$ & $\begin{array}{l}5.6 \% \\
4.5 \% \\
3.0 \% \\
3.2 \% \\
-2.3 \% \\
2.9 \% \\
\end{array}$ & $\begin{array}{l}40.5 \% \\
31.8 \% \\
23.7 \% \\
27.9 \% \\
-26.3 \% \\
38.9 \% \\
\end{array}$ & $\begin{array}{l}16.8 \% \\
14.7 \% \\
17.4 \% \\
15.5 \% \\
14.0 \% \\
11.0 \%\end{array}$ & $\begin{array}{l}22.2 \% \\
22.6 \% \\
29.7 \% \\
26.5 \% \\
29.1 \% \\
25.0 \% \\
\end{array}$ & $\begin{array}{l}10.7 \% \\
17.7 \% \\
16.3 \% \\
17.8 \% \\
19.8 \% \\
10.0 \%\end{array}$ & $\begin{array}{r}4.1 \% \\
8.6 \% \\
10.0 \% \\
9.1 \% \\
8.6 \% \\
12.1 \% \\
\end{array}$ & $\begin{array}{r}30.5 \% \\
18.0 \% \\
26.8 \% \\
12.2 \% \\
-8.0 \% \\
4.4 \% \\
\end{array}$ \\
\hline Day & $\begin{array}{l}\text { Weekday } \\
\text { Saturday-Sunday }\end{array}$ & $\begin{array}{l}4.4 \% \\
3.1 \% \\
\end{array}$ & $\begin{array}{l}31.2 \% \\
33.2 \% \\
\end{array}$ & $\begin{array}{l}16.0 \% \\
15.7 \% \\
\end{array}$ & $\begin{array}{l}25.9 \% \\
24.3 \% \\
\end{array}$ & $\begin{array}{l}14.9 \% \\
15.3 \%\end{array}$ & $\begin{array}{l}7.6 \% \\
8.4 \% \\
\end{array}$ & $\begin{array}{l}74.8 \% \\
25.2 \%\end{array}$ \\
\hline Time & $\begin{array}{l}\text { Midnite-5:59 am } \\
6: 00-9: 59 \mathrm{am} \\
10: 00 \mathrm{am}-3: 59 \mathrm{pm} \\
4: 00-7: 59 \mathrm{pm} \\
8: 00-11: 59 \mathrm{pm}\end{array}$ & $\begin{array}{l}2.8 \% \\
2.3 \% \\
6.4 \% \\
3.3 \% \\
3.1 \% \\
\end{array}$ & \begin{tabular}{l|}
$24.0 \%$ \\
$35.1 \%$ \\
$32.2 \%$ \\
$34.2 \%$ \\
$26.0 \%$ \\
\end{tabular} & $\begin{array}{l}17.9 \% \\
15.6 \% \\
14.1 \% \\
16.8 \% \\
17.3 \% \\
\end{array}$ & \begin{tabular}{l|}
$24.0 \%$ \\
$24.2 \%$ \\
$27.4 \%$ \\
$25.6 \%$ \\
$23.4 \%$ \\
\end{tabular} & $\begin{array}{l}13.3 \% \\
14.2 \% \\
13.4 \% \\
14.2 \% \\
20.8 \% \\
\end{array}$ & $\begin{array}{r}18.1 \% \\
8.6 \% \\
6.5 \% \\
5.9 \% \\
9.5 \% \\
\end{array}$ & $\begin{array}{r}6.4 \% \\
13.8 \% \\
30.9 \% \\
32.2 \% \\
16.7 \% \\
\end{array}$ \\
\hline Location & $\begin{array}{l}\text { Dadway } \\
\text { other }\end{array}$ & $\begin{array}{l}4.0 \% \\
5.5 \% \\
\end{array}$ & $\begin{array}{l}31.9 \% \\
28.0 \% \\
\end{array}$ & $\begin{array}{l}16.0 \% \\
15.2 \% \\
\end{array}$ & $\begin{array}{l}26.3 \% \\
12.5 \% \\
\end{array}$ & $\begin{array}{l}15.3 \% \\
10.8 \% \\
\end{array}$ & $\begin{array}{r}6.5 \% \\
28.1 \% \\
\end{array}$ & $\begin{array}{r}94.0 \% \\
6.0 \% \\
\end{array}$ \\
\hline $\begin{array}{l}\text { Roadway } \\
\text { Width }\end{array}$ & $\begin{array}{l}2 \text { lanes or } 1 \\
3 \text { or } 4 \text { lanes } \\
5+\text { lanes. } \\
\text { Unknown }\end{array}$ & $\begin{array}{r}5.2 \% \\
1.6 \% \\
1.5 \% \\
4.6 \% \\
\end{array}$ & $\begin{array}{r}33.3 \% \\
12.1 \% \\
-4.8 \% \\
42.3 \% \\
\end{array}$ & $\begin{array}{r}14.6 \% \\
16.3 \% \\
-12.7 \% \\
17.3 \% \\
\end{array}$ & $\begin{array}{r}19.5 \% \\
38.2 \% \\
-43.5 \% \\
22.0 \% \\
\end{array}$ & $\begin{array}{r}14.6 \% \\
23.9 \% \\
33.4 \% \\
8.9 \% \\
\end{array}$ & $\begin{array}{r}12.8 \% \\
8.0 \% \\
-4.0 \% \\
4.9 \% \\
\end{array}$ & $\begin{array}{r}31.6 \% \\
16.1 \% \\
-7.8 \% \\
44.5 \% \\
\end{array}$ \\
\hline $\begin{array}{l}\text { Intersec- } \\
\text { tion } \mathrm{Y} / \mathrm{N} \\
\text { and } \\
\text { Traffic } \\
\text { Control }\end{array}$ & $\begin{array}{l}\text { Intsctn-no control } \\
\text { RYG signal } \\
\text { Stop/yield/etc. } \\
\text { Non-intersection } \\
\text { Other/Unknown }\end{array}$ & $\begin{array}{r}5.6 \% \\
1.1 \% \\
5.2 \% \\
4.4 \% \\
7.0 \% \\
\end{array}$ & $\begin{array}{l}33.2 \% \\
24.7 \% \\
47.9 \% \\
-31.6 \% \\
32.1 \% \\
\end{array}$ & $\begin{array}{l}13.6 \% \\
20.7 \% \\
11.7 \% \\
-15.3 \% \\
21.8 \% \\
\end{array}$ & $\begin{array}{r}28.8 \% \\
37.9 \% \\
22.8 \% \\
-20.7 \% \\
29.6 \% \\
\end{array}$ & $\begin{array}{r}13.9 \% \\
14.6 \% \\
8.5 \% \\
16.6 \% \\
3.5 \% \\
\end{array}$ & $\begin{array}{r}5.1 \% \\
0.9 \% \\
3.9 \% \\
.1 .4 \% \\
6.0 \% \\
\end{array}$ & $\begin{array}{r}15.5 \% \\
18.8 \% \\
6.8 \% \\
-56.8 \% \\
2.1 \% \\
\end{array}$ \\
\hline Weather & $\begin{array}{l}\text { No adverse } \\
\text { Rain } \\
\text { All other (incl unk) }\end{array}$ & $\begin{array}{l}4.1 \% \\
2.2 \% \\
7.7 \% \\
\end{array}$ & $\begin{array}{l}32.0 \% \\
30.2 \% \\
26.0 \% \\
\end{array}$ & $\begin{array}{l}16.0 \% \\
15.2 \% \\
18.3 \% \\
\end{array}$ & $\begin{array}{l}25.8 \% \\
24.3 \% \\
20.0 \% \\
\end{array}$ & $\begin{array}{l}15.0 \% \\
15.5 \% \\
13.7 \% \\
\end{array}$ & $\begin{array}{r}7.1 \% \\
12.6 \% \\
14.4 \% \\
\end{array}$ & $\begin{array}{r}87.7 \% \\
9.6 \% \\
2.7 \% \\
\end{array}$ \\
\hline Area & $\begin{array}{l}\text { Urban } \\
10 \% \text { rural } \\
20 \%-30 \% \text { rural } \\
40 \% \text { or more rural }\end{array}$ & $\begin{array}{l}2.9 \% \\
4.4 \% \\
4.8 \% \\
7.5 \% \\
\end{array}$ & $\begin{array}{l}33.1 \% \\
33.0 \% \\
35.7 \% \\
18.4 \%\end{array}$ & $\begin{array}{l}18.1 \% \\
17.6 \% \\
10.5 \% \\
12.3 \%\end{array}$ & $\begin{array}{l}31.3 \% \\
17.1 \% \\
17.7 \% \\
21.2 \% \\
\end{array}$ & $\begin{array}{l}10.6 \% \\
22.2 \% \\
20.8 \% \\
17.6 \%\end{array}$ & $\begin{array}{r}4.0 \% \\
5.8 \% \\
10.4 \% \\
23.0 \% \\
\end{array}$ & $\begin{array}{l}54.7 \% \\
14.8 \% \\
17.8 \% \\
12.6 \%\end{array}$ \\
\hline Light & $\begin{array}{l}\text { Daylight } \\
\text { Dark } \\
\text { Dark, lighted } \\
\text { Dawn or dusk }\end{array}$ & $\begin{array}{l}4.9 \% \\
1.2 \% \\
3.1 \% \\
3.5 \% \\
\end{array}$ & $\begin{array}{l}36.2 \% \\
16.7 \% \\
25.1 \% \\
33.7 \% \\
\end{array}$ & $\begin{array}{r}15.1 \% \\
8.3 \% \\
20.3 \% \\
21.6 \% \\
\end{array}$ & $\begin{array}{l}25.7 \% \\
15.2 \% \\
29.5 \% \\
23.7 \% \\
\end{array}$ & $\begin{array}{l}12.5 \% \\
31.1 \% \\
16.0 \% \\
11.3 \%\end{array}$ & $\begin{array}{r}5.6 \% \\
27.5 \% \\
6.0 \% \\
6.3 \% \\
\end{array}$ & $\begin{array}{r}63.3 \% \\
9.4 \% \\
22.9 \% \\
4.4 \% \\
\end{array}$ \\
\hline $\begin{array}{l}\text { Striking } \\
\text { Vehicle }\end{array}$ & $\begin{array}{l}\text { Cars \& related } \\
\text { SUV/van/pickup } \\
\text { Bus/trk/tractor_trlt - } \\
\text { Other/Unknown }\end{array}$ & $\begin{array}{r}4.0 \% \\
5.4 \% \\
-1.7 \% \\
0.8 \% \\
\end{array}$ & $\begin{array}{r}31.1 \% \\
31.4 \% \\
-33,3 \% \\
39.4 \% \\
\end{array}$ & $\begin{array}{l}16.6 \% \\
13.9 \% \\
17.2 \% \\
14.5 \%\end{array}$ & $\begin{array}{r}26.2 \% \\
23.4 \% \\
23.9 \% \\
25.7 \% \\
\end{array}$ & $\begin{array}{l}14.9 \% \\
17.0 \% \\
10.4 \% \\
11.9 \% \\
\end{array}$ & $\begin{array}{r}7.3 \% \\
8.9 \% \\
-13.6 \% \\
7.8 \% \\
\end{array}$ & $\begin{array}{r}71.2 \% \\
20.5 \% \\
-2.2 \% \\
5.6 \% \\
\end{array}$ \\
\hline $\begin{array}{l}\text { Pre-crash } \\
\text { Vehicle } \\
\text { Action }\end{array}$ & $\begin{array}{l}\text { Go straight } \\
\text { Turn right } \\
\text { Turn left } \\
\text { Slow/stop in lane } \\
\text { Backing not prkng } \\
\text { Other/Unknown }\end{array}$ & $\begin{array}{r}3.8 \% \\
1.8 \% \\
3.4 \% \\
3.9 \% \\
4.4 \% \\
1.2 \% \\
\end{array}$ & $\begin{array}{l}31.0 \% \\
32.9 \% \\
32.8 \% \\
47.3 \% \\
-40.4 \% \\
24.1 \% \\
\end{array}$ & $\begin{array}{l}15.2 \% \\
16.8 \% \\
19.6 \% \\
20.2 \% \\
-13.4 \% \\
18.9 \% \\
\end{array}$ & $\begin{array}{l}25.4 \% \\
32.0 \% \\
32.6 \% \\
14.8 \% \\
-19.0 \% \\
16.9 \% \\
\end{array}$ & $\begin{array}{r}16.2 \% \\
13.8 \% \\
10.6 \% \\
7.9 \% \\
-6.6 \% \\
15.8 \% \\
\end{array}$ & $\begin{array}{r}8.4 \% \\
2.7 \% \\
1.0 \% \\
5.9 \% \\
-16.2 \% \\
13.0 \% \\
\end{array}$ & $\begin{array}{r}73.7 \% \\
6.3 \% \\
8.6 \% \\
3.0 \% \\
-2.9 \% \\
5.5 \% \\
\end{array}$ \\
\hline $\begin{array}{l}\text { Pedestrian } \\
\text { Crash } \\
\text { Type }\end{array}$ & $\begin{array}{l}\text { Backing } \\
\text { Walk along road } \\
\text { Waithot in road } \\
\text { Veh tum/merge } \\
\text { Intersection dash } \\
\text { Intersection-other } \\
\text { Midblock dartouts } \\
\text { Midblock dash } \\
\text { Midblock-other } \\
\text { Non-ped in road } \\
\text { Specl/other/weird }\end{array}$ & $\begin{array}{l}7.1 \% \\
4.0 \% \\
4.0 \% \\
2.9 \% \\
4.2 \% \\
3.0 \% \\
9.7 \% \\
4.0 \% \\
4.1 \% \\
3.9 \% \\
3.6 \% \\
\end{array}$ & $\begin{array}{l}50.6 \% \\
25.3 \% \\
24.9 \% \\
30.5 \% \\
37.4 \% \\
31.3 \% \\
51.2 \% \\
34.5 \% \\
27.4 \% \\
27.3 \% \\
27.7 \% \\
\end{array}$ & $\begin{array}{l}15.2 \% \\
18.4 \% \\
14.1 \% \\
18.9 \% \\
15.9 \% \\
15.0 \% \\
15.5 \% \\
16.4 \% \\
14.9 \% \\
14.5 \% \\
16.6 \% \\
\end{array}$ & $\begin{array}{l}12.7 \% \\
15.4 \% \\
14.7 \% \\
32.9 \% \\
22.1 \% \\
33.6 \% \\
13.0 \% \\
24.2 \% \\
26.1 \% \\
17.0 \% \\
18.6 \% \\
\end{array}$ & $\begin{array}{r}3.0 \% \\
21.9 \% \\
12.3 \% \\
12.4 \% \\
17.6 \% \\
14.8 \% \\
6.8 \% \\
15.5 \% \\
18.6 \% \\
14.4 \% \\
17.7 \% \\
\end{array}$ & $\begin{array}{r}11.3 \% \\
15.0 \% \\
29.9 \% \\
2.5 \% \\
2.9 \% \\
2.3 \% \\
3.8 \% \\
5.4 \% \\
8.9 \% \\
22.8 \% \\
15.9 \% \\
\end{array}$ & $\begin{array}{r}4.1 \% \\
4.6 \% \\
3.9 \% \\
15.1 \% \\
3.1 \% \\
20.5 \% \\
5.1 \% \\
10.1 \% \\
24.9 \% \\
3.6 \% \\
4.9 \% \\
\end{array}$ \\
\hline
\end{tabular}


- By NHTSA-developed pedestrian crash type (e.g., NHTSA, 1998): Backing and Midblock Dartout crashes occurred much more often on 20 and 25 mph roads; crash types more concentrated on roads with high speed limits included Pedestrian not in Road, NonPedestrian Activity in Roads, Walking Along the Road, Backing, and Special/Other/Weird types.

\section{State of Florida}

In Florida in 1993 - 1996, 32,651 (91 percent) of the pedestrians in crashes were in singlevehicle crashes. These incidents were analyzed for the relationship between vehicle speed and pedestrian injury. For the pedestrians in single-vehicle crashes, 23,831 ( 74 percent) were struck by vehicles with estimated travel speeds and 21,864 (67 percent) were struck on roads with recorded speed limits. Of the pedestrians, 31,354 (96 percent) had known ages and 32,506 (99.6 percent) had known severity of injury (including no injury). The tables, figures, and text below are based on known data.

\section{Vehicle speeds and pedestrian injuries}

For pedestrians involved in Florida single-vehicle crashes in which estimated vehicle travel speeds were reported, there were 1,550 (6.5 percent) fatalities, 6,414 (27 percent) with A (incapacitating) injuries, 9,206 (39 percent) with $B$ (non-incapacitating) injuries, and 6,583 (28 percent) with C (possible) or no injuries. The proportion of $A$ injuries and fatalities increased steadily with increasing vehicle speeds (as estimated by the investigating police officer), although the A injuries leveled off and actually decreased above $45 \mathrm{mph}$ as the fatalities increased sharply with higher vehicle travel speeds, reaching 36 percent of all cases with vehicles traveling above $45 \mathrm{mph}$. The distribution is shown in Table 5 .

Table 5. Vehicle travel speed and pedestrian injury severity.

(Florida, 1993-1996; pedestrians in single-vehicle crashes)

\begin{tabular}{||l|r|r|r|r|r|r|r||}
\hline & \multicolumn{6}{|c|}{ Travel Speed (Officer Estimates) } & \multirow{2}{*}{ Total } \\
\cline { 2 - 8 } Injury Severity & $1-20 \mathrm{mph}$ & $21-25 \mathrm{mph}$ & $26-30 \mathrm{mph}$ & $31-35 \mathrm{mph}$ & $36-45 \mathrm{mph}$ & $46+\mathrm{mph}$ & $6.5 \%$ \\
\hline Fatal (K) injury & $1.1 \%$ & $3.7 \%$ & $6.1 \%$ & $12.5 \%$ & $22.4 \%$ & $36.1 \%$ & $27.0 \%$ \\
Incapacitating (A) & $19.4 \%$ & $32.0 \%$ & $35.9 \%$ & $39.3 \%$ & $40.2 \%$ & $33.7 \%$ & $2 \%$ \\
Nonincapacitating (B) & $43.8 \%$ & $41.2 \%$ & $36.8 \%$ & $31.6 \%$ & $24.7 \%$ & $20.5 \%$ & $38.8 \%$ \\
Possible inj (C) or none & $35.6 \%$ & $23.0 \%$ & $21.2 \%$ & $16.6 \%$ & $12.7 \%$ & $9.7 \%$ & $27.7 \%$ \\
\hline Total frequency & 13,368 & 1,925 & 2,873 & 2,188 & 2,493 & 906 & 23,753 \\
\hline
\end{tabular}

As noted earlier, younger pedestrians are generally more able to resist serious injury and death, while elderly pedestrians are much more susceptible to more serious consequences as crash victims. The distribution of fatality rates is shown in Table 6 and illustrated in Figure 2. Overall, pedestrians age 65 and older are more than 5 times as likely to die in crashes than pedestrians age 14. or less, and the likelihood of death increases steadily for ages in between. For vehicle travel speeds above $45 \mathrm{mph}$, pedestrians above age 65 die in about 5 of 8 crashes.

The pattern of differences varies by vehicle travel speeds. For speeds less than $20 \mathrm{mph}$, risk of fatality is about the same for all ages up to age 65, where the rate triples. For speeds of $21-30 \mathrm{mph}$, fatality rates are roughly the same to age 45 , but the rate is about 2.5 times higher for pedestrians age 45 - 64 and doubles again for pedestrians age 65 and older. By speeds of $31-35 \mathrm{mph}$, the fatality rate of 25 - 44 year olds is nearly double the rates of younger pedestrians; by speeds of $36-45 \mathrm{mph}$ the fatality rate 
for pedestrians $15-24$ years old exceeds that of the youngest pedestrians, and the fatality rate for each succeeding age group is greater than that of the younger group.

Table 6. Fatality rates by estimated vehicle travel speeds, by pedestrian age.

(Florida, 1993-1996; pedestrians in single-vehicle crashes)

\begin{tabular}{|c|c|c|c|c|c|c|c|}
\hline \multirow[b]{2}{*}{ Pedestrian Age } & \multicolumn{6}{|c|}{ Travel Speed (Officer Estimates) } & \multirow{2}{*}{$\begin{array}{c}\text { Row } \\
\text { Total } \\
(\mathrm{N}=23,753)\end{array}$} \\
\hline & $\begin{array}{c}1-20 \mathrm{mph} \\
(\mathrm{N}=13,368)\end{array}$ & $\begin{array}{c}21-25 \mathrm{mph} \\
(\mathrm{N}=1,925) \\
\end{array}$ & $\begin{array}{l}26-30 \mathrm{mph} \\
(\mathrm{N}=2,873)\end{array}$ & \begin{tabular}{|l|}
$31-35 \mathrm{mph}$ \\
$(\mathrm{N}=2,188)$ \\
\end{tabular} & $\begin{array}{l}36-45 \mathrm{mph} \\
\mathrm{N}=2,493)\end{array}$ & $\begin{array}{l}46+\mathrm{mph} \\
(\mathrm{N}=906)\end{array}$ & \\
\hline Ages 14 or less & $0.7 \%$ & $2.0 \%$ & $3.7 \%$ & $5.5 \%$ & $9.8 \%$ & $18.2 \%$ & $2.4 \%$ \\
\hline Ages 15 - 24 & $0.2 \%$ & $2.0 \%$ & $2.3 \%$ & $6.4 \%$ & $14.4 \%$ & $27.9 \%$ & $4.1 \%$ \\
\hline Ages 25 - 44 & $0.8 \%$ & $2.2 \%$ & $4.4 \%$ & $10.7 \%$ & $20.0 \%$ & $36.0 \%$ & $7.1 \%$ \\
\hline Ages 45 - 64 & $1.0 \%$ & $5.7 \%$ & $10.4 \%$ & $18.3 \%$ & $28.3 \%$ & $45.5 \%$ & $9.3 \%$ \\
\hline Ages $65+$ & $3.1 \%$ & $15.6 \%$ & $18.5 \%$ & $28.1 \%$ & $46.9 \%$ & $62.5 \%$ & $13.0 \%$ \\
\hline All Pedestrians & $1.1 \%$ & $3.7 \%$ & $6.1 \%$ & $12.5 \%$ & $22.4 \%$ & $36.1 \%$ & $6.5 \%$ \\
\hline
\end{tabular}

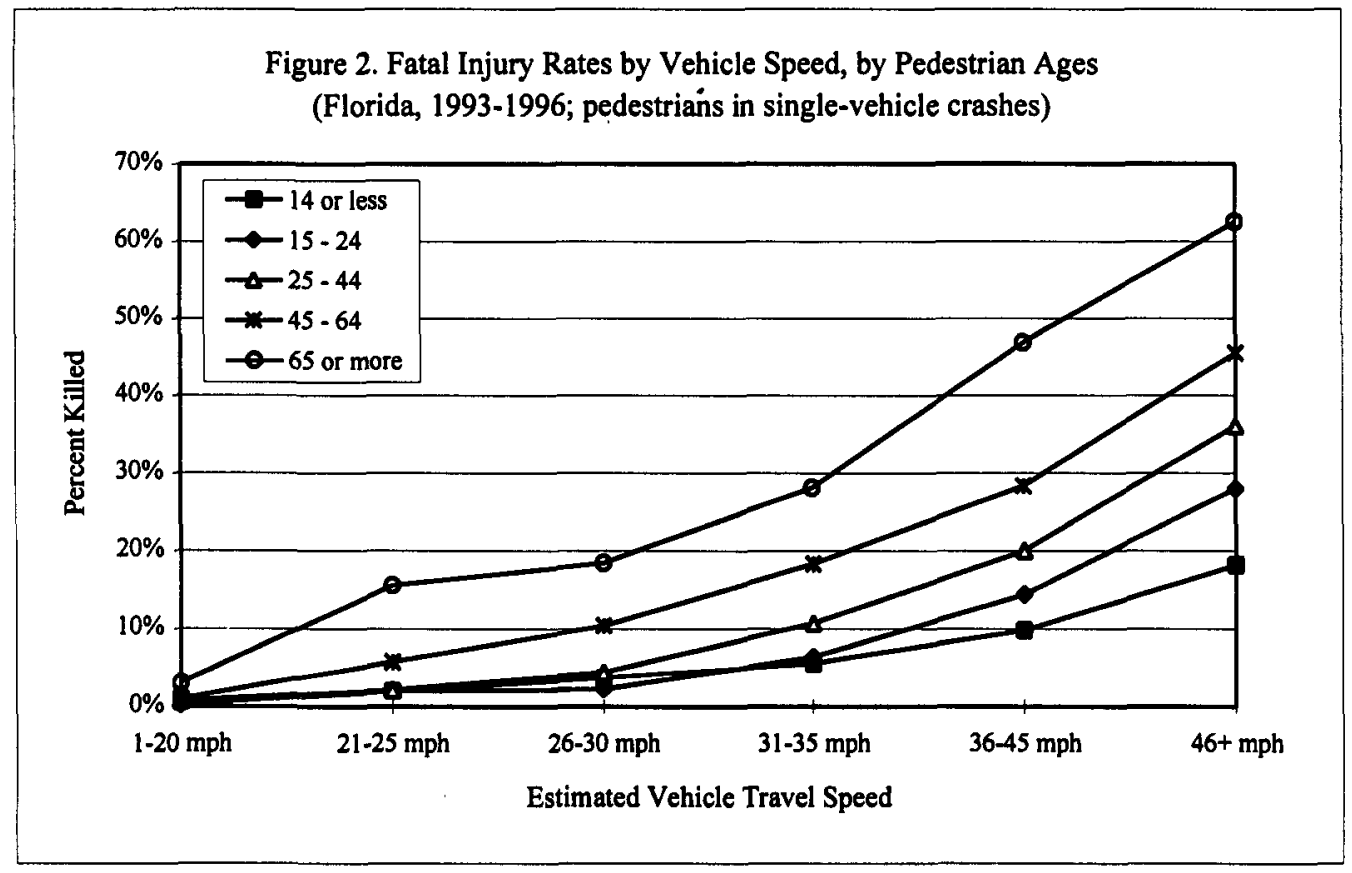

The same pattern is seen for combined fatalities and A injuries, although the age differences are smaller. At speeds of $20 \mathrm{mph}$ or less, about 20 percent of all pedestrians suffer serious injury or death, and the rates increase gradually with speed until at speeds of $46 \mathrm{mph}$ or more 70 percent of all pedestrians suffer A injuries or fatalities. The oldest pedestrians, ages 65 and above, receive higher percentages of serious injury or death than any younger age group at every speed level. These values are shown in Table 7. 
Table 7. (Fatality + serious injury) rates by estimated vehicle travel speeds, by pedestrian age.

(Florida, 1993-1996; pedestrians in single-vehicle crashes)

\begin{tabular}{|c|c|c|c|c|c|c|c|}
\hline \multirow[b]{2}{*}{ Pedestrian Age } & \multicolumn{6}{|c|}{ Travel Speed (Officer Estimates) } & \multirow{2}{*}{$\begin{array}{c}\text { Row } \\
\text { Total } \\
(\mathrm{N}=23,753) \\
\end{array}$} \\
\hline & $\begin{array}{c}1-20 \mathrm{mph} \\
(\mathrm{N}=13,368)\end{array}$ & $\begin{array}{l}21-25 \mathrm{mph} \\
(\mathrm{N}=1,925)\end{array}$ & $\begin{array}{l}26-30 \mathrm{mph} \\
(\mathrm{N}=2,873)\end{array}$ & $\begin{array}{l}31-35 \mathrm{mph} \\
\mathrm{N}=2,188)\end{array}$ & $\begin{array}{c}36-45 \mathrm{mph} \\
(\mathrm{N}=2,493)\end{array}$ & $\begin{array}{l}46+\mathrm{mph} \\
(\mathrm{N}=906)\end{array}$ & \\
\hline Ages 14 or less & $20.2 \%$ & $32.8 \%$ & $35.2 \%$ & $36.9 \%$ & $49.0 \%$ & $65.9 \%$ & $27.2 \%$ \\
\hline Ages 15 - 24 & $18.3 \%$ & $29.0 \%$ & $35.8 \%$ & $39.5 \%$ & $56.3 \%$ & $65.1 \%$ & $29.8 \%$ \\
\hline Ages 25-44 & $18.2 \%$ & $34.9 \%$ & $42.5 \%$ & $55.2 \%$ & $64.2 \%$ & $67.9 \%$ & $35.5 \%$ \\
\hline Ages $45-64$ & $20.3 \%$ & $41.6 \%$ & $50.7 \%$ & $62.3 \%$ & $67.6 \%$ & $77.6 \%$ & $37.5 \%$ \\
\hline Ages $65+$ & $27.3 \%$ & $54.4 \%$ & $58.7 \%$ & $65.7 \%$ & $77.4 \%$ & $83.8 \%$ & $41.2 \%$ \\
\hline All Pedestrians & $20.4 \%$ & $35.7 \%$ & $42.0 \%$ & $51.8 \%$ & $62.6 \%$ & $69.8 \%$ & $33.5 \%$ \\
\hline
\end{tabular}

\section{Posted speed limits and pedestrian injuries}

There was a strong relationship between the speeds of crash vehicles and the speed limits that were posted. Over 90 percent of striking vehicles were reported as traveling at their speed limit or slower, and half or more were reported as traveling $5 \mathrm{mph}$ or more below their speed limit.

The relationships between posted speed limits and pedestrian injuries are shown beginning with Table 8. The percentage of pedestrians who were killed rose from less than 1 percent for speed limits of $20 \mathrm{mph}$ or less to 28 percent for speed limits of $50 \mathrm{mph}$ or more. Percentages of pedestrians receiving A injuries rose to a plateau of about 35 percent for speed limits of $35 \mathrm{mph}$ or more. Pedestrians with B injuries remained at just over 40 percent for speed limits up to $30 \mathrm{mph}$ and then dropped steadily with increasing speed limits. Pedestrians with minor (C) injuries or no injuries dropped steadily, from more than 40 percent at the lowest speed limits to just 12 percent at speed limits of $50 \mathrm{mph}$ or more.

Table 8. Speed limit and pedestrian injury severity.

(Florida, 1993-1996; pedestrians in single-vehicle crashes)

\begin{tabular}{|c|c|c|c|c|c|c|c|c|}
\hline \multirow[b]{2}{*}{ Injury Severity } & \multicolumn{7}{|c|}{ Speed Limit } & \multirow[b]{2}{*}{ Total } \\
\hline & $<=20 \mathrm{mph}$ & $25 \mathrm{mph}$ & $30 \mathrm{mph}$ & $35 \mathrm{mph}$ & $40-45 \mathrm{mph}$ & $\overline{50+\mathrm{mph}}$ & None/Oth & \\
\hline Fatal (K) injury & $0.7 \%$ & $2.2 \%$ & $3.9 \%$ & $8.1 \%$ & $14.6 \%$ & $28.0 \%$ & $3.4 \%$ & $7.5 \%$ \\
\hline Incapacitating (A) & $13.7 \%$ & $22.2 \%$ & $25.5 \%$ & $32.2 \%$ & $35.9 \%$ & $33.8 \%$ & $21.4 \%$ & $27.0 \%$ \\
\hline Nonincapacitating (B) & $44.1 \%$ & $42.0 \%$ & $42.5 \%$ & $36.3 \%$ & $31.6 \%$ & $26.3 \%$ & $40.7 \%$ & $38.1 \%$ \\
\hline Possible inj (C) or none & $41.5 \%$ & $33.6 \%$ & $28.1 \%$ & $23.4 \%$ & $17.8 \%$ & $11.9 \%$ & $34.5 \%$ & $27.4 \%$ \\
\hline Total frequency & 1,244 & 1,626 & 4,905 & 3,409 & 4,948 & 1,212 & 6,771 & 24,115 \\
\hline
\end{tabular}

At the same speed limits, older pedestrians were much more likely to be killed, or killed or seriously injured, than younger pedestrians. The pattern was much like that seen for vehicle travel speeds, above. The picture for serious injuries and fatalities combined is given in Table 9. Pedestrians age 65 and older are more likely to be killed or seriously injured at all speed limits of $25 \mathrm{mph}$ or more; pedestrians age 45- 64 are more likely to be killed or seriously injured than younger pedestrians, as are pedestrians age 25 - 44. Pedestrians age $15-24$ and pedestrians age 14 and less show similar fatal+serious injury rates at all speed limits.

\section{FARS}

The Fatality Analysis Reporting System (FARS) is not suited to providing direct information on the relationship between speed and injury severity, since it looks only at fatalities. However, the FARS data can provide extensive information about the characteristics of the most serious pedestrian crashes. By relating these characteristics to vehicle speeds and speed limits, it is possible to identify the situations or conditions most strongly associated with pedestrian fatalities. This, in turn, can benefit 
countermeasure development by identifying factors that may be causal in the crashes and by limiting the countermeasure focus to the situations of greatest danger.

Table 9. (Fatality + serious injury) rates by posted speed limits, by pedestrian age. (Florida, 1993-1996; pedestrians in single-vehicle crashes)

\begin{tabular}{|c|c|c|c|c|c|c|c|c|}
\hline \multirow[b]{2}{*}{ Pedestrian Age } & \multicolumn{7}{|c|}{ Speed Limit } & \multirow{2}{*}{$\begin{array}{c}\text { Row } \\
\text { Total } \\
(\mathrm{N}=24,115) \\
\end{array}$} \\
\hline & $\begin{array}{l}<=20 \mathrm{mph} \\
(\mathrm{N}=1,244)\end{array}$ & $\begin{array}{c}25 \mathrm{mph} \\
(\mathrm{N}=1,626)\end{array}$ & $\begin{array}{c}30 \mathrm{mph} \\
(\mathrm{N}=4,905)\end{array}$ & $\begin{array}{c}35 \mathrm{mph} \\
(\mathrm{N}=3,409)\end{array}$ & $\begin{array}{l}40-45 \mathrm{mph} \\
(\mathrm{N}=4,948)\end{array}$ & $\begin{array}{c}50+\mathrm{mph} \\
(\mathrm{N}=1,212)\end{array}$ & $\begin{array}{l}\text { None/Oth } \\
(\mathrm{N}=6,771)\end{array}$ & \\
\hline Ages 14 or less & $17.2 \%$ & $21.7 \%$ & $26.8 \%$ & $29.3 \%$ & $38.5 \%$ & $58.7 \%$ & $20.5 \%$ & $26.3 \%$ \\
\hline Ages $15-24$ & $11.5 \%$ & $21.4 \%$ & $25.0 \%$ & $32.0 \%$ & $43.2 \%$ & $55.0 \%$ & $20.5 \%$ & $29.2 \%$ \\
\hline Ages 25 - 44 & $13.0 \%$ & $24.9 \%$ & $29.5 \%$ & $43.6 \%$ & $50.4 \%$ & $60.2 \%$ & $26.2 \%$ & $37.2 \%$ \\
\hline Ages $45-64$ & $12.3 \%$ & $27.8 \%$ & $34.5 \%$ & $48.3 \%$ & $59.9 \%$ & $68.1 \%$ & $27.7 \%$ & $41.8 \%$ \\
\hline Ages $65+$ & $17.9 \%$ & $41.8 \%$ & $42.9 \%$ & $54.8 \%$ & $66.6 \%$ & $82.4 \%$ & $33.7 \%$ & $47.4 \%$ \\
\hline All Pedestrians & $14.5 \%$ & $24.4 \%$ & $29.4 \%$ & $40.2 \%$ & $50.5 \%$ & $61.8 \%$ & $24.8 \%$ & $34.5 \%$ \\
\hline
\end{tabular}

For these analyses, information about the crash and about the striking vehicle were linked to information about each fatally injured pedestrian. Between 1989 and 1997, there were 51,866 pedestrians killed in 50,985 crashes. Speed limits were known for 97 percent of the crashes, and vehicle travel speeds known for 42 percent. The tables below are produced for the travel speeds of the striking vehicles, since striking speed is the most proximate measure of the severity of the impact on the pedestrian, and again for posted speed limits, since speed limits are known for nearly all of the crashes and since speed limit is a fixed descriptor of the crash environment.

The distribution of pedestrian fatalities across travel speeds is shown for different pedestrian ages in Table 10. For all ages, the proportion of fatalities increases with speeds above $25 \mathrm{mph}$ to about 45 $\mathrm{mph}$. At speeds of $46+\mathrm{mph}$, the proportion of fatalities for pedestrians between 15 and 44 years of age increases sharply, while it drops somewhat for younger and older pedestrians, possibly reflecting different exposure patterns on the highest-speed roadways.

Table 10. Pedestrian fatalities by vehicle travel speed: By pedestrian age.

(FARS, 1989-1997; crashes with known striking vehicle speed)

\begin{tabular}{|c|c|c|c|c|c|c|c|}
\hline \multirow[b]{2}{*}{ Pedestrian Age } & \multicolumn{6}{|c|}{ Travel Speed (Officer Estimates) } & \multirow[b]{2}{*}{$\begin{array}{c}\text { Row } \\
\text { Frequency }\end{array}$} \\
\hline & $\begin{array}{l}1-20 \mathrm{mph} \\
(\mathrm{N}=1,766)\end{array}$ & $\begin{array}{l}21-25 \mathrm{mph} \\
(\mathrm{N}=1,144)\end{array}$ & $\begin{array}{l}26-30 \mathrm{mph} \\
(\mathrm{N}=2,089)\end{array}$ & $\begin{array}{l}31-35 \mathrm{mph} \\
(\mathrm{N}=3,144)\end{array}$ & $\begin{array}{l}36-45 \mathrm{mph} \\
(\mathrm{N}=6,133)\end{array}$ & $\begin{array}{c}46+\mathrm{mph} \\
(\mathrm{N}=7,240)\end{array}$ & \\
\hline Ages 14 or less & $13.8 \%$ & $9 . \overline{7 \%}$ & $12.1 \%$ & $17.1 \%$ & $25.5 \%$ & $21.8 \%$ & 3,010 \\
\hline Ages $15-24$ & $3.7 \%$ & $2.3 \%$ & $5.9 \%$ & $9.6 \%$ & $27.4 \%$ & $51.1 \%$ & 2,571 \\
\hline Ages $25-44$ & $4.1 \%$ & $2.5 \%$ & $6.7 \%$ & $12.0 \%$ & $29.8 \%$ & $44.9 \%$ & 6,866 \\
\hline Ages $45-64$ & $6.7 \%$ & $5.1 \%$ & $9.7 \%$ & $16.3 \%$ & $31.9 \%$ & $30.3 \%$ & 4,296 \\
\hline Ages $65+$ & $14.4 \%$ & $8.5 \%$ & $14.5 \%$ & $18.0 \%$ & $26.1 \%$ & $18.5 \%$ & 4,773 \\
\hline All Pedestrians & $8.2 \%$ & $5.3 \%$ & $9.7 \%$ & $14.6 \%$ & $28.5 \%$ & $33.6 \%$ & 21,516 \\
\hline
\end{tabular}

The distribution of pedestrian fatalities by speed limits shows considerable variation among pedestrian age groups. The youngest pedestrians (age 14 or less) and the oldest pedestrians (age 65 or more) show relatively flat proportions of fatalities across speed limits of $25 \mathrm{mph}$ and higher, perhaps reflecting a difference in patterns of occurrence (younger pedestrians more often found on lower-speed roads) and resilience (older pedestrians more often killed at lower impact speeds). The other age groups show a gradual increase in fatalities with increasing speed limits, but - as for vehicle speeds - for speed limits of $50 \mathrm{mph}$ or more the proportion of fatalities is much higher for pedestrians age $15-44$, only slightly higher for pedestrians age $45-64$. These values are shown in Table 11. 
Table 11. Pedestrian fatalities by posted speed limits: By pedestrian age.

(FARS, 1989-1997; crashes with known speed limits)

\begin{tabular}{|c|c|c|c|c|c|c|c|c|}
\hline \multirow[b]{2}{*}{ Pedestrian Age } & \multicolumn{7}{|c|}{ Speed Limit } & \multirow[b]{2}{*}{$\begin{array}{c}\text { Row } \\
\text { Frequency }\end{array}$} \\
\hline & $\begin{array}{c}<=20 \mathrm{mph} \\
(\mathrm{N}=423)\end{array}$ & $\begin{array}{c}25 \mathrm{mph} \\
(\mathrm{N}=4,766)\end{array}$ & $\begin{array}{c}30 \mathrm{mph} \\
(\mathrm{N}=7,999)\end{array}$ & $\begin{array}{c}35 \mathrm{mph} \\
(\mathrm{N}=9,005)\end{array}$ & $\begin{array}{c}40-45 \mathrm{mph} \\
\mathrm{N}=10,657)\end{array}$ & $\begin{array}{c}50+\mathrm{mph} \\
(\mathrm{N}=16,751)\end{array}$ & $\begin{array}{r}\text { Unknown } \\
(\mathrm{N}=1,667)\end{array}$ & \\
\hline Ages 14 or less & $2.1 \%$ & $18.5 \%$ & $19.3 \%$ & $16.9 \%$ & $17.6 \%$ & $22.5 \%$ & $3.2 \%$ & 6,724 \\
\hline Ages 15-24 & $0.7 \%$ & $4.4 \%$ & $9.7 \%$ & $12.2 \%$ & $19.9 \%$ & $50.1 \%$ & $3.0 \%$ & 6,194 \\
\hline Ages $25-44$ & $0.4 \%$ & $5.1 \%$ & $10.9 \%$ & $14.9 \%$ & $21.8 \%$ & $44.0 \%$ & $3.0 \%$ & 16,447 \\
\hline Ages $45-64$ & $0.6 \%$ & $8.3 \%$ & $15.7 \%$ & $20.3 \%$ & $22.8 \%$ & $29.0 \%$ & $3.3 \%$ & 10,217 \\
\hline Ages $65+$ & $0.9 \%$ & $13.5 \%$ & $23.1 \%$ & $22.2 \%$ & $19.9 \%$ & $16.6 \%$ & $3.8 \%$ & 11,686 \\
\hline All Pedestrians & $0.8 \%$ & $9.3 \%$ & $15.6 \%$ & $17.6 \%$ & $20.8 \%$ & $32.7 \%$ & $3.3 \%$ & 51,268 \\
\hline
\end{tabular}

Tables 12 and 13 summarize the distribution of pedestrian fatalities across a number of factors and vehicle speed (Table 12) and speed limit (Table 13). Overall, about one-third of all pedestrian fatalities occur in crashes with vehicle speeds of $46 \mathrm{mph}$ or more and at locations where speed limits are $50 \mathrm{mph}$ or more. Conditions associated with significantly more high-speed crashes or significantly fewer high-speed crashes are noted below.

- Males show relatively few fatalities at low travel speeds and speed limits, steadily increasing involvement with increasing speed/limits until $37 \%(38 \%)$ of pedestrian fatalities occurred with travel speeds $46 \mathrm{mph}$ and above (speed limits of $50 \mathrm{mph}$ and above). Females showed a much broader distribution across speeds and speed limits.

- Pedestrians of ages $15-44$, as described above, showed sharply increasing involvement with increasing speeds and speed limits; the distribution was much broader for other age groups.

- Crash distributions with half or more occurring on sites with speed limits of $50 \mathrm{mph}$ or more and travel speeds of 46 mph or more include: Pedestrians age 15-24; midnight - 5:59 a.m.; not in roadway; weather conditions of snow, ice, other unusual or unknown (not clear or rainy); rural locations; dark and not lighted; and two or more vehicles. For these conditions, very few of the fatalities occurred at locations with low speeds or speed limits.

- Crash distributions with 40 percent - 49 percent high-speed site occurrence include: Pedestrians age 25-44; pedestrian BACs of .10\% or more; Saturday or Sunday; and pedestrians struck by trucks or buses. Non-intersection crashes just miss this category.

- Crash distributions which include fewer than 30 percent of the crashes at high-speed locations, and relatively more at low-speed sites, include: Female pedestrians and pedestrians age 14 or less or 65 or more; pedestrians of unknown (often, untested) BAC; daytime crashes, between 6 a.m. and 7:59 p.m.; crashes at intersections; crashes in the rain; urban areas; daylight and dark-but-lighted settings; and drivers age 75 and above.

Factors that seem relatively unrelated to the speed of striking vehicles or of roadways included roadway width and driver sex.

Taken together, the GES, Florida, and FARS crash data strongly support the relationship that higher speeds for vehicles striking pedestrians result in more serious consequences. The GES data and the FARS data were further analyzed to show some of the other characteristics of the crashes that were associated with more severe injuries and with higher vehicle speeds and higher speed limits. These factors will be relevant to the development of countermeasures to the consequences of high impact speeds that are presented in Chapter V. 
Table 12. Distribution of pedestrian crash "covariates" by striking vehicle speed.

(FARS, 1989-1997; crashes with known striking vehicle speed)

\begin{tabular}{|c|c|c|c|c|c|c|c|c|}
\hline & \multicolumn{6}{|c|}{ Estimated Travel Speed } & \multirow{2}{*}{$\begin{array}{c}\text { Row } \\
\text { Total } \\
(\mathbf{N}=21,751)\end{array}$} \\
\hline & & $\begin{array}{c}1-20 \mathrm{mph} \\
(\mathrm{N}=1,776)\end{array}$ & $\begin{array}{l}21-25 \mathrm{mph} \\
(\mathrm{N}=1,149)\end{array}$ & $\begin{array}{l}26-30 \mathrm{mph} \\
(\mathrm{N}=2,105)\end{array}$ & $\begin{array}{l}31-35 \mathrm{mph} \\
\mathrm{N}=3,167)\end{array}$ & $\begin{array}{l}36-45 \mathrm{mph} \\
(\mathrm{N}=6,184)\end{array}$ & $\begin{array}{c}46+\mathrm{mph} \\
(\mathrm{N}=7,370)\end{array}$ & \\
\hline \multirow[t]{2}{*}{ Sex } & Male & $6.7 \%$ & $4.7 \%$ & $8.9 \%$ & $14.0 \%$ & $28.7 \%$ & $37.0 \%$ & $70.2 \%$ \\
\hline & Female & $11.7 \%$ & $6.6 \%$ & $11.6 \%$ & $15.9 \%$ & $27.8 \%$ & $26.4 \%$ & $29.8 \%$ \\
\hline \multirow[t]{6}{*}{ Age } & 0.14 & $13.8 \%$ & $9.7 \%$ & $12.1 \%$ & $17.1 \%$ & $25.5 \%$ & $21.8 \%$ & $13.8 \%$ \\
\hline & $15-24$ & $3.7 \%$ & $2.3 \%$ & $5.9 \%$ & $9.6 \%$ & $27.4 \%$ & $51.1 \%$ & $11.8 \%$ \\
\hline & $25 \cdot 44$ & $4.1 \%$ & $2.5 \%$ & $6.7 \%$ & $12.0 \%$ & $29.8 \%$ & $44.9 \%$ & $31.6 \%$ \\
\hline & $45 \cdot 64$ & $6.7 \%$ & $5.1 \%$ & $9.7 \%$ & $16.3 \%$ & $31.9 \%$ & $30.3 \%$ & $19.8 \%$ \\
\hline & 65 or older & $14.4 \%$ & $8.5 \%$ & $14.5 \%$ & $18.0 \%$ & $26.1 \%$ & $18.5 \%$ & $21.9 \%$ \\
\hline & Unknown & $4.3 \%$ & $2.1 \%$ & $6.8 \%$ & $9.8 \%$ & $21.7 \%$ & $55.3 \%$ & $1.1 \%$ \\
\hline \multirow{5}{*}{$\begin{array}{l}\text { Pedestrian } \\
\text { BAC }\end{array}$} & Zero & $7.7 \%$ & $5.3 \%$ & $9.2 \%$ & $13.6 \%$ & $27.3 \%$ & $36.9 \%$ & $32.2 \%$ \\
\hline & $.01 \%-.09 \%$ & $3.9 \%$ & $3.3 \%$ & $7.4 \%$ & $14.1 \%$ & $28.2 \%$ & $43.2 \%$ & $4.2 \%$ \\
\hline & $.10 \%-.19 \%$ & $2.7 \%$ & $2.2 \%$ & $6.6 \%$ & $12.7 \%$ & $31.8 \%$ & $43.9 \%$ & $8.6 \%$ \\
\hline & $.20 \%+$ & $2.8 \%$ & $2.6 \%$ & $7.4 \%$ & $13.2 \%$ & $31.6 \%$ & $42.4 \%$ & $16.0 \%$ \\
\hline & Unknown & $12.4 \%$ & $7.3 \%$ & $11.9 \%$ & $16.3 \%$ & $27.4 \%$ & $24.7 \%$ & $38.9 \%$ \\
\hline \multirow[t]{2}{*}{ Day } & Weekday & $9.4 \%$ & $5.7 \%$ & $10.4 \%$ & $15.1 \%$ & $28.6 \%$ & $30.9 \%$ & $68.6 \%$ \\
\hline & Saturday-Sunday & $5.6 \%$ & $4.4 \%$ & $8.2 \%$ & $13.4 \%$ & $28.0 \%$ & $40.5 \%$ & $31.4 \%$ \\
\hline \multirow[t]{5}{*}{ Time } & Midnite-5:59 am & $2.6 \%$ & $1.7 \%$ & $5.4 \%$ & $10.0 \%$ & $27.0 \%$ & $53.3 \%$ & $16.9 \%$ \\
\hline & 6:00 - 9:59 am & $14.6 \%$ & $7.8 \%$ & $11.2 \%$ & $14.3 \%$ & $25.7 \%$ & $26.3 \%$ & $9.6 \%$ \\
\hline & $10: 00 \mathrm{am}-3: 59 \mathrm{pm}$ & $20.3 \%$ & $7.2 \%$ & $11.8 \%$ & $13.9 \%$ & $22.2 \%$ & $24.5 \%$ & $15.4 \%$ \\
\hline & 4:00 - 7:59 pm & $8.6 \%$ & $7.6 \%$ & $11.8 \%$ & $17.1 \%$ & $28.3 \%$ & $26.7 \%$ & $27.9 \%$ \\
\hline & $8: 00-11: 59 \mathrm{pm}$ & $2.7 \%$ & $3.4 \%$ & $8.5 \%$ & $15.2 \%$ & $33.4 \%$ & $36.8 \%$ & $30.2 \%$ \\
\hline \multirow[t]{2}{*}{ Location } & In roadway & $8.0 \%$ & $5.5 \%$ & $10.1 \%$ & $15.2 \%$ & $29.3 \%$ & $31.9 \%$ & $92.1 \%$ \\
\hline & All other & $9.8 \%$ & $3.2 \%$ & $4.4 \%$ & $7.7 \%$ & $17.9 \%$ & $57.0 \%$ & $7.9 \%$ \\
\hline \multirow{4}{*}{$\begin{array}{l}\text { Roadway } \\
\text { Width }\end{array}$} & 2 lanes or 1 & $9.3 \%$ & $6.0 \%$ & $9.7 \%$ & $13.9 \%$ & $27.6 \%$ & $33.4 \%$ & $63.3 \%$ \\
\hline & 3 or 4 lanes & $5.6 \%$ & $3.9 \%$ & $9.9 \%$ & $16.2 \%$ & $29.3 \%$ & $35.1 \%$ & $28.9 \%$ \\
\hline & $5+$ lanes & $4.0 \%$ & $2.3 \%$ & $8.0 \%$ & $13.8 \%$ & $35.1 \%$ & $36.7 \%$ & $6.3 \%$ \\
\hline & Unknown & $28.0 \%$ & $13.8 \%$ & $11.6 \%$ & $13.5 \%$ & $15.4 \%$ & $17.6 \%$ & $1.5 \%$ \\
\hline \multirow{5}{*}{$\begin{array}{l}\text { Intersec- } \\
\text { tion Y } \mathbf{N} \\
\text { and } \\
\text { Traffic } \\
\text { Control } \\
\end{array}$} & Intsctn-no control & $8.3 \%$ & $7.6 \%$ & $14.4 \%$ & $19.5 \%$ & $29.6 \%$ & $20.6 \%$ & $4.7 \%$ \\
\hline & RYG signal & $22.7 \%$ & $6.3 \%$ & $13.8 \%$ & $17,1 \%$ & $29.0 \%$ & $11.1 \%$ & $3.1 \%$ \\
\hline & Stop/yield/etc. & $26.5 \%$ & $8.1 \%$ & $13.0 \%$ & $15.2 \%$ & $20.2 \%$ & $17.0 \%$ & $1.0 \%$ \\
\hline & Non-intersection & $6.2 \%$ & $4.9 \%$ & $8.9 \%$ & $14.1 \%$ & $28.8 \%$ & $37.2 \%$ & $77.6 \%$ \\
\hline & Other/Unknown & $14.8 \%$ & $6.4 \%$ & $11.6 \%$ & $15.0 \%$ & $25.8 \%$ & $26.4 \%$ & $13.5 \%$ \\
\hline \multirow[t]{3}{*}{ Weather } & No adverse & $8.2 \%$ & $5.1 \%$ & $9.3 \%$ & $14.4 \%$ & $28.4 \%$ & $34.5 \%$ & $89.7 \%$ \\
\hline & Rain & $7.5 \%$ & $7.9 \%$ & $13.9 \%$ & $16.1 \%$ & $27.9 \%$ & $26.7 \%$ & $7.7 \%$ \\
\hline & All other (incl unk) & $8.0 \%$ & $5.0 \%$ & $8.7 \%$ & $13.9 \%$ & $30.7 \%$ & $33.7 \%$ & $2.6 \%$ \\
\hline \multirow[t]{2}{*}{ Area } & Urban & $9.7 \%$ & $6.7 \%$ & $12.4 \%$ & $17.5 \%$ & $28.6 \%$ & $25.1 \%$ & $62.9 \%$ \\
\hline & Rural & $5.5 \%$ & $2.9 \%$ & $5.2 \%$ & $9.6 \%$ & $27.9 \%$ & $48.9 \%$ & $37.1 \%$ \\
\hline \multirow[t]{4}{*}{ Light } & Daylight & $18.3 \%$ & $8.2 \%$ & $11.3 \%$ & $14.4 \%$ & $22.5 \%$ & $25.4 \%$ & $31.9 \%$ \\
\hline & Dark & $1.9 \%$ & $2.0 \%$ & $5.0 \%$ & $9.5 \%$ & $31.2 \%$ & $50.5 \%$ & $36.8 \%$ \\
\hline & Dark, lighted & $5.0 \%$ & $6.2 \%$ & $13.5 \%$ & $21.7 \%$ & $31.7 \%$ & $21.9 \%$ & $27.4 \%$ \\
\hline & Dawn or dusk & $6.7 \%$ & $6.7 \%$ & $13.3 \%$ & $13.9 \%$ & $27.8 \%$ & $31.6 \%$ & $3.9 \%$ \\
\hline \multirow{2}{*}{$\begin{array}{l}\text { Number of } \\
\text { Vehicles }\end{array}$} & One & $8.5 \%$ & $5.5 \%$ & $10.0 \%$ & $14.9 \%$ & $28.7 \%$ & $32.3 \%$ & $92.6 \%$ \\
\hline & Two or more & $3.9 \%$ & $2.7 \%$ & $5.6 \%$ & $10.2 \%$ & $24.5 \%$ & $53.0 \%$ & $7.4 \%$ \\
\hline \multirow{4}{*}{$\begin{array}{l}\text { Striking } \\
\text { Vehicle }\end{array}$} & Cars \& related & $5.3 \%$ & $5.5 \%$ & $10.4 \%$ & $15.9 \%$ & $30.2 \%$ & $32.7 \%$ & $60.8 \%$ \\
\hline & SUV/van/pickup & $9.4 \%$ & $5.0 \%$ & $9.4 \%$ & $14.1 \%$ & $28.2 \%$ & $33.8 \%$ & $29.5 \%$ \\
\hline & Bus/trk/tractor trlr & $26.1 \%$ & $4.5 \%$ & $5.2 \%$ & $6.3 \%$ & $15.2 \%$ & $42.6 \%$ & $7.6 \%$ \\
\hline & Other/Unknown & $8.6 \%$ & $4.0 \%$ & $8.6 \%$ & $13.7 \%$ & $27.5 \%$ & $37.5 \%$ & $2.1 \%$ \\
\hline \multirow{9}{*}{\begin{tabular}{|l} 
Driver \\
Sex \\
Driver \\
Age
\end{tabular}} & Male & $7.7 \%$ & $5.1 \%$ & $9.2 \%$ & $13.9 \%$ & $27.7 \%$ & $36.3 \%$ & $74.0 \%$ \\
\hline & Female & $8.2 \%$ & $6.1 \%$ & $11.4 \%$ & $16.8 \%$ & $30.7 \%$ & $26.8 \%$ & $26.0 \%$ \\
\hline & $16-17$ & $4.6 \%$ & $4.5 \%$ & $11.7 \%$ & $14.7 \%$ & $32.7 \%$ & $31.8 \%$ & $4.2 \%$ \\
\hline & $18 \cdot 20$ & $4.7 \%$ & $4.2 \%$ & $10.0 \%$ & $14.9 \%$ & $31.5 \%$ & $34.7 \%$ & $9.7 \%$ \\
\hline & $21-24$ & $5.9 \%$ & $4.2 \%$ & $9.1 \%$ & $14.3 \%$ & $30.1 \%$ & $36.4 \%$ & $12.2 \%$ \\
\hline & $25-54$ & $7.9 \%$ & $4.9 \%$ & $9.2 \%$ & $14.2 \%$ & $27.9 \%$ & $35.9 \%$ & $56.2 \%$ \\
\hline & $55-74$ & $10.9 \%$ & $7.9 \%$ & $11.4 \%$ & $16.6 \%$ & $27.1 \%$ & $26.2 \%$ & $11.6 \%$ \\
\hline & $75+$ & $16.5 \%$ & $13.7 \%$ & $16.2 \%$ & $19.1 \%$ & $22.2 \%$ & $12.4 \%$ & $2.7 \%$ \\
\hline & Other/Unknown & $14.4 \%$ & $3.5 \%$ & $6.5 \%$ & $10.6 \%$ & $27.6 \%$ & $37.4 \%$ & $3.3 \%$ \\
\hline
\end{tabular}


Table 13. Distribution of pedestrian crash "covariates" by posted speed limit.

(FARS, 1989-1997; crashes with known speed limits)

\begin{tabular}{|c|c|c|c|c|c|c|c|c|}
\hline & \multicolumn{6}{|c|}{ Speed Limit } & \multirow{2}{*}{$\begin{array}{c}\text { Row } \\
\text { Total } \\
(\mathrm{N}=50,147)\end{array}$} \\
\hline & & $\begin{array}{c}<=20 \mathrm{mph} \\
(\mathrm{N}=424)\end{array}$ & $\begin{array}{c}25 \mathrm{mph} \\
(\mathrm{N}=4,786)\end{array}$ & $\begin{array}{c}30 \mathrm{mph} \\
(\mathrm{N}=8,069)\end{array}$ & $\begin{array}{c}35 \mathrm{mph} \\
(\mathrm{N}=9,079)\end{array}$ & $\begin{array}{c}40-45 \mathrm{mph} \\
(\mathrm{N}=10,765)\end{array}$ & $\begin{array}{c}50+\mathrm{mph} \\
(\mathrm{N}=17,024)\end{array}$ & \\
\hline \multirow[t]{2}{*}{ Sex } & Male & $0.7 \%$ & $8.2 \%$ & $14.4 \%$ & $17.1 \%$ & $21.5 \%$ & $38.0 \%$ & $69.4 \%$ \\
\hline & Female & $1.1 \%$ & $12.5 \%$ & $19.9 \%$ & $20.4 \%$ & $21.3 \%$ & $24.8 \%$ & $30.6 \%$ \\
\hline \multirow[t]{6}{*}{ Age } & $0-14$ & $2.2 \%$ & $19.1 \%$ & $19.9 \%$ & $17.4 \%$ & $18.1 \%$ & $23.2 \%$ & $13.0 \%$ \\
\hline & $15 \cdot 24$ & $0.7 \%$ & $4.6 \%$ & $9.9 \%$ & $12.5 \%$ & $20.5 \%$ & $51.7 \%$ & $12.0 \%$ \\
\hline & $25-44$ & $0.4 \%$ & $5.2 \%$ & $11.3 \%$ & $15.4 \%$ & $22.5 \%$ & $45.3 \%$ & $31.8 \%$ \\
\hline & $45-64$ & $0.6 \%$ & $8.6 \%$ & $16.2 \%$ & $21.0 \%$ & $23.6 \%$ & $30.0 \%$ & $19.7 \%$ \\
\hline & 65 or older & $1.0 \%$ & $14.0 \%$ & $24.0 \%$ & $23.1 \%$ & $20.7 \%$ & $17.3 \%$ & $22.4 \%$ \\
\hline & Unknown & $0.2 \%$ & $3.7 \%$ & $12.8 \%$ & $13.6 \%$ & $19.8 \%$ & $50.0 \%$ & $1.1 \%$ \\
\hline \multirow{5}{*}{$\begin{array}{l}\text { Pedestrian } \\
\text { BAC }\end{array}$} & Zero & $0.7 \%$ & $10.5 \%$ & $19.4 \%$ & $18.0 \%$ & $19.4 \%$ & $32.0 \%$ & $34.0 \%$ \\
\hline & $.01 \%=.09 \%$ & $0.3 \%$ & $6.9 \%$ & $15.3 \%$ & $16.9 \%$ & $21.5 \%$ & $39.2 \%$ & $4.5 \%$ \\
\hline & $.10 \%-.19 \%$ & $0.4 \%$ & $4.6 \%$ & $11.3 \%$ & $16.3 \%$ & $22.4 \%$ & $45.1 \%$ & $8.7 \%$ \\
\hline & $.20 \%+$ & $0.3 \%$ & $4.3 \%$ & $9.3 \%$ & $16.9 \%$ & $25.7 \%$ & $43.6 \%$ & $15.3 \%$ \\
\hline & Unknown & $1.4 \%$ & $12.3 \%$ & $17.1 \%$ & $19.3 \%$ & $21.3 \%$ & $28.6 \%$ & $37.5 \%$ \\
\hline \multirow[t]{2}{*}{ Day } & Weekday & $1.0 \%$ & $10.2 \%$ & $17.2 \%$ & $18.5 \%$ & $21.6 \%$ & $31.4 \%$ & $68.1 \%$ \\
\hline & Saturday-Sunday & $0.6 \%$ & $8.1 \%$ & $13.7 \%$ & $17.2 \%$ & $21.2 \%$ & $39.3 \%$ & $31.9 \%$ \\
\hline \multirow[t]{5}{*}{ Time } & Midnite-5:59 am & $0.5 \%$ & $4.7 \%$ & $9.9 \%$ & $13.7 \%$ & $20.1 \%$ & $51.1 \%$ & $18.4 \%$ \\
\hline & $6: 00-9: 59$ am & $1.7 \%$ & $13.2 \%$ & $19.9 \%$ & $19.3 \%$ & $18.8 \%$ & $27.0 \%$ & $9.7 \%$ \\
\hline & $10: 00 \mathrm{am}-3: 59 \mathrm{pm}$ & $1.7 \%$ & $15.3 \%$ & $23.5 \%$ & $18.0 \%$ & $16.5 \%$ & $24.9 \%$ & $16.4 \%$ \\
\hline & $4: 00-7: 59 \mathrm{pm}$ & $0.8 \%$ & $12.0 \%$ & $17.8 \%$ & $20.5 \%$ & $22.4 \%$ & $26.5 \%$ & $26.5 \%$ \\
\hline & $8: 00-11: 59 \mathrm{pm}$ & $0.3 \%$ & $5.9 \%$ & $13.0 \%$ & $18.4 \%$ & $25.3 \%$ & $37.0 \%$ & $29.1 \%$ \\
\hline \multirow[t]{2}{*}{ Location } & In roadway & $0.8 \%$ & $9.5 \%$ & $16.5 \%$ & $18.7 \%$ & $22.2 \%$ & $32.2 \%$ & $90.9 \%$ \\
\hline & All other & $1.2 \%$ & $9.5 \%$ & $11.7 \%$ & $12.3 \%$ & $14.3 \%$ & $50.9 \%$ & $9.1 \%$ \\
\hline Roadway & 2 lanes or 1 & $1.1 \%$ & $11.9 \%$ & $16.0 \%$ & $16.2 \%$ & $19.4 \%$ & $35.5 \%$ & $64.0 \%$ \\
\hline \multirow[t]{3}{*}{ Width } & 3 or 4 lanes & $0.2 \%$ & $5.0 \%$ & $14.6 \%$ & $22.9 \%$ & $25.0 \%$ & $32.3 \%$ & $28.7 \%$ \\
\hline & $5+$ lanes & $0.0 \%$ & $2.8 \%$ & $9.3 \%$ & $17.6 \%$ & $35.1 \%$ & $35.2 \%$ & $4.7 \%$ \\
\hline & Unknown & $2.6 \%$ & $14.6 \%$ & $47.8 \%$ & $13.6 \%$ & $8.6 \%$ & $12.8 \%$ & $2.6 \%$ \\
\hline \multirow{5}{*}{$\begin{array}{l}\text { Intersec- } \\
\text { tion } \mathrm{Y} / \mathrm{N} \\
\text { and } \\
\text { Traffic } \\
\text { Control } \\
\end{array}$} & Intsctn-no control & $0.7 \%$ & $14.2 \%$ & $21.0 \%$ & $25.8 \%$ & $22.7 \%$ & $15.6 \%$ & $4.8 \%$ \\
\hline & RYG signal & $0.9 \%$ & $14.4 \%$ & $29.1 \%$ & $24.6 \%$ & $22.7 \%$ & $8.3 \%$ & $3.7 \%$ \\
\hline & Stop/yield/etc. & $1.9 \%$ & $24.0 \%$ & $24.0 \%$ & $23.0 \%$ & $16.3 \%$ & $10.9 \%$ & $1.0 \%$ \\
\hline & Non-intersection & $0.7 \%$ & $8.2 \%$ & $13.2 \%$ & $16.4 \%$ & $22.2 \%$ & $39.2 \%$ & $75.2 \%$ \\
\hline & Other/Unknown & $1.5 \%$ & $12.5 \%$ & $25.2 \%$ & $22.2 \%$ & $17.3 \%$ & $21.4 \%$ & $15.2 \%$ \\
\hline \multirow[t]{3}{*}{ Weather } & No adverse & $0.9 \%$ & $9.6 \%$ & $15.5 \%$ & $18.2 \%$ & $21.8 \%$ & $34.1 \%$ & $87.9 \%$ \\
\hline & Rain & $0.6 \%$ & $10.4 \%$ & $22.3 \%$ & $19.2 \%$ & $20.9 \%$ & $26.7 \%$ & $9.1 \%$ \\
\hline & All other (incl unk) & $1.2 \%$ & $5.5 \%$ & $15.3 \%$ & $12.6 \%$ & $14.3 \%$ & $51.1 \%$ & $3.0 \%$ \\
\hline \multirow[t]{2}{*}{ Area } & Urban & $0.9 \%$ & $11.8 \%$ & $20.9 \%$ & $22.3 \%$ & $22.9 \%$ & $21.2 \%$ & $70.5 \%$ \\
\hline & Rural & $0.8 \%$ & $4.1 \%$ & $4.6 \%$ & $8.0 \%$ & $17.9 \%$ & $64.6 \%$ & $29.5 \%$ \\
\hline \multirow[t]{4}{*}{ Light } & Daylight & $1.8 \%$ & $15.8 \%$ & $22.1 \%$ & $18.8 \%$ & $16.7 \%$ & $24.8 \%$ & $32.7 \%$ \\
\hline & Dark & $0.3 \%$ & $2.6 \%$ & $5.4 \%$ & $9.4 \%$ & $22.7 \%$ & $59.6 \%$ & $31.9 \%$ \\
\hline & Dark, lighted & $0.4 \%$ & $9.9 \%$ & $20.1 \%$ & $26.2 \%$ & $25.3 \%$ & $18.0 \%$ & $31.6 \%$ \\
\hline & Dawn or dusk & $0.8 \%$ & $11.4 \%$ & $20.5 \%$ & $17.6 \%$ & $20.0 \%$ & $29.6 \%$ & $3.9 \%$ \\
\hline \multirow{2}{*}{$\begin{array}{l}\text { Number of } \\
\text { Vehicles }\end{array}$} & One & $8.5 \%$ & $5.5 \%$ & $10.0 \%$ & $14.9 \%$ & $28.7 \%$ & $32.3 \%$ & $92.6 \%$ \\
\hline & Two or more & $3.9 \%$ & $2.7 \%$ & $5.6 \%$ & $10.2 \%$ & $24.5 \%$ & $53.0 \%$ & $7.4 \%$ \\
\hline \multirow{4}{*}{$\begin{array}{l}\text { Striking } \\
\text { Vehicle }\end{array}$} & Cars \& related & $0.6 \%$ & $9.3 \%$ & $16.4 \%$ & $19.2 \%$ & $23.2 \%$ & $31.2 \%$ & $57.3 \%$ \\
\hline & SUV/van/pickup & $1.1 \%$ & $9.9 \%$ & $14.2 \%$ & $17.5 \%$ & $21.8 \%$ & $35.6 \%$ & $28.0 \%$ \\
\hline & Bus/trk'tractor trlr & $1.7 \%$ & $11.7 \%$ & $18.8 \%$ & $12.0 \%$ & $10.7 \%$ & $45.1 \%$ & $7.8 \%$ \\
\hline & Other/Unknown & $0.8 \%$ & $7.5 \%$ & $18.6 \%$ & $18.0 \%$ & $18.0 \%$ & $37.1 \%$ & $7.0 \%$ \\
\hline \multirow{9}{*}{\begin{tabular}{|l|} 
Driver \\
Sex \\
Driver \\
Age
\end{tabular}} & Male & $0.8 \%$ & $9.4 \%$ & $16.4 \%$ & $17.6 \%$ & $21.2 \%$ & $34.6 \%$ & $75.1 \%$ \\
\hline & Female & $1.0 \%$ & $9.9 \%$ & $13.8 \%$ & $19.4 \%$ & $24.5 \%$ & $31.4 \%$ & $24.9 \%$ \\
\hline & $16 \cdot 17$ & $1.3 \%$ & $10.5 \%$ & $12.9 \%$ & $18.8 \%$ & $26.5 \%$ & $29.9 \%$ & $3.6 \%$ \\
\hline & $18-20$ & $0.7 \%$ & $9.7 \%$ & $15.8 \%$ & $17.7 \%$ & $25.0 \%$ & $31.0 \%$ & $8.6 \%$ \\
\hline & $21-24$ & $0.8 \%$ & $8.8 \%$ & $15.9 \%$ & $18.0 \%$ & $23.2 \%$ & $33.3 \%$ & $11.3 \%$ \\
\hline & $25 \cdot 54$ & $0.8 \%$ & $8.9 \%$ & $15.2 \%$ & $17.5 \%$ & $21.4 \%$ & $36.2 \%$ & $52.4 \%$ \\
\hline & $55-74$ & $0.9 \%$ & $10.4 \%$ & $16.4 \%$ & $18.3 \%$ & $21.6 \%$ & $32.4 \%$ & $10.4 \%$ \\
\hline & $75+$ & $1.6 \%$ & $14.1 \%$ & $19.7 \%$ & $23.8 \%$ & $21.1 \%$ & $19.7 \%$ & $2.5 \%$ \\
\hline & Other/Unknown & $0.9 \%$ & $10.4 \%$ & $20.4 \%$ & $20.0 \%$ & $16.3 \%$ & $31.9 \%$ & $11.2 \%$ \\
\hline
\end{tabular}




\section{SPEED CONTROL LITERATURE}

Speed control is a very broad term which can cover any mechanism used to limit or reduce vehicle speeds. In the U.S., speed control has traditionally emphasized reduced speed limits and enforcement on continuous segments of roadway, and the installation of stop signs or traffic signals at intersections. Education, in the sense of informing the public of the dangers of excessive speed and the likely presence of police enforcement, has also been used. Increasingly in the U.S. and commonly in Europe, Australia, and Canada, roadways and intersections have seen engineering changes designed to encourage or require drivers to reduce their speeds. Engineering approaches are often given the general title of "traffic calming," and the title is also applied to plans that combine engineering changes with public information and education in order to affect whole neighborhoods, towns, or cities.

This chapter is divided into three sections. The first deals with speed management through means other than traffic engineering. The most common technique for this is using police enforcement along with posted speed limits, and this has received most of the research on effectiveness. One perspective makes speed enforcement a battle between police and speeders, and research on radar detectors, a prime weapon in the battle, is discussed. Finally, other speed management techniques are reviewed.

The second section reviews engineering-based approaches to speed management. While they often include aspects of speed management discussed in the first section of the chapter, the engineeringrelated approaches always include some physical change to the roadway or road environment intended to cause drivers to proceed more slowly. The final section of this chapter looks at the topic of traffic calming as it applies to wide area schemes for managing traffic and speeds.

\section{Speed Limits, Enforcement, and Speed}

The most straightforward approach to speed management is, if you want to slow people down, lower the speed limit. This tends to be only marginally effective. Reducing speed limits reduces speeds by, at best, about one-quarter of the speed limit reduction. However, several European studies which examined the broad implementation of lower urban speed limits showed that lower limits could be well accepted by all road users and that they could reduce speeds, to some extent, and reduce crashes and injuries.

As described in Chapter 3 (Jensen, 1998), in Denmark, general speed limits were introduced in 1974 , and urban speed limits were reduced in 1985. In both cases, measured speeds came down (as did overall crashes and injuries and pedestrian crashes and injuries). When urban speed limits dropped 10 $\mathrm{km} / \mathrm{h}$ (6 mph), corresponding speeds dropped $2-3 \mathrm{~km} / \mathrm{h}$ (1.2-1.9 mph), consistent with ratios found elsewhere.

Johansson (1996) studied the long-term effects of reducing the speed limit from $110 \mathrm{~km} / \mathrm{h}(68$ $\mathrm{mph}$ ) to $90 \mathrm{~km} / \mathrm{h}(56 \mathrm{mph})$ on Swedish trafficways in June 1989 . He analyzed monthly data from January 1982 through December 1991. Statistical models which included seasonal factors showed that fatalities, serious injuries, minor injuries, and vehicle-damage-only crashes all declined after the speed limit change; the reduction was statistically significant only for minor injuries and property damage crashes. He did not provide any actual speed data.

In France, the basic urban speed limit was decreased from $60 \mathrm{~km} / \mathrm{h}(37 \mathrm{mph})$ to $50 \mathrm{~km} / \mathrm{h}(31$ $\mathrm{mph}$ ) in November 1990. According to Page and Lassarre (1994), although there was a general public 
information campaign to introduce the change, the different cities and regions implemented the signage supporting the regulation gradually and on their own schedules. Enforcement was not increased for the new law. On main roads in small towns, between 1990 and 1992 speeds of cars decreased slightly during daytime (from $65 \mathrm{~km} / \mathrm{h}(40 \mathrm{mph})$ to $60-63 \mathrm{~km} / \mathrm{h}(37-39 \mathrm{mph})$ ) but speeds were unchanged at night (about $74 \mathrm{~km} / \mathrm{h}(46 \mathrm{mph})$ ). For the entire country, injury crashes in urban areas decreased 14.5 percent from the two years before the speed reduction to the two years immediately after; in rural areas, where speed limits did not change, the decrease was 9.1 percent. Over the same period, fatalities decreased 12.3 percent in urban areas and 10.2 percent in rural areas. The effect was most prominent in urban areas of less than 5,000 inhabitants. The authors felt that the results, somewhat less than expected, might improve as areas better understand and implement the speed regulation (which also provides for $70 \mathrm{~km} / \mathrm{h}$ ( 44 $\mathrm{mph}$ ) arterials and $30 \mathrm{~km} / \mathrm{h}(19 \mathrm{mph})$ neighborhood roads).

In Graz, Austria, a city-wide $30 \mathrm{~km} / \mathrm{h}$ (19 mph) limit on all residential streets $(50 \mathrm{~km} / \mathrm{h}(31 \mathrm{mph})$ on through "priority" streets) was implemented in September 1992 (Sammer, 1997; Pischinger et al., 1995). The change was implemented in response to increasing requests from citizen groups to participate in an area-by-area traffic calming scheme that was gradually including more areas over a ten-year period. The comprehensive areawide program included traffic regulation (signs, roadway markings), extensive and varied public information and awareness campaigns, and supervision (enforcement and speed display boards). About 75 percent of all roads became $30 \mathrm{~km} / \mathrm{h}(19 \mathrm{mph})$. Injuries decreased from the year before the change to the year after. Minor injuries declined 12 percent, serious injuries dropped 24 percent, and all pedestrian injuries fell by 17 percent. Economic savings from the injury decreases were calculated to be about $\$ 6,000,000$, a 26 percent drop. Mid-block average and 85 th percentile speeds dropped immediately, then gradually recovered to a level slightly below pre-law speeds. Intersection speeds also dropped, by $2.5 \mathrm{~km} / \mathrm{h}(1.5 \mathrm{mph})$ on average, and the proportion of extreme speeds dropped sharply. Drivers exceeding $50 \mathrm{~km} / \mathrm{h}(31 \mathrm{mph})$ dropped from 7.3 percent "pre" to 3.0 percent "post." Surveys showed that approval of the reduced speed limits increased steadily after implementation, reaching 68 percent after 18 months for private car drivers, who were the least enthusiastic group throughout. Noise levels, measured on $30 \mathrm{~km} / \mathrm{h}(19 \mathrm{mph})$ streets, decreased; overall air pollution did not change.

Moving to the U.S., Casey and Lund (1992) showed that the effects of increasing speed limits can extend beyond the roads on which speed limits are raised. In 1987, some California highways had their speed limits raised from $55 \mathrm{mph}$ to $65 \mathrm{mph}$. Casey and Lund had studied speed adaptation - the tendency to drive faster on a medium-speed road after coming off of a high-speed road - while California's maximum speed limit was $55 \mathrm{mph}$. They repeated the study after some roads, but not those at the test sites, had speed limits raised to 65 . They found that: speeds on the still-55 mph freeways had increased, by 2 - $5 \mathrm{mph}$; speeds on adjacent roads had also increased, for speed-adapted drivers and nonadapted drivers; and the differential between adapted and non-adapted drivers remained. They concluded that raising speed limits in some locations may, through "some indirect process of speed generalization," also increase speeds elsewhere.

Parker (1997) described a study in which states and localities lowered and raised speed limits on short roadway segments. Sites included urban and rural community roads and rural roads. Speed limits were raised or lowered (only one change per site) by 5, 10, 15, or $20 \mathrm{mph}$. Actual speeds changed significantly, but only by as much as $1.5 \mathrm{mph}$. Crash rates did not change significantly, possibly because of the limited numbers of crashes overall but also possibly due to the very small change in mean speeds.

\section{Speed Enforcement}

Police enforcement of speed limits has been a primary tool to reduce speeds, but it is a technique with long-recognized limitations. Driver expectations are key. According to general psychology 
guidelines, speed enforcement will have the greatest effects on drivers if it is: 1) believed likely to occur, 2 ) meaningfully costly to the offenders, 3 ) associated with driving in general rather than any specific time of day or roadways, and 4) not associated with any specific cues that signal the presence or absence of enforcement efforts.

For enforcement to have continuing effects, the first point is essential: drivers must have a continuing expectation that enforcement will occur. This is a basic weakness with nearly all real-world enforcement schemes. Bjørnskau and Elvik (1992) describe the enforcement system in game-theoretic terms, where driver behavior is influenced by the enforcement and the enforcement program is affected by driver behavior. Simply, higher enforcement will lead to reductions in driver violations, leading to reductions in arrest "benefits" to the enforcers, leading to a reduction in enforcement (as assets are diverted to now-higher priority problems), leading to decreased expectations of arrest, leading to increases in driver violations, leading to higher enforcement, ... etc. Reviewing a number of studies on enforcement, the authors make several points: 1) large increases in enforcement do reduce the violation rate and can also reduce crash rates; 2) road users modify their behavior according to the enforcement pattern as they understand it, i.e., less or no change outside the "danger zone" for enforcement and quick reversion to pre-enforcement behaviors once the enforcement is restored to normal; 3 ) enforcement agencies focus enforcement efforts on perceived problems; 4) the authors have no documentation of enforcement cutbacks because the program was judged successful, but such cutbacks are quite plausible; 5) stiffer penalties (above an attention-getting threshold) do not bring down violation rates; and 6) permanent surveillance can produce permanently low violation rates. A recommendation, though one not judged likely to be followed, is for enforcement to be allocated randomly according to a nearly permanent overall plan that ensures minimally effective results.

Specific studies are reviewed below.

One unique study examined the effects of a widely known, complete absence of enforcement, in Finland during a national police strike (Summala et al., 1980). During the two-week strike, mean speeds increased only slightly, but the percentage of speeding more than $10 \mathrm{~km} / \mathrm{h}$ above the speed limit increased by $50-100$ percent. This increased speed standard deviation by about 20 percent, likely increasing crash risks. Also, "suspicious-looking" cars parked beside the road, which ordinarily would have caused drivers to slow down, evoked no response during the strike.

Council (1970) reviewed earlier speed enforcement literature and studied the effects of stationary and moving marked police units on the speeds of oncoming vehicles, on two-lane roads with speed limits of 55 and $60 \mathrm{mph}$. He found that speeds were depressed by $5-6 \mathrm{mph}$ alongside the stationary vehicle but that there was only minimal change alongside the moving vehicle. Speeds of vehicles 1.25 miles after passing the stationary marked car dropped slightly; speeds of vehicles 1.25 miles after passing the moving marked car were up slightly. No actual enforcement (stopping of motorists and issuing tickets) was done.

Dart and Hunter (1976) examined speeds at "treatment" points, two miles upstream, and two miles downstream on a two-lane rural roadway. Mean speeds alongside a partially concealed radarequipped marked police car (with a visible "Speed Check" sign), a manned parked police car, and an "enforcement scene" of a police car with flashers activated parked behind an "arrestee's" vehicle, all dropped by $5-6 \mathrm{mph}$ compared to the same site with no treatment. Mean speeds alongside a visual speed indicator sign, "Your speed is __" plus, for speeds over $55 \mathrm{mph}$, "Slow Down," were not significantly decreased compared to the no-treatment condition. In all three enforcement conditions, mean speeds had increased to recover about half the speed decrease by 1000 feet beyond the treatment, and by two miles downstream mean speeds in all conditions were comparable. 
Edwards and Brackett (1978) noted that the effectiveness of enforcement depends on increasing the drivers' belief that they may be apprehended if they speed, so that they will adjust their behavior and slow down. The goal is to make the "subjective probability" independent of time and place, so that drivers are encouraged to drive more slowly no matter when or where they are driving. They cited research that stationary marked-car enforcement is more effective than moving patrols or unmarked cars. Their study tested a two-phase approach: begin with intensive enforcement to effectively slow drivers down (two weeks), then continue with a schedule of minimum police presence that is still adequate to maintain the slower speeds (four weeks). They placed enforcement vehicles randomly along a 17-mile stretch. The strategy reduced average speeds and also extreme speeds, for up to 14 miles for the course of the study. The authors noted that vehicles with CB radio antennae traveled faster than vehicles without, although CB radio reports of enforcement activity did not have any effect on average vehicle speeds.

In The Netherlands, motorway speed enforcement routinely uses photo radar, with or without police present to stop some speeders, to cite all drivers exceeding a threshold speed level (de Waard and Rooijers, 1994). The authors tested several variations on $120 \mathrm{~km} / \mathrm{h}$ speed limit roadways, based on the proportion of speeders who were apprehended, the presence of police to do visible roadside stops, and for mail-out citations, whether mail notification arrived the next day or two weeks later. "Inconspicuous" radar sites and speed loops were about $5 \mathrm{~km}$ apart. When on-view stops were done, the stops were made in full view in the emergency lane between the radar and the speed loops. For all but the lowest enforcement level, speeds at the downstream loops were reduced; effects were greatest with the highest level of on-view enforcement, which was also the only condition to continue to show speed reductions in the four-week post-enforcement period. Speed variability (essentially, the prevalence of very fast speeders) also decreased during the treatments. (For the mail-out conditions, because speeds were reduced, the authors hypothesized that the enforcement camera's flash must have been visible and that it caused the speed reductions.) Questionnaires were sent to apprehended speeders, speeders who had not been apprehended, and non-speeders, of whom 80 - 91 percent were male. Speeders reported regularly driving faster, more frequently thought the $120 \mathrm{~km} / \mathrm{h}$ speed limit was too low, and rated speeding positively. There were no differences between apprehended and non-apprehended speeders. In a second study, de Waard and Rooijers were able to keep the level of speeding to 5 percent or less (about $40 \%$ below baseline levels) by adjusting their level of enforcement from week to week.

In the UK, Holland and Conner (1996) implemented an intensive enforcement campaign on a busy commuter dual carriageway. The campaign was based on police speed check warning signs for three weeks and visible enforcement in the middle week. Speeds declined significantly during the intervention weeks, most when police were visible and active. One week afterward speeds were still somewhat depressed, and some residual effect was present six weeks later. Surveys were given to users of the road at service stations before and after the treatment. Young and male drivers (young males most) showed high "intentions to speed" before the treatment, as did all drivers who self-reported more frequent speeding. After the enforcement treatment, women under 25 had lower intentions to speed, but men under 25 showed even higher intentions to speed.

Vaa (1997) reported on a study of police enforcement on a 35-km segment of two-lane road with speed limits of $60-80 \mathrm{~km} / \mathrm{h}$. The police developed their own schedule of enforcement, emphasizing irregular timing and placement of enforcement locations and ultimately averaging about 40 hours/week for six weeks. Speeds were reduced by up to $5 \mathrm{~km} / \mathrm{h}$ based on week and time of day, significant in all time periods. Percentages of speeding drivers also declined, with only morning rush hour speeds not significantly decreased. The effects lasted for up to eight weeks. A subsequent study was done to identify the minimum level of enforcement that would achieve comparable speed reductions (Vaa et al., 1995). 
In 1992, the National Highway Traffic Safety Administration assembled its recommendations on speed enforcement into "Beyond the Limits: A Law Enforcement Guide to Speed Enforcement" (NHTSA, 1992). Much of the guide was devoted to police department activities necessary to implement a speed enforcement program, including department policy and commitment, training, staffing, and support. Major emphasis was also placed on: data evaluations to document the problem (speeding, speedrelated crashes, etc.) and identify problem situations, designing an effective approach, strategic use of public information and education to increase knowledge and gain support, and program effectiveness evaluation. It was noted that "a comprehensive traffic program requires the joint efforts of law enforcement personnel, prosecutors, courts, driver licensing agencies, and public and private organizations."

In reviewing evidence on the contribution of speed to crashes on limited access roads, NHTSA (1992) cited TRB (1984) as concluding that, on limited access roads, the relationship between average speeds and crashes is not clear, but that vehicles traveling much faster or much slower than average are much more likely to be involved in crashes. The risk for vehicles traveling very slowly is problematic, because such vehicles may have problems or special circumstances, such as vehicle defects or special characteristics, driver limitations, or turning, merging, or stopping maneuvers - that make them particularly vulnerable. For very fast vehicles, though, excess speed and possible related risky maneuvers are the primary factors that distinguish them from vehicles traveling at average speeds.

The NHTSA guide did not offer suggestions on the kinds of enforcement strategies and patterns to obtain the most effective long term and wide area speed reductions, although it emphasized the importance of public information and education components. More than half the book was devoted to illustrations of active enforcement programs.

\section{Radar and Laser Detectors}

One topic within speed enforcement that has aroused considerable interest, if not emotion, is the use of radar detectors. Graham's (1996) overview article reviewed the controversy between the enforcement community and the pro-detector community. She also described the kinds of police strategies and technology to render radar detectors ineffective, including "instant on" radars that measure speeds before drivers can react, narrow-beam radars, radars that use patterns or frequencies not picked up by most radar detectors, laser speed measurement devices, VASCAR (a vehicle average speed calculator and recorder, based on the time taken to travel a known distance), and drone radar that triggers radar detectors even though no enforcement is being conducted. Radar detectors are illegal in many countries, including France, where the driver's vehicle can be seized, and in the District of Columbia and Virginia.

Drivers who use radar detectors drive faster and are less safe than drivers who don't use them. Teed and Lund (1993) conducted speeding enforcement campaigns in Charleston County, South Carolina. When laser enforcement devices were used (compared to standard police radar), more speeding tickets were issued and speeders were four times as likely to have radar detectors. Cooper et al. (1992) compared the crash and speeding convictions of 174 drivers who had special insurance covering radar detectors with a sociodemographically matched comparison group. Those with detector insurance had significantly more crash claims and speeding convictions.

Teed et al. (1993) cited research showing sharp reductions in actual traffic speeds when hidden police radar was activated, indicating that users of radar detectors were among the fastest drivers on the roads. They examined the effects of radar on the travel speeds of drivers on Interstate 70 in Maryland, then a 55-mph-limit road. Drivers exceeding $65 \mathrm{mph}$ were targeted by conventional police radar and their speeds were re-measured .05 miles later and again one, two, and five miles downstream. Forty-four 
percent of passenger vehicles were initially traveling more than $65 \mathrm{mph}$; this dropped to 32 percent immediately after they were hit by police radar, but the effect was essentially gone one mile later, where 42 percent were above $65 \mathrm{mph}$. Of 185 vehicles tracked at all sites, 81 showed brake lights and/or slowed by more than $5 \mathrm{mph}$ just after being targeted by the police radar, likely indications that they were using radar detectors. They were going somewhat faster initially (than drivers who did not react, i.e., who probably didn't have active radar detectors) but were slower immediately after, and the speed differences had vanished by 3 miles downstream. Fifty-eight percent of speeding tractor-trailers seemed to have radar detectors, as compared to 38 percent of light trucks and 32 percent of passenger cars.

Pezoldt and Brackett (1987) examined speeds along a thousand miles of 55-mph Texas highways. They found that trucks averaged $2 \mathrm{mph}$ slower when radar was activated, and - largest for trucks and very fast passenger vehicles - the proportion of vehicles exceeding $70 \mathrm{mph}$ dropped dramatically when radar was active. They noted, however, that their results did not show that users of radar detectors would drive faster than others if no one had radar detectors.

As early as 1987 , Christoffel argued that radar detectors should be banned. He cited case law in Virginia, the District of Columbia, and Connecticut (where detectors were illegal until 1992) upholding the validity of those jurisdictions' prohibitions. Fields and Hricko (1987) reviewed essentially the same court cases and came to the same conclusion. The one case in which courts ruled against enforcing a ban on radar detectors was cited in both articles and dismissed by the authors. Police in Michigan had attempted to charge a motorist under a Prohibition-era law against receiving police radio signals, but the courts eventually ruled that radar speed measurement devices were outside the scope of the law.

One constant in all radar (and laser) detectors so far has been that their only function has been to detect police speed enforcement efforts. Graham (1996) described the Safety Warning System ${ }^{\mathrm{TM}}$ device, which can receive signals from special radar transmitters that could be placed at crash scenes, near construction zones, or at other hazards. The Safety Warning System ${ }^{\mathrm{TM}}$ device would display one of up to 64 messages as to the nature of the hazard ahead. Naturally, the device would also respond to police speed radar, and the transmitted signals would cause standard radar detectors to trigger alarms. This device has not been tested in court.

\section{Automated Speed Enforcement (ASE)}

A next step in enforcing speed limits is photo radar, which clocks vehicle speeds and photographs vehicles traveling above a variable threshold value, usually set at $5-10 \mathrm{mph}$ above the speed limit. (Measuring vehicle speed can be done in any of a number of ways while being faithful to the basic premise of automatic speed enforcement.) The photos are used to identify the offending vehicle and mail speeding tickets to the registered owner. (If the owners were not driving, they are usually required to identify the drivers so that they can be cited.) The devices can yield a large number of citations with little on-site personnel expense. Traffic safety concerns about the devices are that, because the citation is delayed and remote from the actual violation, it may have little effect on speeding behavior. Legal concerns (Hoff, 1997) center on lack of officer discretion in deciding whether to cite, the delay between event and citation preventing the defendant from having an adequate chance to present a successful defense, and the relatively small consequences making it unreasonable to accept the expense of mounting a defense. Without directly relevant cases, Hoff concluded that, since photo radar is the combination of photographic evidence and radar speed measurement and since both are acceptable separately to courts, the combination is likely also acceptable.

Similar devices are used to detect, photograph, and cite drivers who run red lights. In this country, they are used in places like New York, Los Angeles, San Francisco, Paradise Valley, Arizona, 
Commerce City and Fort Collins, Colorado, Jackson, Michigan, and Fairfax City, Virginia. Installations typically include "Red Light Camera Ahead" and "Violators Photographed" signs, to maximize the changes in driver behaviors as well as provide fair warning.

Studies of automated speed enforcement (ASE) systems were reviewed and results synthesized by Blackburn and Gilbert (1995). Programs from the United States, Australia, Canada, and Europe were studied, including many of the ones specifically referenced here. The authors concluded that the devices can reduce speeds, crashes, and injuries, but that the extent of benefits depend heavily on the details of the situations. They reviewed the history of the use of ASE systems in the U.S. and elsewhere, considered legal and technical requirements for using the systems, and reviewed problems in their operation. They recommended scientifically controlled tests of the effectiveness of the systems in reducing speeding and crashes, development of certification and training procedures for the use of the devices, and passage of state-level legislation permitting local jurisdictions to use ASE systems.

Oei (1997) reviewed three kinds of automatic speed management in The Netherlands, based on whether they were for specific locations (e.g., intersections), specific rural road segments, or provincial road networks. Speed limit signs that flash when approaching drivers are speeding reduced speeds significantly at an urban and a rural intersection, and crash savings of $24-65$ percent were projected. On rural road segments, photo radar was used. The program began with an information campaign, and installations included a "Radar Check" sign, a speed limit sign, a variable "You Are Speeding" sign, and finally the photo radar. After a warning-only period, automatic enforcement was conducted for 3.5 months (with a brief interlude to repair vandalism damage, a problem cited frequently in reports of automatic traffic enforcement). Across four sites, average speeds and 85th percentile speeds dropped in the warning-only phase and dropped again during the enforcement phase. Speeders dropped from 38 percent in baseline to 28 percent and 11 percent in the test phases. Drivers were observed to brake when closing in on the devices and speed up after passing them. Injury (including fatal) and property damage only crashes dropped about 35 percent in the test periods when compared to control roads. In three provinces, 120 road segments were selected for photo radar enforcement. As police resources permitted, photo radar was operated from unmarked cars; downstream was a sign, "Your speed has been checked. Police"; and violators were cited by mail. Eighty-fifth percentile speeds dropped by $4-5 \mathrm{~km} / \mathrm{h}$, and the percentage of speeders dropped from 42 to 31 percent. Surveys were mailed to drivers in one province, and completed surveys were received from 76 percent. About three-quarters of them accept photo radar enforcement. Half said they comply with speed limits anyway, 70 percent said they would comply with monthly enforcement campaigns, and all said they would comply with weekly enforcement.

Norway has used photo radar for speed enforcement since 1988. Elvik (1997) examined crash reductions along 64 road sections with photo radar, finding an overall reduction of 20 percent in injury crashes and 12 percent in property damage only crashes (the former was statistically significant). After a number of installations had been made, warrants for their installation were developed (older units were not removed). Photo radar was appropriate if: crash rates were higher than for similar roads; there were at least 0.5 injury crashes per kilometer per year; and the mean travel speed was above the speed limit. On segments meeting the warrants, injury crashes dropped by 26 percent; on other segments, the decrease was only 5 percent. Traffic speeds were not directly measured, nor were other possibly relevant parameters and consequences, providing opportunities for subsequent research.

Photo radar installations have also been used in Kuwait (Ali et al., 1997). At eight test sites, drivers slowed significantly at the camera positions but were traveling at unreduced speeds at sites $1 \mathrm{~km}$ before and after the cameras. Some drivers used higher speeds downstream of some sites, perhaps in order to "make up" for the lost time passing the cameras. The authors note that even drivers "caught 
speeding" by photo radar almost never receive speeding citations in Kuwait, and that the absence of true enforcement makes photo radar essentially ineffective.

Portland, Oregon, is conducting a two-year demonstration project with photo radar in school zones and residential neighborhoods (Price and Hunter-Zaworski, 1998). The photo radar apparatus is mounted in a marked van and uses a reader board to advise drivers being ticketed for exceeding the speed limit. The city also posted signs at all entrances to the city advising of the use of photo radar. The authors summarize photo radar experiences in Australia, Canada, and various European countries. One U.S. study in National City, California, produced 14,000 speeding tickets in 20 months and reduced crashes from about 70 per month to less than 50 per month (Repard, 1993, cited in Price and HunterZaworski, 1998). In Portland, five streets received photo radar enforcement, and three control streets were included in the study. Tested streets had 25,30 , or $35 \mathrm{mph}$ speed limits. The test showed significant decreases in mean speeds and in percentages of drivers going more than $10 \mathrm{mph}$ above the speed limits, on test streets as compared with control streets. The authors recommend continuing and expanding the program, citing several possible benefits that might come from a broader and better known program.

\section{ASE "User" Surveys}

Freedman et al. (1990) conducted a telephone survey among residents of two communities (Paradise Valley, Arizona, and Pasadena, California) where photo radar is being used; they also surveyed residents of nearby communities. They found that between 75 and 96 percent of the respondents knew of the use of photo radar, 52 - 89 percent had seen it in use, 49 - 62 percent approved of its use, and - of those approving - $63-70$ percent thought its use should be expanded. Almost half of the respondents who knew that photo radar was being used said that they were driving more slowly as a result.

More recently, Streff and Molnar (1995) surveyed drivers in Michigan in areas where there was a NHTSA-sponsored pilot test of automated speed enforcement devices (ASEDs). About 29 percent of drivers returned the mailed surveys, roughly equal percentages of all licensed drivers, drivers who received warning letters based on ASED detection, and drivers detected as speeding by the ASED but not warned. (Michigan law did not allow issuing tickets based on photo evidence.) The study did not change drivers' speeds (not surprising to the authors because of the lack of "teeth" and minimal program publicity). Survey respondents favored use of ASEDs in select situations, particularly in school zones, in areas where traffic enforcement is dangerous for police, for heavy trucks, and in construction zones. The survey also showed opposition to ASED use on freeways, on bridges, and on "all roads." The observed speeders and persons who reported having multiple citations in the previous two years expressed greater opposition to the use of ASEDs than the general population.

Corbett (1995) conducted a similar survey in the UK after the experimental introduction of speed cameras. Overall, results indicated that speed cameras were effective in reducing the speeds adopted by some drivers, and there was some self-reported reduction in driving speeds in other areas. Drivers who reported driving fastest in general were most likely to report driving slowly as they passed the cameras but also did not reduce their speeds in other areas. In general, the surveyed drivers favored the speed cameras. The author recommended that placement of the cameras should be varied to increase the areas in which drivers slow down, while also noting that permanent placement at accident black spots may also meet objectives.

\section{Other Speed Management Approaches}

Hashimoto (1979) reported the use of police surveillance, without enforcement, on intersection problems in Japan. Posting one, two, or three uniformed police on the corners of a dangerous 
intersection, where they simply watched traffic in the intersection, led to reductions in "vulnerable behaviors." The behaviors were part of a model which described vulnerable behaviors as ones which placed drivers at risk of crashes, with subsequent circumstances, not under the control of the driver, key to whether a crash resulted. The author concluded that the vulnerable behaviors were valid indices of possible crash involvement and that they could be reduced by police presence.

Another technique used to reduce speeds is speed display boards, devices attached to trailers or police vehicles which display the speed of passing vehicles and may show a warning to speeders. Casey and Lund (1993) tested trailer-mounted speed boards labeled "police" and including the posted speed limit in Santa Barbara, California. When speed boards were deployed, speeds decreased by about 10 percent next to the boards and about 7 percent about one-half mile downstream, but effects rapidly disappeared when the boards were removed. Using varied deployment schedules, the authors found that speed reductions at the boards continued through two weeks of speed display board use but essentially vanished during the third week; throughout, downstream measurements showed little speed reduction. With intermittent enforcement, speed reductions continued through the third week at the speed display boards, but they were virtually gone at the downstream locations. When tested at school zones during hours when students would be present, speed boards produced drops of about $5 \mathrm{mph}$ at three sites, $1-2$ mph at two others with slower baseline speeds.

Webster (1995) reviewed vehicle-activated speed reminder signs in the UK, Europe, and the U.S. Most of the signs were "secret," i.e., with a blank face until activated by a speeding vehicle. Overall, the signs appeared to reduce vehicle speeds by a few $\mathrm{mph}$, and some of the reduction was maintained downstream. In the UK where the signs were used at entrances to villages, speed reductions were sustained into the middle of the villages. Speed reductions appeared to be maintained over time. Crash reductions were not statistically significant, although all cited changes in crashes were in the proper direction. As a practical concern, the authors noted that vandalism had been a problem in The Netherlands and in the U.S. (rifle fire).

Bloch (1998) compared photo radar, an unenforced speed display board, and speed display board with intermittent enforcement. The test was done in Riverside, California, on $25 \mathrm{mph}$ speed limit residential collector roads with average daily traffic of $800-2400$ vehicles in each direction. Speed data were collected for two baseline weeks, one week with the treatments in place, and one week after they were removed. Alongside the treatments, photo radar and the display boards reduced speeds by $4-5 \mathrm{mph}$ below baseline speeds of $34-35 \mathrm{mph}$. Speeds had nearly returned to normal by 0.2 miles downstream for photo radar and the standalone speed display board, but they remained depressed for the condition with intermittent enforcement. Speed decreases had vanished by one week later, and in fact were absent during the treatment week during the hours when the treatments were not present.

Eagle and Winter (1980) tested speed warning signs in the UK: "Police: Speed Check Area." They found that speeds declined throughout a 12-week test period, more so when enforcement was added, but the effects disappeared when the signs were removed.

School zones are an area of concern in most communities. Studies by Aggarwal and Mortensen (1993) in California and Hawkins (1993) in Iowa tested school warning signs with flashers which were illuminated in periods when students would be going to or from school. Both studies showed significant speed declines when the flashers were operating, although the amount of decrease varied from site to site and was not significant at all sites. Hawkins found the effect persisted for twelve months with the signs in operation although the size of the speed reduction decreased by about 30 percent. In Philadelphia, Jordan (1998) examined child pedestrian crash patterns. Although only about 5 percent of the crashes 
occur in school zones during key time periods, the city is planning to select schools with greater crash problems to install school zone flashing warnings.

Advisory devices, when used in specific situations, can be effective in reducing speeds. Maroney and Dewar (1987) used transverse lines painted on the roadway at progressively diminishing distances. The objective was to produce an alerting response and, with the illusion of acceleration, an actual slowing of the vehicles to compensate. Tested on an exit to a freeway in Calgary, Alberta, Canada, the transverse lines reduced speeds initially but the effect began to disappear after three weeks. The lines also led to increased speed variance, as some drivers heeded the warning and others didn't. Griffin and Reinhardt (1996) reviewed 10 studies, including Maroney and Dewar, and concluded that most studies showed the transverse painted lines could be effective in reducing speeds, more so at high speeds (such as 85 th percentile) than for means. The conditions tested varied, along with the effects. Some studies showed no changes, some showed changes that persisted for long times, and others showed changes that dissipated rapidly. Griffin and Reinhardt suggested that the primary mechanism by which the stripes worked was as a warning device, not through psychophysical illusions. Griffin and Reinhardt also looked at patterns of converging chevrons on the pavement in Japan, and they concluded that the chevron patterns may reduce crashes by as much as $25-50$ percent.

Retting and Farmer (1998) looked at pavement markings, "Slow" with a large arrow, on a rural road in Virginia just before a sharp curve. In their study, mean speeds dropped by up to 7 percent, compared to nearby untreated curves, and that the percent of drivers exceeding $40 \mathrm{mph}$ on approach dropped significantly.

\section{Summary}

Speed control through reducing speed limits and providing a mix of enforcement and public information has proven to have modest but real effectiveness. The basic situation is that the roads and vehicles are such that a large percentage of drivers, with no other constraints, would travel faster than is desired by the authorities, and that the official efforts are to slow drivers down. The purpose of lower speed limits and public education messages, often in conjunction with enforcement, is to have more and more of the population believe that slower speeds are appropriate and reasonable. The purpose of enforcement is to increase the perceived negative consequences of driving fast and to draw more attention to the public information and education.

Changing speed limits has proved to have significant effects on average speeds. When speed limits are reduced, average speeds decrease by about one-quarter of the reduction in the speed limit. In these cases, the speed limit changes are to new levels deemed reasonable or appropriate by the authorities and thus might be characterized as "moderate" changes. It is not reasonable to assume that the relationship would continue if speed limits were changed more drastically - that, for example, a true 10 mph drop in speeds could be effected by a $40 \mathrm{mph}$ drop in speed limits.

Enforcement is often used in conjunction with speed limits to control vehicle speeds, but its effects are also limited. Enforcement reduces speeds where and when the likelihood of apprehension is perceived to be high. However, enforcement is often an expensive, manpower-intensive operation, and the effects diminish rapidly away from the site and time of visible enforcement. Driver behavior suggests that many of them believe it is all right to drive quite a bit faster than the posted limits, and that the perceived high likelihood of enforcement is just a brief interruption to their normal driving patterns. The popularity of radar detectors, and the quick but transient response of radar detector users to perceived police radar, reinforces this conclusion. In the war of technologies, automated speed enforcement 
approaches such as photo radar allow enforcement to be more frequent, more broadly located, and more effective.

However, speed limits and enforcement are indirect means of controlling speeds. Direct approaches, like those which make it physically impossible, difficult, or unpleasant to travel faster than the authorities desire, are covered next.

\section{Engineering Approaches to Speed Management}

This section reviews speed management approaches that include traffic engineering components. Particularly with respect to non-motorized participants in traffic, these engineering solutions are designed to make the traffic environment and the actions of motor vehicles safer and more pleasant.

Until recently, the goal of traffic engineering has seemed to be to increase the mobility of motor vehicles by providing for greater numbers of motor vehicles and allowing them to travel at higher speeds with fewer interruptions and delays. Under that approach, pedestrians and bicycles became second-class (or worse) roadway citizens. Their safety was achieved by separating them from motor vehicles. Separations could be temporal, through traffic signals, sometimes having pedestrian-only phases (and prohibiting pedestrian movement at all other times), or physical, through separate facilities like overpasses, underpasses, bike lanes, or totally separate bike paths. While these approaches achieved some safety benefits for pedestrians and bicycles, they also added inconvenience, delays, and often discomfort. This has discouraged many from walking and bicycling. If the activities are sufficiently inconvenient and unpleasant, and if desired destinations are too far away, then fewer people will walk or bicycle.

Another result of this approach has been an unacceptably high level of pedestrian and bicycle casualties. Many roadways are not well designed to accommodate pedestrians and bicyclists, but they use them anyway. In trying to do so, they often place themselves at risk because of impatience or ignorance . or confusion about how they should negotiate the roadways. The result is crashes, injuries, and sometimes deaths.

Traffic engineering approaches have been developed to address the noxiousness of the traffic environment for non-motorists as well as the unacceptably high numbers of crashes, injuries, and deaths. This section of this chapter looks at individual techniques that have been used to control vehicle speeds and improve pedestrian and bicycle safety. It describes the techniques as well as studies of their effects, but it focuses primarily on their results for pedestrian safety. Although the interests of pedestrians and bicyclists overlap extensively, very little about bicycle safety and convenience will be covered, except where pedestrian solutions may have significant negative consequences for bicyclists.

\section{Road Humps}

"Road humps" can be successful in reducing both average and very high speeds, and the result is often a reduction in crashes, injuries, and deaths. Road humps are placed in roadways to cause vehicles to move up and down in a way that is uncomfortable if done too rapidly, thus encouraging drivers to slow down. Road humps have been used in foreign countries and in this country for decades, and a great deal of experience and research has been done to determine what shapes and spacings are appropriate to obtain what kinds of traffic control. (It should be emphasized that this does not refer to common American speed bumps, which are short, relatively high, and produce a jarring sensation if traversed at faster than walking speed.) 
Speed humps are typically about 12 feet in cross-section, flat or rounded on top, and $3-4$ inches high. Cars can cross them comfortably at $20-30 \mathrm{mph}$, depending on their exact shape. The British Department of Transport (DoT) (now the Department of Environment, Transport, and the Regions, or DETR), for example, has conducted extensive research and issued guidelines for hump design and placement, most recently in Traffic Advisory Leaflet 7/96, Highways (road humps) regulations 1996. That leaflet also contains recommended markings and signs for use in the UK, guidelines that provide useful input for U.S. applications. (See also Hodge, 1993, for a test of a variety of vehicles across speed humps; Webster, 1993a, for the danger of vehicles "grounding" on humps as a function of vehicle and hump dimensions; Webster, 1993b, for a study of hump implementations and effects on speeds, traffic flows, and crashes; Webster, 1994, comparing thermoplastic "thumps" and $50 \mathrm{~mm}$ high humps; Webster and Layfield 1996, reviewing the effects of $75 \mathrm{~mm}$ high humps at 72 sites; also DoT-TAU Traffic Advisory Leaflets 2/90, Speed control humps; 7/94, "Thumps," thermoplastic road humps; and 2/96, 75 mm high road humps).

One problem with speed humps is that different vehicles are affected in different ways. Trucks, buses, and most emergency vehicles bounce severely at speeds at which cars can travel comfortably. Kjemtrup (1988) reports on Danish studies into shapes of humps which could apply to different vehicle types, including the "K-hump" which includes two cross-sections, a standard speed hump in the center of the traffic lane and a hump with much longer cross-section at both edges. The K-hump intends for cars, which have relatively narrow tread measurements, to pass over the standard cross-section portion, and trucks and buses, with wide treads, to pass entirely on the extended-length hump sections. (The longer the hump cross-section, for any specific vehicle type, the faster the speed at which it can cross comfortably; their objective was to design the outer portion so that long-wheelbase buses and trucks could cross at the same speeds as cars could cross the center section.)

In the UK, the recommended solution to mixed car, bus, and truck traffic has become the "speed cushion." Speed cushions have the same cross section as standard speed humps, but they are at full height only in the center of the lane; toward the edges of the lane, speed cushions taper off until they are flush with the roadway. This requires cars, with narrow treads, to cross the cushions and be slowed by them, while allowing buses and trucks, with wider treads, to cross with their wheels at the tapered edges of the cushions and be much less affected. Research on their effectiveness, and recommendations for speed cushion dimensions, are presented in DoT-TAU Traffic Advisory Leaflets 4/94, Speed cushions, and $1 / 98$, Speed cushion schemes.

Zaidel et al (1992) described road humps as proven speed control devices with three general obstacles to wider implementation: They are perceived as being obstructions and degradations to the smooth paved surface of roadways; their early designs (including rumble strips and speed bumps) were ineffective or hazardous; and there is concern that they may become overused: The authors explored community issues, noise and vibration, and the impact of road humps on pedestrians (positive), bicycles (neutral or positive), large buses and trucks (negative but solvable), and emergency vehicles (also negative but solvable). Public opinion is a major concern, according to the authors, because there are a number of relevant classes of people who may have differing opinions and perspectives about them and because some negative responses appear to be well-founded. They emphasize that obtaining public support requires a combination of proper education and consultation and proper project needs analysis, design, and implementation.

In the U.S., speed humps have been a relatively recent element of the speed management arsenal. Gonzalez (1993) describes their use in Bellevue, Washington, along with a number of other techniques. They have also been employed in Maryland (Walter, 1995) as part of a coordinated program of speed management. The Institute of Transportation Engineers (ITE) published Recommended Practice: 
Guidelines for the Design and Application of Speed Humps in 1993 (see ITE, 1993, for a summary). This document includes guidelines for developing community involvement and support as well as design specifics for speed humps and markings.

Other uses of vertical deflections include: Crosswalks, where the raised section has a flat surface and it is marked and intended as a pedestrian crosswalk; raised intersections, in which the entire center area of an intersection is raised (and flat) with appropriate markings, thus making the intersection stand out from others and requiring all traffic to slow; and gateways, transitions from standard roadways into traffic-calmed villages or neighborhoods with appropriate signage. These are discussed below.

\section{Horizontal Traffic Deflections}

Roads which are broad and straight encourage higher speeds. Making them narrower and less straight encourages lower speeds. Wallwork and Burden (1998) present graphic illustrations of numerous techniques used to accomplish this. The midblock techniques include roadway narrowings through buildouts and parking; medians to narrow the roadway and often redirect traffic; chicanes 3 ; and midblock barriers to create two short cul-de-sacs. In practice, these may be combined, and vertical deflections such as speed humps and raised crosswalks may also be mixed in. For intersections, techniques include roundabouts, sidewalk buildouts to shorten pedestrian paths and slow turning traffic, one-way entry or exit treatments to eliminate some possible traffic flows, various diverters to eliminate some possible traffic flows, and barriers across one or more legs to close them off, simplifying the intersection and creating cul-de-sacs. Particularly at intersections, specific treatments are often part of comprehensive neighborhood or wide area traffic management plans that involve significant traffic redirection.

Chicanes have been examined in test track and field implementations by TRL in the UK. Sayer and Parry (1994) tested chicanes constructed of interlocking plastic lane curbing on the TRL test track. They varied lane width (symmetric before and after the single deflection), stagger length (length from the beginning of the chicane to the end), free view width (offset between the near curb and the offside curb seen across the stagger), and visual restrictions (barriers to forward visibility installed at the beginning and end of the chicane). In general, narrow lanes, short stagger, negative free view width (wider offsets), and visual restrictions all reduce speeds through the chicane. The effects of chicanes depend heavily on the length and width of the vehicle passing through; large vehicles must track more precisely and turn more sharply, and thus go more slowly. Some chicanes are too tight and narrow for some large vehicles to pass at all, and "overrun areas," of contrasting paving and texture and not used by most vehicles, may be added to allow large vehicles to go through narrow chicanes. Chicanes may be single lane (shared, on a two-way roadway), two lane, or two lane with a center divider. Chicanes may be combined to present a complex path and generate additional slowing. (See also DoT-TAU Traffic Advisory Leaflet 9/94, Horizontal deflections.)

Davies et al. (1997) examined the safety aspects of road narrowings such as chicanes for bicyclists. Half of 62 local highway authorities indicated they did consider bicyclists in designing traffic calming schemes. Twenty-eight sites were examined. Ones safe for bicycles tended to have bypass pathways through the obstruction. Observations showed that motorists overtaking or passing bicyclists did not wait but passed them in the narrowings, often at reduced clearances, and motorists often intruded into bike lanes when going through the restrictions. Overall, bicycle-motor vehicle crashes decreased by

\footnotetext{
${ }^{3}$ In this paper, "chicane" refers to any midblock construction which forces vehicles to swerve or weave laterally.
} 
about 35 percent, but this was not statistically significant and changes in bicycle flow rates were not monitored.

Sayer et al. (1998) studied 142 individual chicanes in 49 chicane schemes. Mean speeds through the chicanes were $23 \mathrm{mph}$, and 85 th percentile speeds were $28 \mathrm{mph}$, both reflecting a $12 \mathrm{mph}$ reduction from pre-chicane measurements. Speeds between chicanes, where more than one were installed, dropped by $7-8 \mathrm{mph}$ from the "before" speeds for means and 85th percentiles. Traffic flows were reduced by about 15 percent at single-lane chicanes and 7 percent at two-lane chicanes (all on two-way roads). Several of the chicane sites had no injury accidents in the "before" period. For the 17 schemes with known crash data, there was a 54 percent decrease in crashes after the chicanes were installed. (See also DETR-TAU Traffic Advisory Leaflet 12/97, Chicane schemes.)

Traffic islands have also been used to reduce vehicle speeds. They can be used to narrow roadways, guide vehicles over speed cushions, and serve as refuges for pedestrians. They also are used in chicane schemes on wider roads to channel traffic through paths that lower speeds. In DoT-TAU Traffic Advisory Leaflet $7 / 95$, a number of schemes are presented. Guidelines for accommodating pedestrians and bicyclists are also included.

One problem with chicanes (and roundabouts, below) is that when they are sized to evoke the desired behavior from cars they are too tight or small for trucks, buses, and most emergency equipment. One solution is "overrun areas," which are widenings or extensions that allow larger vehicles to pass through. Overrun areas are designed with slight rises and are paved of rough material like cobblestones so that car drivers will choose to stay on the smoothly paved roadways, not use the overrun areas, and be subject to the full slowing effects. (See, e.g., DoT-TAU Traffic Advisory Leaflet 12/93, Overrun areas.)

\section{Roundabouts}

Roundabouts are essentially forms of intersections at which traffic entering the intersection area is deflected into a circular pattern and vehicles travel around the circle until they find their desired exit point. Key features of roundabouts are that: entering traffic always yields to traffic on the circle (which prevents gridlock in heavy traffic and provides a simple set of rules for drivers encountering unfamiliar roundabouts); traffic must be deflected from its original path in order to enter the circle (which enforces traffic slowing even in light traffic); there may be flared areas upstream (to add high capacity for holding vehicles waiting to enter the circle and allow several to enter at once when the way is clear); and there may be islands for each entry/exit pair (which direct the traffic flow and provide refuge for pedestrians).

(The other term is "traffic circle," which is reserved for designs, often older, which violate one or more of the roundabout principles, such as giving priority to approaching traffic, giving different priorities to different approach legs, or allowing some roadways to pass through the traffic "circle" without diverting from a straight path. To the extent that they are not like roundabouts, traffic circles can present unique requirements that confuse unfamiliar drivers, and they can be considerably more dangerous than roundabouts or even standard intersections. "Traffic circles," such as those in Seattle, Washington, can also be quite safe, when their design requires traffic to slow and change path and share access equally.)"

Roundabouts range in size from mini-roundabouts, which have center islands of four meters diameter or less (the islands may be raised or may simply be painted), to full-size ones with central diameters of 25 meters or larger. Complex designs are also possible, with the final configuration a function of the number and layout of the entering roads. Some "pseudo-roundabouts" have been built to control traffic, essentially as a roundabout dropped into the middle of a stretch of roadway where there 
are no intersecting roadways. Roundabouts are intended to improve safety, to improve the traffic capacity of the intersection, and to minimize vehicle wait times.

In The Netherlands, Schoon and van Minnen (1993) examined the safety changes for 181 intersections converted from standard geometry to roundabouts. Motor vehicle traffic on the roundabouts varied from about 4,000 per day (ADT) to nearly 18,000 ADT, and bicycle traffic from about 200 per day to over 6,000 per day. From the five years prior to two years after conversion, fatal crashes dropped 76 percent and fatalities dropped 72 percent (adjusted for national drops in fatal crashes and fatalities over the same time period); pedestrian crashes (all injury severities) dropped 73 percent and pedestrian casualties dropped 89 percent. A small number of roundabouts were converted from old-style "priority to the right" traffic circles, in which traffic on the circle was required to yield to entering traffic; this change led to a 75 percent reduction in casualties, underscoring the importance of giving priority to traffic on the circle.

Schoon and van Minnen looked closely at bicycle safety as a function of how bicycles were accommodated on the roundabouts. The safest approach was to construct separate bike paths so that the bicycles crossed, usually yielding to vehicles, on bike paths that were outside of the roundabouts (i.e., crossed the approach roads very near the circle). Circles which had no separate provision for bicycles or ones that defined bike lanes around the outside edge of the circle were much less safe at high-volume locations (other work shows that bicyclists in that situation are particularly vulnerable to motor vehicles exiting the roundabout across the bike lane). Bike lanes on the roundabout which were painted red showed fewer crashes than those marked off with just a line on the pavement.

An ITE Technical Council Committee (1992) surveyed traffic control agencies throughout the world on their experiences with roundabouts. Benefits cited included "free flow of traffic," "use in residential areas," "safer," "reduce delays," and "good at low to moderate traffic volumes." Negative comments included "high crash rates," "potentially confusing," "take much space," "high delays," and "limited capacity." None of the negative comments came from England, where roundabouts are a mature design, and the authors conclude that many of the negative comments are based on implementations which do not correspond to current design standards.

Mundell and Grigsby (1997) reviewed an ongoing program of installing traffic circles at intersections in residential neighborhoods in Seattle, Washington. Over 600 circles have been implemented since 1973, and about 700 requests are received each year; a minimum of 30 per year are added. The paper reviews the selection process, circle design, crash reduction (for the 119 circles constructed in 1991-1994, the 187 crashes in the year before construction dropped to 11 in the year after; injuries dropped from 153 to 1), and neighborhood acceptance (only two have ever been removed, none in the last 12 years).

Bared (1997) reviewed roundabouts as alternative intersection treatments for the U.S. He cited European results showing significant safety benefits in The Netherlands, France, Norway, and Germany (but noted that, in Germany, crash rates at traditional traffic circles, with priority to entering traffic, were double that for signalized intersections and five times that for roundabouts). U.S. results cited by Bared also showed safety improvements.

Many of the roundabouts that have been built in the U.S. have been justified on the basis of traffic flow and vehicle safety improvements. They are relevant to this review only indirectly: they indicate that the traffic engineering community is becoming familiar with using them (and may use them for pedestrian safety purposes), and they provide opportunities for American drivers to become familiar with driving through them. Some examples, briefly: 
In Vail, Colorado, two roundabouts have been built at an interchange with a limited access road (Ourston and Hall, 1997; Doctors, 1996); they significantly improved traffic capacity and reduced operating costs.

Myers (1994) reviewed roundabouts in Maryland, including ones at interchanges. He described a statewide Roundabout Task Force, charged with identifying problem locations where roundabouts would represent cost-effective solutions; when the article was written, 25 such intersections had been identified. For one finished example, Myers cited no crashes since completion and positive community response.

Flannery et al. (1997) reviewed five single-lane roundabouts in Florida and Maryland. The roundabouts had ADT values from 7,600 to 17,800 vehicles. Crashes dropped by about 75 percent on each of four of the intersections, but rose slightly at the fifth; overall, injury crashes dropped from 20 in the two years prior to conversion to just one in the two years after. Average traffic delays dropped sharply at four intersections and rose at the fifth. The authors used the SIDRA software model to estimate traffic delays; they corresponded closely to actual measurements.

\section{Gateways and Entries}

When entire areas have been redesigned for slower traffic and pedestrian accommodations, it is important to identify the areas to approaching drivers so that their expectations and driving behaviors are adjusted. Entrances to towns and villages in the UK are called "gateways." For areas or roads that have been treated within towns or cities, the same function is performed by "entries." Gateways and entries typically include signs, which establish the ground rules (e.g., $20 \mathrm{mph}$ zone) and may give the name of the town or neighborhood, and should include roadway modifications which require drivers to begin driving in the manner appropriate within the area. When specific neighborhoods within towns or cities have been modified, often the entries are at the corners of perimeter streets that allow turns into the modified areas. For entire towns or villages, gateways are often located just outside the built-up area.

Wheeler et al. (1993) reviewed gateway treatments for 16 villages and two small towns in the UK. Speed reductions of up to $9 \mathrm{mph}$ were observed, with larger reductions associated with contrasting surface materials or paintings, actual or visual road narrowing, and advance warning of traffic calming. Speeds through the villages, without additional treatments, were depressed by up to $3 \mathrm{mph}$ for the 85 th percentile.

Gateway treatments are illustrated and described in the DoT-TAU Traffic Advisory Leaflet 13/93. Entries into traffic-calmed side roads or neighborhoods are illustrated in the DoT-TAU Traffic Advisory Leaflet $2 / 94$. The entries include buildouts, pinch points, changes in surface color or texture, vertical deflections (speed humps or speed tables), bollards (thick, low posts) and plantings, tactile paving, signing, and vertical design elements (posts, pillars, walls, fences, etc.).

\section{Other Approaches}

Most of the techniques already reviewed focus on ways of changing existing streets. One approach which begins with the design of new residential areas looks at traditional, or neotraditional, street design guidelines.

The ITE is developing a Recommended Practice for Traditional Neighborhood Development Street Design Guidelines (Chellman, 1997). Looking at "New Urbanism" communities, the guidelines emphasize designing the street systems to foster pedestrian and bicycle use and safety and require slow auto speeds. Specifics include narrow streets with on-street parking, alleys for access to parking and as 
utility corridors, and short curb corner radii at intersections. (However, NHTSA research has shown that parked vehicles on residential streets screen moving vehicles and pedestrians from each other and contribute to "dart-out" pedestrian crashes (e.g., Snyder and Knoblauch, 1971).)

Szplett and Sale (1997) review some characteristics of neotraditional neighborhood design, highlighting differences with existing design policies. They emphasize: sidewalks set back from roadways, ADTs of no more than 2,000 on residential streets (less is more desirable), convenient access to businesses on streets adjacent to the residential area, narrower streets with on-street parking, and alleys for access to backyard garages. The authors suggest that problems still remain in making neotraditional designs safe and attractive.

The city of Athens, Greece, sought to reduce traffic pollution in the city center by limiting vehicle access to only those necessary to support residents, businesses, and city services. After trying police enforcement and special regulations without success, they went to a system of retractable bollards at the perimeter of the city center. The area was open to anyone at certain hours, and once inside vehicles could always exit freely. During restricted periods, the bollards could be lowered by electronic ID cards held by those authorized to enter. In Athens, the system also included full-time video monitoring from a central site with fiber optic connections (Verra, 1998).

Webster and Layfield (1993) examined the use of rumble strips and rumble areas at 35 sites in the UK. Their report concluded that the devices can produce a modest speed reduction and a possible reduction in injury accident frequency. They provide guidelines on where and how the devices may be applied, including concerns about the noise they create and recommendations to maintain cyclist safety. DoT-TAU Traffic Advisory Leaflet 11/93, which reviewed a number of possible rumble device designs and presented application guidelines, is based largely on Webster and Layfield's findings.

Cynecki et al. (1993) tested the effects of rumble strips on pedestrian safety in Phoenix, Arizona. One or two clusters of rumble strips were placed in advance of marked, uncontrolled pedestrian crosswalks. This was done as part of a citywide pedestrian safety campaign which included public information, crosswalk warning signs, and using solid lane-line markings approaching crosswalks. Noise was a problem only in a few locations with unique characteristics. Speeds at the crosswalks were generally unaffected by the rumble strips. Pedestrian crashes, which averaged only about 13 per year at the test sites in the three years before the rumble strips, increased slightly in the next three years, to 15 per year. Citywide, possibly due to the ongoing pedestrian safety campaign, pedestrian crashes decreased slightly over the same time period.

Rumble strips are used in a number of applications beyond speed control. They work by alerting and warning drivers rather than forcing speed reductions. Harwood (1993) reviewed the use of rumble strips and their safety benefits. He listed six general applications for them on the traveled way: Approaching intersections, approaching toll plazas, approaching horizontal curves, in a tane to be closed, approaching a mainline lane drop, and around work zones. In all these cases, the goals are to warn, alert, and slow drivers. When applied continuously along the edge of the road shoulder, rumble strips in the form of grooves in asphalt can reduce run-off-road crashes by up to 63 percent. The author concluded that rumble strips can be quite effective in reducing crashes, but they don't work by reducing travel speeds. Some drivers reduce speeds when going over rumble strips, but many others don't, increasing the speed variance at the affected locations. Harwood provided general guidelines on where rumble strips could be used and how they should be configured. 


\section{Wide Area Traffic Management}

The kinds of engineering approaches described in the preceding section are effective in reducing vehicle speeds, and they may include other features which additionally increase safety and convenience for pedestrians and bicyclists. They can have other results as well. When traffic is slowed or impeded on some roadways and there are alternative routes available, drivers will often divert to the alternatives, which can increase congestion and crashes there. The solution requires real planning, with consideration of areas besides those in which the engineering techniques are proposed for implementation, and careful solicitation and management of public opinion. (Public input can help guide and improve the planning process and increase public knowledge and acceptance, and positive public opinion is often crucial to the positive outcome of these projects.)

Wide area traffic management is practiced today in some form in many, if not most, areas of the U.S. In residential neighborhoods and urban areas, where pedestrians and their safety are critical, use of the engineering approaches described above is being increasingly considered in this country along with pioneering and extensive application abroad. The general term applied to most of these schemes and approaches is "traffic calming."

A number of definitions of traffic calming have been offered. Most narrowly, it refers to ways of reducing vehicle speeds and possibly volumes. Hass-Klau (1990, cited in Lockwood, 1997) defined it as "'an overall transportation policy concept' to promote non-automobile modes of transportation" including such things as road pricing, taxation changes, and parking restrictions (Lockwood, 1997, p. 22). A group of British engineers and surveyors called it "the application of traffic engineering and other physical measures designed to control traffic speeds and encourage driving behavior appropriate to the environment" (County Surveyors Society et al., 1994, cited in Lockwood, 1997). ITE's definition is, "Traffic calming is the combination of mainly physical measures that reduce the negative effects of motor vehicle use, alter driver behavior, and improve conditions for non-motorized street users" (Lockwood, 1997). In practice, a wide range of techniques and applications all receive the name "traffic calming." Even though traffic calming nearly always includes engineering to cajole, coerce, or command driver cooperation, full implementation also requires community collaboration, information, and education and traditional support such as police enforcement.

The goal of reviewing traffic calming in this report is to assess its effect on pedestrian safety, but in many of the traffic calming studies cited that effect may not be measured directly. The accumulated weight of evidence from studies of traffic calming is that pedestrian injuries and total, or motor vehicle, crashes and injuries are closely related. Traffic calming which reduces motor vehicle crashes and injuries also reduces pedestrian injuries and severities. Thus the evidence cited in this chapter offers two kinds of support for traffic calming and vehicle speeds and pedestrian safety: direct, where speed and pedestrian injury changes are measured and compared, and indirect, where improvements for pedestrian safety must be inferred from demonstrated improvements in overall safety.

Controlled traffic calming evaluation studies which tabulated injuries before and after the traffic calming implementation, have regularly shown a decrease in total injuries and in the severity of the remaining injuries. Occasional studies have estimated actual vehicle speeds, and they find stronger relationships between vehicle speed and injury. 


\section{Traffic Calming Review Articles}

Many articles have been written which review the history, findings, and recommendations for traffic calming. They provide interesting and convenient introductions to the literature. Some of those which have come to our attention are listed in this section.

In September 1993, a U.S. FHWA-sponsored study team examined traffic calming practices and policies in England, The Netherlands, Germany, and Basel, Switzerland. The special focus was on improving pedestrian and bicyclist safety and encouraging the use of those modes. The full report (Zegeer et al., 1994; see also Tan and Zegeer, 1995) covered: background and government objectives; facilities in each country; education and promotion programs; enforcement and regulation issues; research and development activities; and conclusions and transferability to the U.S. Topics of major findings included ways of reducing vehicle speed, restricting traffic movements, reducing travel distances, and responses to highway capacity problems. Pedestrian and bicycle facilities were carefully reviewed.

Kjemtrup and Herrstedt (1992) provided a historical view of European activities. They distinguished between speed management as regulating the speed of vehicles and traffic calming as reducing the passability or accessibility of vehicles. They described three periods. Up to 1968, traffic accommodations emphasized bigger and better facilities for the dramatically increasing numbers of vehicles. When it became apparent that vehicles had an insatiable appetite for facilities and that trying to cater to it created cost and safety problems, the next emphasis (1968 - 1979) was on providing separation of vehicles and non-motorized roadway users. This approach was truly feasible only in new developments, though, and it created competitions for space that often resulted in resolutions that impeded and discouraged pedestrians and bicyclists. From 1980 to 1990, emphasis came to be placed on wide area traffic management, which included traffic calmed areas, speed restraint measures on some arterials and collector roads, and traffic redistribution through building bypasses or designating certain roads as priority traffic through roads. By this time, expertise was gained on what techniques work, how they can be done cost-effectively and attractively, and how it can all be coordinated through wide area planning.

Herrstedt (1996) also reviewed the status of speed management from a European perspective. European experts estimated that reducing average speeds by $5 \mathrm{~km} / \mathrm{h}$ could eliminate 11,000 fatal crashes and 180,000 injury crashes per year in the European Union (EU) countries. In Denmark, urban and transition-area roads are split into two categories, traffic roads and local roads, each with three speed ranges. The author cited four speed management approaches: road engineering (traffic calming), enforcement by police and speed cameras, public information and education, and - on heavy vehicles speed limiters. Her main categories for engineering speed reducers included prewarnings, gateways, roundabouts, chicanes, narrowing and islands, humps, raised areas, and pedestrian-only or pedestrianpriority malls. She recommended that any specific countermeasures be part of a town-wide traffic management plan, and that early public participation is essential.

Schlabbach (1997) briefly reviewed the development of traffic calming from one traffic hump in Delft in 1970 through "woonerven" ("residential yards" where pedestrians have priority over motorists) to the second generation areawide traffic calming starting in 1978-80 to present-day third generation town and transportation planning approaches. In general, the third generation may be characterized as broader and more integrated planning using the proven second generation tools. Schlabbach organized the goals of traffic calming into a triangle with nodes of: speed reduction; transportation system management; and improvement of ecological modes of transport. 
A brief introduction to the Dutch experiences with traffic calming was presented by Kraay (1987), from woonerven to the $30 \mathrm{~km} / \mathrm{h}$ zones. He concludes that injuries can be reduced by about half,. and that a key element in implementing these changes is converting research knowledge into information and education for politicians, decision makers, and ordinary citizens.

German experience at the same time (briefly reviewed by Clarke and Tracy, 1995) divided urban streets into three classes: arterials, $50 \mathrm{~km} / \mathrm{h}$ with synchronized traffic signals, bike lanes, crosswalks, wide sidewalks, and median refuges; collectors, $30 \mathrm{~km} / \mathrm{h}$, narrower, with speed tables, bike lanes, and other devices to slow traffic to the speed limit; and residential streets encouraging walking speeds and pedestrian priority through more extensive traffic calming engineering.

A large number of German traffic calming studies have shown overall and pedestrian safety benefits from traffic calming. Keller (1987) reviewed work on "areawide traffic restraint," which sought to extend the results in residential areas to large areas of cities. The key feature to this work was application of speed control mechanisms to the main roads in cities, not just low-speed, low-volume residential streets. Keller described tests in model areas of six cities. Emphasis was on resistance to fast driving, through road narrowing, buildouts, speed humps, parking, and chicanes. One-way streets and street closures, which would have extensively disrupted travel patterns, were avoided. Some roads were rebuilt to divert traffic so that they were no longer major through routes. Adjustments to speed humps were made for buses (resulting in "speed cushions" in British terminology), and tailored solutions were developed for cities with ring-road systems. Keller also described calming techniques applied to through roads in villages, including gentle "waves" in the road that didn't affect slow traffic but effectively tamed the higher speeds.

Brindle (1997) examined the state of traffic calming in Australia. In the 1970s, Australia focused on street closures to break up interconnected paths in residential areas. In the 1980 s, the emphasis shifted to speed reduction and "streetscaping" to improve the appearances of roads. At the time of the article, speed reduction dominated. Brindle presented a matrix of types of measures (physical/environmental techniques and social/cultural/attitudinal changes) and scopes of measures (local, street or neighborhood; intermediate, zone, corridor, or regional road; and city-wide). He emphasized that community and society changes in values and expectations need to occur to support continuing efforts to expand traffic calming, with social change perhaps the dominant area of operation for wide area traffic calming.

Earlier, Brindle (1992) noted the then-common use of the term traffic calming to mean reduction of car travel demand rather than restraint on driver behavior and route choice. He suggested that citywide suppression of traffic goes beyond "traffic calming" as it was commonly understood, into the realm of travel demand management and cultural change.

Ribbens (1996) reviewed pedestrian facilities in South Africa. Approaches were distinguished by whether they involved integrating pedestrians with traffic or separating them. The report was organized by crossing situation (e.g., intersection, midblock), operational problems, and solutions. Wide area plans were also discussed. Overall improvement in recent years was noted, and it was attributed to development of a research-based pedestrian facility manual (in 1993) and the gradual implementation of its guidelines.

Ewing (1994) looked at the distribution of road functions - mobility vs. land access - for arterials, collectors, and local streets according to several schemes. In the U.S., there is a gradual increase of emphasis on land access (and deemphasis of mobility) from arterials to local streets. Neotraditional designers blur functional distinctions, so that all of the road classes would have nearly equal emphasis on mobility and land access. By contrast, the Australian-British model would assign high mobility functions to all arterials and larger collectors and high land access functions to smaller 
collectors and all local streets, with a very sharp break occurring at mid-size collectors. Accordingly, for local roads the British and Australian design guidelines call for narrower roads and sharper curves and corners than American design guidelines (AASHTO, ITE, and ASCE/NAHB/ULI), and they are also more generous in calling for sidewalks. The result is that British and Australian local roads are designed for slower motor vehicle speeds and more safety and convenience for pedestrians. Where sidewalks are not required, according to Ewing, the British and Australians "take extraordinary measures to slow down traffic" (Ewing, 1994, p. 46). Ewing also contrasted specifications for collectors, intersections, networks, and traffic calming devices. He concluded that American understanding of residential street functions and approaches to traffic management are behind those of Britain and Australia.

Leonard and Davis (1997) performed a similar exercise, comparing engineering requirements for traffic calming measures with AASHTO and MUTCD design guidelines. They concluded that in order to permit intersection diverters, roundabouts, street narrowing, angle points, and driveway links, existing guidelines needed significant alteration. They recommended updates to such manuals to facilitate and guide the use of traffic calming measures.

For the Insurance Corporation of British Columbia, Geddes et al. (1996; Zein et al., 1997) reviewed the safety and cost benefits of traffic calming. Their review looked at Europe, Australia, the United States, and four British Columbia neighborhood calming projects. For 85 case studies reviewed, the median post-measure crash reduction was about 80 percent; in the 15 cases with expected numbers of crashes 5 or more, the median reduction was about 70 percent. Looking at case studies where it was possible to isolate the effectiveness of individual types of countermeasures, Geddes et al. found the following levels of crash reduction: Traffic circles and chicanes, 82 percent; narrowings, 74 percent; speed humps, 75 percent; stop signs, 70 percent; multiple measures, 65 percent; pedestrian refuges, 57 percent; and speed limit reductions, 30 percent. Cost-benefit analyses were performed on the BC projects, and on average the costs of the modifications were paid back in just six months in crashreduction savings. The authors recommended that the client (an insurance company which financially benefits from crash reductions) should aggressively work with municipalities to identify areas suitable for traffic calming, to underwrite part of the costs, and to perform before-and-after studies to confirm the safety benefits.

Sarkar et al. (1997) reviewed traffic calming, areawide traffic management, and other countermeasure approaches from the perspective of pedestrian activity and safety. They summarized the kinds of traffic calming tools and their conditions of use and briefly noted the kinds of results obtained with traffic calming. They argued that the U.S. was well behind other countries in striking a balance between motor vehicles and other road users, and that a broad and concerted effort to implement traffic calming approaches would directly benefit all road users and provide cost savings to society in general.

Ewing and Kooshian (1997) surveyed traffic calming sites within the U.S. and provided a practical summary of the results. Over 16 locales, they found speed control measures, súch as speed humps, roundabouts, and chicanes, more popular than volume controls, such as street closures and diverters. Six sites had implemented areawide traffic calming, and one planned to do so. They reviewed implementation difficulties, particularly with fire and emergency departments, determined that liability issues were rare and minor, and noted that traffic calming was usually quite popular with residents.

Most reports or reviews of traffic calming include some measure of public responses to the projects. Webster (1998; see also Windle and Mackie, 1992, and Windle and Hodge, 1993) summarized the results of public attitude surveys on 40 traffic calming projects in the UK and 5 outside the UK. Most of the projects were initiated with some level of public consultation and approval (but not all; see Wheeler et al., 1996, and Wheeler et al., 1997), so it would be expected that reactions to the projects 
would be positive. Overall UK approval ratings were 65 percent, ranging from a low of 18 percent to a high of 93 percent; six response rates were below 50 percent. Four of 14 non-UK surveys showed negative responses; all were part of a broad Australian study. Schemes with road humps were approved by 72 percent of respondents (range, 47 - 93 percent). Projects with speed cushions were approved by 53 percent of respondents. Chicane projects received highly variable responses, ranging from 18 percent to 89 percent approval. The least-liked chicane was a one-way design which produced backup queues of up to 25 vehicles during peak times and was subsequently removed. Road closures were rare but received generally positive responses; mini-roundabouts were not well received, possibly because driver behaviors were inconsistent and often showed no slowing at all. Webster plotted perceived speed reduction against actual reduction, perceived volume reduction against actual reduction, and perceived crash reduction against actual reduction. All plots showed a small positive relationship between perceptions and reality, but correlations were very small. A reasonable conclusion is that approval ratings for traffic calming projects is largely dependent on factors other than how well the projects met their engineering objectives. Other work, which emphasizes the process for designing and implementing the safety countermeasures, suggests that the "other factors" are closely related to how much the residents, businesses, and drivers were involved in the needs analysis and project design and pre-approved it.

\section{Roadway Modifications and Their Effects}

Many of the studies cited earlier in this review anticipated this topic. Articles reviewed in this section are overview articles and ones for broad and long-standing projects in the U.S.

Proctor and Belcher (1997; Proctor, 1997) reviewed a national database of over 200 pedestrian road safety measures in the UK. Crash reductions by type of safety measure ranged from 66 percent to 29 percent; the measures, in decreasing order of effectiveness, were: vertical traffic calming (speed humps, tables, and cushions); areawide traffic calming; "improvement" to pedestrian crossing; horizontal traffic calming (chicanes, buildouts, narrowings, etc.); pedestrian refuge islands; controlled pedestrian crossings; and pedestrian guard rails. Much of the crash reductions they attribute to reduced walking; the number of walking trips per person dropped by 12 percent from 1985/86 to 1993/95, and total distance walked dropped by 18 percent; journeys by other modes went up 12 percent and distance traveled increased 24 percent. Proctor argues for evaluating walking danger reduction and trip encouragement as well as just casualty reduction in formulating transportation policy and selecting and designing specific projects.

The city of Portland, Oregon, has implemented a wide range of traffic speed control projects through devices such as speed humps and roundabouts (Portland, 1997a). Most of the projects have been in response to identified traffic problems and were conducted after neighborhood meetings and ballots of approval (cited figures are up to 70 percent approval rates). Summary data show speeds reduced 15 - 30 percent, traffic volumes down $14-38$ percent, and reported crashes down 30 - 39 percent.

In Portland, the fire department and emergency services were quite skeptical about the effects of traffic calming on their operations. Atkins and Coleman (1997) described empirical tests of the delays on response time due to the street modifications; the work provided the material for constructive discussions among the relevant parties and formed the basis for expanded design criteria and considerations. The result was broader support for the speed control programs.

In the same city, the Arterial Traffic Calming Program (Portland, 1997b) began in 1992 to address excess speeds on primarily residential, neighborhood collector streets - ones that link residential streets and arterials. Every three years, the 275 neighborhood collector streets would be rated, by segment, to determine project priorities, with citizen participation solicited. Speed and volume are 
primary criteria, along with residential density, lack of sidewalks, elementary school crossings, other pedestrian activity generators such as retail areas and parks, and street width. Two or three projects could be done each year. Crashes, noise, local/non-local mix, percent trucks, percent single-occupant vehicles, etc. are not selection criteria. Two pilot project sites were treated with 22 -foot speed humps and other lesser measures; 85th percentile speeds dropped in one instance from $33-40 \mathrm{mph}$ to $24-35 \mathrm{mph}$ and in the other from $26-40 \mathrm{mph}$ to $24-30 \mathrm{mph}$. Crash data were not reviewed.

Eugene, Oregon, developed a Local Street Plan in part to address problems with speed, system fragmentation, and functional uses and access (West and Lowe, 1997). The LSP project changed the street design and development city code to allow more flexibility in street widths, for example, and connectivity. The project, which included a comprehensive review of the existing code, added traffic calming; bicycle, pedestrian, and transit connections, and new sidewalk mandates to produce a system supportive of all modes of transportation. The authors emphasized including all components of the community in the planning process.

Seattle, Washington, has had a Neighborhood Traffic Calming program in effect since the 1970s; the program has installed over 600 residential area traffic circles (islands usually 12-16 feet in diameter with center plantings, not requiring modifications to existing curbs) (Mundell and Grigsby, 1997; see also Seattle Engineering Department, 1986; Von Borstel, 1985; and Dare and Schoneman, 1982). In the 1990 s, the program was budgeted for 30 intersections/year, selected based on crashes, 85th percentile speeds, and traffic volume. Conversions are made only if 60 percent of the affected residents favor it and a volunteer is found to maintain the center plantings. Between 1991 and 1994, 119 traffic circles were installed; crashes went from 187 the year before to 11 in the year after installation. Injuries went from 153 to one. Figures were similar for the 32 intersections which had been controlled by stop or yield signs before conversion: 90 percent fewer crashes ( 49 to 5) and 97 percent fewer injuries (38 to 1). The program is extremely popular; 700 requests are received each year, 80-90 percent of mailback survey responses feel the circles are effective and want to keep them permanently, and only two have been removed, none in the last 12 years.

Also in Seattle, a neighborhood project has been designed and implemented with collaboration between the city engineering department and the neighborhood community council (Seattle Engineering Department, 1993). The objective was to reduce cut-through traffic on two residential streets and divert the through traffic to adjoining arterials. The project included two circles, four chicane areas, and one curb bulb (a curb extension that narrows the vehicle path at the entrance to an intersection) along with one pedestrian signal and was implemented in summer 1992. Through traffic dropped by 22 percent, 85th percentile speeds "dropped, and the number of motorists traveling at the fastest speeds has dropped dramatically." Volumes on neighboring streets were not adversely affected. Phase II, a comprehensive plan for the neighborhood, was scheduled.

Walter (1995) described traffic calming measures applied in Howard County, Maryland, to counter excessive speeds on the broad residential streets built to a $35 \mathrm{mph}$ design speed. A number of speed hump applications were cited, including round humps, 22-foot long flat-top humps, and raised crosswalks. Traffic circles and roundabouts have also been installed in several Maryland counties. Traffic circles were noted to have problems with large trucks, which executed left turns by turning in front of the circle. Roundabouts, with splitters on the entry roads, eliminated the problem. At roundabouts, reductions in 85 th percentile speeds from $40 \mathrm{mph}$ to $20-22 \mathrm{mph}$ were cited. Road restrictions - "chokers," or chicanes - had also been installed, as well as medians and "twisted chokers" (double chicanes). Traffic engineering and resident approval criteria were noted. 


\section{Traffic Management Guidelines}

At a summary level, there have been a number of published guidelines on traffic management treatments. Some of them are cited in this section.

The Dutch "began" traffic calming in 1970 in Delft with a road hump at the end of an alley (Schlabbach, 1997). Over the next several years, a number of Dutch cities developed approaches to reduce vehicle speeds. In 1976, new regulations took effect and the first design standards for residential precincts ("woonerf"; woonerven) were published in The Netherlands. A woonerf was designed to eliminate through traffic, to reduce vehicle speeds to near-walking levels, to make the roadways extensions of the rest of the surface, and to give pedestrians and bicyclists full and equal access to the roadways. Woonerven created to the original model represented major changes, ones which were quite expensive. In 1984, the Dutch Government passed laws enabling designated areas with maximum speed limits of $30 \mathrm{~km} / \mathrm{h}$. From these laws came a Dutch $30 \mathrm{~km} / \mathrm{h}$ zone design manual.

The Dutch manual was translated into English and annotated to apply to the UK by Lines and Castelijn (1991). It began with overall goals for residential areas (reduced crashes, more relaxed and secure environment, easy and safe use of public spaces) and 10 specific objectives. Objectives relevant to reducing crashes and increasing road security included: good routes to local facilities, reduced vehicular traffic, reduced noise/fumes/vibration, fewer large vehicles, lower speeds in residential areas, adequate sightlines on main roads, and clear views between roads and roadsides. The manual continued with guidelines on evaluating the traffic environment, selecting specific countermeasures (including factors to consider), and illustrations and engineering guidelines for each countermeasure.

Van Loosbroek (1997) described recent conditions in The Netherlands for the design and implementation of traffic calming. His emphasis was on practical considerations for town councils and on the gap between nationwide targets and the ability to take actions at the local level in order to reach the targets. He also described positive examples of cities such as Utrecht implementing schemes in accord with overall traffic safety planning.

The Traffic Calming Act of 1992 led to 1993 Highways (Traffic Calming) Regulations in the UK. They provided guidelines for pinch points, rumble devices, gateways, chicanes, islands, buildouts, and overrun areas along with prior guidelines for roundabouts, pedestrian refuges, varying roadway widths, alterations in the level of the highway, and road humps (see DoT-TAU Traffic Advisory Leaflet $7 / 93$ for an overview). Other issues, such as community and road user consultation, landscaping, access, signing, and monitoring, were also addressed.

The UK has developed extensive procedures for designing and implementing traffic calming measures. The Department of Transport (DoT) produced "Circular Roads 4/90" (described in DoT-TAU Traffic Advisory Leaflet 7/91) with basic guidelines for introducing $20 \mathrm{mph}$ speed limit zones. Emphasis was on self-enforcing measures and consideration of emergency services, buses, and large trucks, and various measures were described. Signing for $20 \mathrm{mph}$ zones is covered in DoT-TAU Traffic Advisory Leaflet $2 / 93$.

The Danish Road Directorate (Herrstedt et al., 1993) developed a comprehensive and attractive guide based on 20 years of traffic calming experiences in Denmark, France, and Germany. In the catalog of ideas, traffic calming was defined as: conversion with the aim to reduce the volume of car traffic and/or reduce car speed on a particular spot, in one or several streets or in a whole precinct. The catalog contained a brief description of the development of the traffic calming concept, the planning process, a short account of what can be achieved by reducing car traffic volume and lowering car speed, and an introduction of the concept of traffic management by design. Subsequent chapters covered: the elements 
of urban space; speed reduction techniques; total (areawide) solutions; and examples from all three countries. Each example included a text description, pictures of the conversion, and the results achieved. Summary sections were provided for gateways, roundabouts, and speed humps. An extensive list of references was provided. (In a complementary document, relating to the principle that roadway modifications must be attractive to win public approval, the Directorate described Danish strategies for developing "beautiful roads" (Nielsen et al., 1995).)

The first serious work on traffic calming in this country was by Appleyard (1981), whose actual topic was moderating the effects of motor vehicles in order to reclaim neighborhoods for people. He extensively reviewed case studies of neighborhood improvement projects in England and in the San Francisco area. One valuable result of his work is the cataloging of mechanisms and procedures by which communities and agencies worked to implement change - successfully and unsuccessfully. His concluding chapters, on a statement of (urban dweller) principles, the politics of the street, street management (he referenced Dutch woonerven), and traffic control devices and systems, have been quoted regularly by more recent advocates of improved environments for pedestrians.

For the FHWA, Clarke and Dornfeld (1994) developed a broad review of traffic calming around the world and in the U.S. They also reviewed traffic calming techniques and offered practical and policy implications for developing traffic calming solutions. They concluded that traffic calming could directly improve pedestrian and bicycle safety and had a number of other direct and indirect benefits as well, and they presented recommendations for this country.

Savage and MacDonald (1996) described "A Guidebook for Residential Traffic Management" developed for Washington State. The guidebook emphasized a toolbox metaphor. The Alliances Toolbox emphasized involvement, learning including formal research, and consensus-building between traffic professionals and the community to develop a shared understanding of the problem, possible solutions, and the recommended solution. There followed toolboxes for speeding, volume, crashes, and miscellaneous tools such as woonerven, neotraditional street design, bike lanes, and landscaping. The first three of these toolboxes were organized by phases. For example, for speeding, Phase I approaches included lesser manipulations like signs, pavement marking, speed display boards, enforcement, speed watch/warning, and photo radar; Phase II approaches included more extensive and permanent measures when Phase I measures aren't adequate, such as speed humps and tables, roundabouts, medians, chokers and buildouts, chicanes, parking redeployment, and landscaping.

Sarkar et al. (1998) developed recommendations for a traffic calming handbook which, they argued, included the tools needed to implement areawide traffic management and neighborhood traffic management programs. Included were guidelines for road humps, speed cushions, speed tables, and other vertical deflection variations; intersection redesigns including bulbouts/neckdowns, roundabouts, and raised junctions; midblock redesigns including chicanes, midblock raised crosswalks, and pinchpoints; street closures, cul-de-sacs, and intersection diagonal diverters; rumble strips, flashers (may be timeactuated), speed monitoring trailers, speed limit signs, bollards, information signs, landscaping, night illumination, stop signs, and crosswalk markings. Installation costs were discussed. The recommendations emphasized U.S. conditions and applications.

At the time this report was prepared, the Institute of Transportation Engineers with the Federal Highway Administration was developing a traffic calming handbook for the U.S. (Ewing, 1998, in process). The handbook includes a section on working with communities to develop optimal plans and solid local support as well as sections on specific countermeasures.

A similar effort is also taking place in Canada (Skene et al., 1997). The product will be the Guide to Neighbourhood Traffic Calming, which specifically limits itself to local streets and residential 
collector roads. It includes: Introduction, with an overview of traffic calming, its conditions of applicability, and Canadian regulative and legislative context; Community Involvement, which describes how to involve local officials and communities; Applicability and Effectiveness, reviewing the benefits, implications, and technical details of each specific measure; and Design Guidelines, showing how each device should be located, constructed, and maintained.

The Institute of Transportation Engineers also developed a Recommended Practice for the Design and Safety of Pedestrians (see Zegeer, 1995). It included 14 chapters. Those relevant to this effort included "Roadway design considerations," "Pedestrian and motorist signing," "Signalization," "School practices," "Neighborhood traffic control measures," and "Pedestrian-oriented environments."

Braaksma (1997) described a community-based process for developing a community traffic management program. The process emphasized bringing engineering and community components together for the entire problem definition and solution development stages, intending to provide solutions better tailored to the community and to build local backing. The process included: creating a communitybased working group, analysis of issues and concerns, problem definition, planning process development, preliminary "traffic calming" designations established for specific streets, public meetings, community workshops, final public meeting, and submission of the community recommendations to the normal political decision process.

Levinger and McDowell (1998) utilized a similar process in Troy, New York, to use traffic management to save and restore a downtown neighborhood. They described a process combining experts and local residents and advocates, and they stressed requiring the experts to be able to discuss their positions and recommendations in the vernacular - in the vocabulary and reflecting the perspectives of the community.

Castellone and Hasan (1998) described neighborhood traffic management in Dade County, Florida. A steering committee of state and local traffic agencies, local municipalities, and a hired consultant was created to develop guidelines and standard procedures for local jurisdictions to follow in implementing small-area traffic control. Through public meetings and surveys, they drafted public and private concerns and assembled a list of traffic calming techniques and tools, ranging from least restrictive (signs, pavement markings) to most restrictive (diagonal diverters, road closures). The result included a formal procedure for requesting and selecting traffic modifications which is currently undergoing an 18-month test.

From a quite different vantage point, the British Department of Transport (1992) elaborated a policy for addressing the problem of excess speeds. Recommendations for reducing speeds included detection and deterrence (police enforcement), changing attitudes of drivers and the general public through public information and education, traffic calming implementation, vehicle speed limiters, fine tuning of speed limits, and continued research into the problem and possible solutions. The report was quite general, and was meant to describe policy and provide direction and support. As such, it put into concrete form the kind of support that is implicit for countries such as Denmark, Germany, and - through recent Federal transportation authorization legislation - the U.S. Without such official support and direction, local implementation efforts would be much more difficult to initiate and sustain.

Wellar (1997a, 1997b, 1998) developed a Walking Security Index (WSI), based on factors of safety, comfort, and convenience, to evaluate intersections as environments for pedestrians. Source material came from an extensive literature review plus input from elected officials, transportation professionals, and lay groups. Variables included structural, or feature, variables, and functional, or performance, variables. The next-to-final WSI specification referenced a total of 212 variables split among: Infrastructure features; vehicular traffic features; pedestrian traffic features; infrastructure 
performance measures; and user (behavior) performance measures for vehicles, drivers, and pedestrians. The final model was based on a subset of those variables, possibly adding others, based on reviews from the three groups of "experts" listed above. The WSI was intended to allow objective coding of pedestrians' safety, comfort, and convenience at specific intersections. This would allow existing intersections to be evaluated along with proposed changes or new intersections as to their adequacy for pedestrian traffic.

\section{Summary}

The literature reviewed in this chapter covers a wide range of techniques that have been used to control vehicle speeds and, directly or indirectly, to increase safety for pedestrians. At one end are traditional approaches built around speed limits, public information and education, and highly visible enforcement. These approaches are most often used for higher speed roadways in order to reduce vehicle-only crashes, but enforcement-based efforts have been targeted at school zones and other sites with at-risk pedestrians. The speed reductions are limited and depend heavily on the perception of likely apprehension, but they can produce safer conditions for pedestrians.

Enforcement-based approaches are most practical on high-volume roadways, where a large number of potential violators can be monitored by a small number of law enforcement officers, and at selected other sites which have high concentrations of crashes.

At the other end are approaches specifically intended to increase safety for pedestrians and other non-motorists and, in many areas, to improve the ambience for residents. These approaches usually include permanent engineering changes to roadways which require slower traffic speeds. The changes can be dramatic and very significantly reduce pedestrian and vehicle crashes. Perhaps more than enforcement does, though, they depend on public understanding, planning involvement, and approval for their success.

The history of roadway engineering to control vehicle speeds is most extensive with the development of traffic calming in Europe and a few other countries, but areas like Seattle, Washington, and Portland, Oregon, have been implementing speed control measures on their roads and at their intersections for nearly 20 years. There, measures have been successful, both in terms of public acceptance and crash and injury reduction. The programs have proceeded slowly, starting at a few sites with well-known crash problems and, with initial success, expanding to more and more sites. Public acceptance has kept up, and new installations can almost always be placed where the public has requested them.

Engineering measures are most practical on moderate and low speed roadways. They are useful at specific high-crash sites, but they also have characteristics that make them suitable for moderatetraffic, moderate-crash sites. Foremost is that, once implemented, they are effective without constant attention (such as enforcement), and they can be placed in areas where regular enforcement could never be afforded. Also, they require little maintenance, so engineering changes can be implemented as funding is available without placing burdens on future budgets. 


\section{RECOMMENDATIONS}

Reductions in vehicle speeds can have a very significant influence on pedestrian crashes and injuries. Pedestrians suffer much more serious injuries when struck by high-speed vehicles than when struck by vehicles going more slowly. Also, many pedestrian crashes would be prevented entirely had the vehicles been traveling more slowly, since driver and pedestrian would have had more time to perceive the threat and react to the risk, averting the crash altogether.

NHTSA has a long history of speed reduction campaigns centering on police enforcement and public information and education, and the agency has countermeasure approaches in this area. Until now, these techniques have not been combined with engineering changes, which have been found to be quite effective in reducing vehicle speeds. The recommendations in this section are aimed toward approaches which emphasize merging enforcement, PI\&E, and engineering changes to produce the desired speed reductions.

Up to now, efforts in this country to change the roadways to reduce travel speeds, including ones that can be characterized as traffic calming, have been led by the traffic engineering community. Key players have included the Institute for Transportation Engineers (ITE) and the Federal Highway Administration (FHWA) at the national level and city and state traffic engineers. Bicycle safety organizations and advocates, plus environmental protection organizations, have also taken active roles. Their experience and the resources they have already mobilized could be very helpful to NHTSA as the latter moves forward to protect pedestrians and other road users. This kind of cooperation has been successful in the past, for example in Community/Corridor Traffic Safety Programs jointly sponsored by NHTSA and FHWA.

Traffic calming - and even wide area traffic management - programs begin at a local level, with very specific countermeasures implemented to impact travel and safety at carefully chosen sites or in neighborhoods or wider areas. The programs begin by affecting drivers and pedestrians primarily in the limited area where they have been implemented, and the publicity and education components do not reach many people outside the area. When the programs become more common, they can become part of nearly everyone's experience in a broader area. At that point, wide-area media, such as newspapers, radio, and TV, can become important tools in a general public information and education campaign. An organization such as NHTSA can effectively deliver the message through numerous media channels and in other creative ways. This kind of campaign, similar to the current Buckle Up America initiative, can make the message pervasive and change perceived societal norms, increasing pressure for individuals to change their behavior and attitudes.

First, however, it is crucial to find ways to make approaches such as traffic calming and wide area traffic management well understood and accepted by the vast majority of the public. NHTSA can take a first step toward this by making case studies of uses of traffic engineering techniques to control vehicle speeds in this country - both successful and unsuccessful ones. Also suitable as case study topics are campaigns to win public support for community projects in general. These examples are widespread, and they can offer blow-by-blow instruction on how to establish the need, how to enlist community understanding and support, and how to implement the changes successfully.

Next, pilot programs can be sponsored by NHTSA to develop and test specific approaches. A list of possible steps that should be included in such programs includes:

1. Enlist community involvement, with a preliminary judgment of a speed-related pedestrian safety problem, to participate in all subsequent steps. 
2. Perform problem identification and evaluation, including identifying the scope of the dangerous areas, assessing traffic speed characteristics, and quantifying the pedestrian crash and injury problems.

3. With full community participation, recommend specific countermeasures and deployment patterns. For engineering changes to roadways and intersections, it is important to estimate the effects of the changes, not only in terms of pedestrian safety but also in terms of traffic distributions, traffic delays, and changes in the affected neighborhoods. These kinds of projections are important for communities to decide whether to make the changes and to defend their choice.

4. Develop an implementation plan. The full plan should include PI\&E, enforcement, and engineering recommendations and should include a timetable for coordinating all of the elements. The plan should identify public information and education needs to support the project, for the community at large as well as for pedestrians, motorists, and other road users. It should also lay out the education and enforcement roles for the law enforcement agencies in supporting the project.

5. Implement the program.

6. Evaluate the program. The kinds of impacts measured for other traffic engineering projects have included: Changes in speed distributions; diversion of traffic to adjoining areas or roads and safety consequences; delays to motorists; safety effects, such as changed numbers of pedestrian and total crashes and injuries, in the modified area and other affected areas; general public, pedestrian, and motorist awareness of the project, knowledge about it and its results, and attitudes toward it; non-traffic benefits such as improved neighborhood quality of life; and cost-benefit calculations.

Traffic engineering changes, such as traffic calming, have shown safety and other benefits in implementations in this country and, much more extensively, in Europe and other heavily motorized countries. A great deal has been learned about what countermeasures are effective and how best to design them. A great deal has also been learned about the route to public acceptance of and enthusiasm for these changes, as well as that it can be a gradual, slow process.

These programs are intended to complement and support current methods of speed control which emphasize speed limits, enforcement, and public information and education. Separately, traffic calming and enforcement tend to be most appropriate for different kinds of situations. The approaches can work together, however, with an integrated approach combining PI\&E, enforcement, and engineering as appropriate to make it more certain that the desired effects will be achieved. NHTSA, with its long history of support for pedestrian safety and for speed control, should be a critical supporter of efforts to bring traffic calming and other such tools into the battle. 


\section{REFERENCES}

Aggarwal, G.C., and Mortensen, S.L. Do advanced school flashers reduce speed? ITE Journal, 63(10), October 1993, pp. 24-30.

Ali, S.Y., Al-Saleh, O., and Koushki, P.A. Effectiveness of automated speed-monitoring cameras in Kuwait. Transportation Research Record 1595, Highway Safety, Traffic Law Compliance, Speed Management, and Heavy Trucks, 1997, 20-26.

Anderson, R.W.G., McLean, A.J., Farmer, M.J.B., Lee, B.H., and Brooks, G.B. Vehicle travel speeds and the incidence of fatal pedestrian crashes. Accident Analysis and Prevention, 29(5), pp. 667-674, 1997.

Appleyard, D. Livable streets. Berkeley: University of California Press, 1981.

Ashton, S.J. A preliminary assessment of the potential for pedestrian injury reduction through vehicle design. Proceedings of the Twenty-fourth Stapp Car Crash Conference, 1980; published 1982.

Atkins, C., and Coleman, M. The influence of traffic calming on emergency response times. ITE Journal, 67(8), August 1997, pp. 42-46.

Bared, J. Roundabouts: Improving road safety and increasing capacity. TR News, 191, July-August 1997, pp. 13-15, 27.

Bjørnskau, T., and Elvik, R. Can road traffic law permanently reduce the number of accidents? Accident Analysis and Prevention, 24, 507-520, 1992.

Blackburn, R.R., and Gilbert, G.T. Photographic enforcement of traffic laws. NCHRP Synthesis of Highway Practice No. 219, 1995. Transportation Research Board, 2101 Constitution Avenue, NW, Washington, DC, 20418, USA.

Bloch, S.A. A comparative study of the speed reduction effects of photo-radar and speed display boards. 22 pp., 29 refs. Paper presented at Transportation Research Board 77th Annual Meeting, January 1115 1998, Washington DC.

Braaksma, J.P. A community-based process for traffic calming. Paper presented at Transportation Research Board 76th Annual Meeting, January 1997, Washington DC. 13 pp.

Brindle, R.E. Local street speed management in Australia - is it "traffic calming"? Accident Analysis and Prevention, 24(1), pp. 29-38, 1992.

Brindle, RE.. Traffic calming in Australia - more than neighborhood traffic management. ITE Journal, 67(7), July 1997, pp. 26-33.

Casey, S.M., and Lund, A.K. Changes in speed and speed adaptation following increase in national maximum speed limit. Journal of Safety Research, 23, 135-146, 1992.

Casey, S.M., and Lund, A.K. The effects of mobile roadside speedometers on traffic speeds. Accident Analysis and Prevention, 25(5), pp. 627-634, 1993. 
Castellone, A.J., and Hasan, M.M. Neighborhood traffic management: Dade County, Florida's street closure experience. ITE Journal, 68(1), January 1998a, 28-32.

Chellman, C.E. Traditional neighborhood development street design guidelines. Washington, DC: ITE Technical Council Committee 5P-8, Publ. No. RP-027, 1997, Draft. (Draft announced for review and comment in ITE Journal, June 1997, 67(6), 44-45.) •

Christoffel, T. Putting the brakes on lawbreaking: state bans on radar detectors. American Journal of Public Health, Vol. 77 (4), April 1987.

Clarke, A., and Dornfeld, M.J. National bicycling and walking study. Case study no. 19: Traffic calming, auto-restricted zones, and other traffic management techniques - their effects on bicycling and pedestrians. Federal Highway Administration, 400 7th Street SW, Washington DC 20590, Report No. FHWA-PD-93-028. January 1994, 64 pp.

Clarke, A., and Tracy, L. Bicycle safety-related research synthesis. Contract No. DTFH61-92-C-00138, Final Report No. FHWA-RD-94-062, 152 pp., April 1995. North Carolina University, Highway Safety Research Center, Chapel Hill NC 27599; Bicycle Federation of America, 150621 st Street NW, Suite 200, Washington DC 20036; Federal Highway Administration, Turner Fairbank Highway Research Center, 6300 Georgetown Pike, McLean VA 22101.

Cooper, P.J., Zuo, Y., and Pinili, M. Are radar detector users less safe than nonusers. Accident Analysis and Prevention, 24(4), 329-338, 1992.

Corbett, C. Road traffic offending and the introduction of speed cameras in England: The first self-report survey. Accident Analysis and Prevention, 27(3), pp. 345-354, 1995.

Council, F.M. A study of the immediate effects of enforcement on vehicular speeds. Highway Safety Research Center, U. NC, Chapel Hill NC, March 1970.

County Surveyors' Society et al.. Traffic calming in practice. Report, November 1994. London, England: Landor Publishing Ltd.

Cynecki, M.J., Sparks, J.W., and Grote, J.L. Rumble strips and pedestrian safety. ITE Journal, August 1993, 63(8), 18-24.

Dare, J.W., and Schoneman, N.F. Seattle's neighborhood traffic control program. ITE Journal, February $1982,52(2), 22-25$.

Dart, O.K., and Hunter, W.W. Evaluation of the halo effect in speed detection and enforcement. in Highway Safety, Traffic Records, and Law Enforcement, Transportation Research Record 609, TRB, 1976.

Davies, D.G., Ryley, T.J., Taylor, S.B., and Halliday, M.E. Cyclists at road narrowings. Crowthorne, Berkshire, UK: TRL, Report 241, 1997.

Department of Transport; Scottish Office. Killing speed and saving lives. The government's strategy for tackling the problem of excess speed on our roads. November 1992, $19 \mathrm{pp}$. 
DeWaard, D., and Rooijers, T. An experimental study to evaluate the effects of different methods and intensities of law enforcement on driving speed on motorways. Accident Analysis and Prevention, 26(6), pp. 751-765, 1994.

Doctors, P. Roundabouts end interchange gridlock. WesternITE, July-August 1996, p. 6.

Eagle, R., and Winter, R. Speed warning signs. Police Research Bulletin, No. 34, pp. 38-41, Spring 1980.

Edwards, M.L., and Brackett, R.Q. The management of speed. Traffic Safety, pp. 18-20, 28-30, October 1978.

Elvik, R. Effects on accidents of automatic speed enforcement in Norway. Transportation Research Record No. 1595, pp. 14-19, 1997.

Ewing, R. Residential street design: Do the British and Australians know something Americans do not? Transportation Research Record Issue No. 1455, Pavement Management Systems, pp. 42-49, 1994. Transportation Research Board, Business Office, 2101 Constitution Avenue NW, Washington DC 20418.

Ewing, R. Traffic Calming Handbook. Institute of Transportation Engineers, 525 School St. SW, Suite 410, Washington DC 20024, in process (1998).

Ewing, R., and Kooshian, C. U.S. experience with traffic calming. ITE Journal, 67(8), August 1997, pp. 28-33.

Fields, M.M., and Hricko, A.R. Prohibiting radar detectors: legal issues. Insurance Institute for Highway Safety, March 1987.

Flannery, A., Elefteriadou, L., Koza, P., and McFadden, J. Safety, Delay and Capacity of Single Lane Roundabouts in the United States. Paper presented at the 77th Annual Transportation Research Board Meeting, January 11-15, 1998. 27 pp.

Freedman, M., Williams, A.F., and Lund, A.K. Public opinion regarding photo radar. Transportation Research Record No. 1270, 1990, pp. 59-65. Transportation Research Board, 2101 Constitution Avenue, NW, Washington, DC, 20418, USA.

Geddes, E., Hemsing, S., Locher, B., and Zein, S.R. Safety benefits of traffic calming. Vancouver, BC, Canada: Hamilton Associates Consulting Ltd., 51 pp. February 1996.

Gonzalez, K.L. Neighborhood traffic control: Bellevue's approach. ITE Journal, May 1993, 63(5), 4345.

Graham, S. Police battle speeders. Traffic Safety, November/December 1996, pp. 8-12.

Griffin, L.I. III, and Reinhardt, R.N. A review of two innovative pavement patterns that have been developed to reduce traffic speeds and crashes. Washington, DC: AAA Foundation for Traffic Safety, February 1996, 59 pp.

Harruff, R.C., Avery, A., and Alter-Pandya, A.S. Analysis of circumstances and injuries in 217 pedestrian traffic fatalities. King County (Washington) Medical Examiner's Office, May 1997, 35 pp. 
Harwood, D.W. Use of Rumble Strips to Enhance Safety. National Cooperative Highway Research Program (NCHRP) Synthesis of Highway Practice 191. Transportation Research Board, Washington DC, 1993,70 pp.

Hashimoto, A. Measuring the effect of police surveillance on the prevention of traffic accidents. Accident Analysis and Prevention, 11, pp. 261-270, 1979.

Hass-Klau, C. The theory and practice of traffic calming. Can Britain learn from the German experience? Brighton, England: Environmental and Transport Planning, January 1990.

Hawkins, N.R. Modified signs, flashing beacons, and school zone speeds. ITE Journal, June 1993, 63(6), 41-44.

Herrstedt, L. Speed management in urban areas and transition zones - European experiences. Paper presented at the Second International Conference on Asian Road Safety, Beijing, October 28-31, 1996.

Herrstedt, L., Kjemtrup, K., Borges, P., and Andersen, P. An improved traffic environment: A catalogue of ideas. Denmark Ministry of Transport, Road Data Laboratory, Road Standards Division, Report 106, 166 pp., 1993.

Hodge, A.R. Speed control humps - a trial at TRL. Crowthorne, Berkshire, UK: TRL, Project Report 32, 1993.

Hoff, C. Legal issues surrounding photo-radar speed enforcement. WesternITE, July-August 1997, 51(4), pp. $1-3,9$.

Holland, C.A., and Conner, M.T. Exceeding the speed limit: an evaluation of the effectiveness of a police intervention. Accident Analysis and Prevention, 28(5), pp. 587-597, 1996.

Institute of Transportation Engineers Technical Council Committee 5B-17. Use of roundabouts. ITE Journal, February 1992, 62(2), 42-45.

Institute of Transportation Engineers Technical Council Task Force on Speed Humps. Summary of a proposed Recommended Practice: Guidelines for the design and application of speed humps. ITE Journal, May 1993, 63(5), 11-15.

Interdisciplinary Working Group for Accident Mechanics (University of Zurich and Swiss Federal Institute of Technology ETH). The car-pedestrian collision: injury reduction, accident reconstruction, mathematical and experimental simulation: head injuries in two-wheeler collisions. The Group, Zurich, 1986.

Jensen, S.U. DUMAS: Safety of pedestrians and two-wheelers. Note No. $51,68 \mathrm{pp}$. Road Directorate, Division of Road Safety and Environment, Niels Juels Gade 13, P.O. Box 1569, DK-1020 Copenhagen K, Denmark, March 1998.

Johansson, P. Speed limitation and motorway casualties: a time series count data regression approach. Accident Analysis and Prevention, 1996, 28(1), 73-87. 
Jordan, G. Child pedestrian-car crashes near schools are a small percent of total child pedestrian crashes in Philadelphia. Paper presented at Transportation Research Board 77th Annual Meeting, January 1115 1998, Washington DC.

Keller, H.H. Major roads in the German area-wide traffic restraint project. In Kraay, JH, Ederveen, GC (Eds.) Proceedings of the international workshop 'Recent developments in road safety research,' The Hague, 19 November 1986. Institute for Road Safety Research SWOV, The Netherlands, Leidschendam, 1987, pp. 72-105.

Kjemtrup, K. Speed reducing measures. Australian Road Research Board Proceedings, Vol. 14, Part 2. Canberra, Australia, 1988.

Kjemtrup, K., and Herrstedt, L. Speed management and traffic calming in urban areas in Europe: A historical view. Accident Analysis and Prevention, 24(1), 57-65, 1992.

Kraay, J.H. Countermeasures in the infrastructure; some Dutch examples. In Kraay, JH, Ederveen, GC (Eds.) Proceedings of the international workshop 'Recent developments in road safety research, ' The Hague, 19 November 1986. Institute for Road Safety Research SWOV, The Netherlands, Leidschendam, 1987, pp. 60-71.

Leonard, J.D. II, and Davis, W.J. Urban traffic calming treatments: Performance measures and design conformance. ITE Journal, 67(8), 34-40, August 1997.

Levinger, D., and McDowell, G. Expertise and the vernacular: Toward cooperative voices in urban transportation. Paper presented at Transportation Research Board 77th Annual Meeting, January 1115 1998, Washington DC.

Lines, C.J., and Castelijn, H.A. Translation of Dutch 30-kph zone design manual. Crowthorne, Berkshire, UK: TRL, Paper PA 2046/91, 1991.

Lockwood, I.M. ITE traffic calming definition. ITE Journal, 67(7), July 1997, pp. 22-24.

Maroney, S., and Dewar, R. Alternatives to enforcement in modifying the speeding behavior of drivers. Transportation Research Record 1111, 1987, pp. 121-126. Washington DC: National Research Council, Transportation Research Board, 1987.

Miles-Doan, R. Alcohol use among pedestrians and the odds of surviving an injury: evidence from Florida law enforcement data. Accident Analysis and Prevention, January 1996, 28(1), 23-31.

Mueller, B.A., Rivara, F.P., Lii, S., and Weiss, N.S. Environmental factors and the risk for childhood pedestrian-motor vehicle collision occurrence. American Journal of Epidemiology, 1990, 132: 550560 .

Mundell, J.E., and Grigsby, D. Neighborhood traffic calming: Seattle's traffic circle program. Paper prepared for the Institute of Transportation Engineers District 6 Annual Meeting, July 20-23 1997, Salt Lake City, Utah. 6 pp.

Myers, E.J. Modern roundabouts for Maryland. ITE Journal, October 1994, 64(10), 18-22.

National Highway Traffic Safety Administration. Beyond the limits: A law enforcement guide to speed enforcement. U.S. Department of Transportation, DOT HS 807-802, February 1992. xiii + 114 pp. 
National Highway Traffic Safety Administration. Traffic Safety Facts 1995. DOT HS 808 471, September 1996, 192 pp.

National Highway Traffic Safety Administration. National Automotive Sampling System (NASS) General Estimates System (GES): Analytical User's Manual 1988-1997. 1998, 136 pp.

Nielsen, N.C.S., Plejdrup, M., Djurhuus, O., Møller, I., and Varming, M. Strategy for beautiful roads 1995. Denmark Ministry of Transport, Road Directorate, March 1995, 26 pp.

Oei, H. Automatic speed management in the Netherlands. In Transportation Research Record 1560, Safety and Human Performance, Transportation Research Board, National Research Council, Washington DC, 1997, 57-64.

Ourston, L., and Hall, G.A. Roundabouts increase interchange capacity. ITE Journal, December 1997, $67(12), 30-36$.

Page, Y. La mise en oeuvre du "50 en ville" et ses effets sur la securite routiere. Les cahiers de l'Observatoire, No. 1, pp. 43-66, July 1994.

Parker, M.R. Jr. Effects of raising and lowering speed limits on selected roadway sections. Report No. FHWA-RD-92-084, January 1997. Final Report to Contract No. DTFH61-85-C-00136.

Pasanen, E. Driving Speeds and Pedestrian Safety; a mathematical model. Technical Report No. REPT77, and Nordisk Kabel- og Traadfabriker, Copenhagen, Denmark, 41 pp., 1992. Helsinki University of Technology, Laboratory of Traffic and Transportation Engineering, Espoo, Finland.

Pasanen, E. The video recording of traffic accidents. Report No. 1993:4, March 1993, Helsinki Finland City Planning Department, $11 \mathrm{pp}$.

Pezoldt, V.J., and Brackett, R.Q. The influence of radar detectors on Texas highway traffic speeds. Texas Transportation Institute, Texas A\&M University, Final report, August 1987.

Pischinger, R., Jammernegg, G., Sudy, Ch., Staska, G., Sturm, P., Sammer, G., Fallast, K., Hochkofler, M., and Wernsperger, F. Tempo 30/50 in Graz. Ergebnisse der wissenschaftlichen Begleituntersuchung für die Bereiche Verkehrsverhalten im Strassenraum, Verkehrsmittel- und Routenwahl, Schadstoffemissionen, Treibstoffverbrauch und Verkehrslärm. Schriftenreihe der Institute für Eisenbahnwesen Strassen- und Verkehrswesen, Technische Universität Graz, Heft Nr. $21,1995$.

Pitt, R., Guyer, B., Chung-Cheng, H., and Malek, M. The Severity of Pedestrian Injuries in Children: An Analysis of the Pedestrian Injury Causation Study. Accident Analysis and Prevention, December $1990,22(6), 549-559$.

Portland, City of (Oregon). Accidents on traffic calmed streets. From http:// www.trans.ci.portland.or.us; August 1997 (1997a).

Portland, City of (Oregon). Arterial traffic calming program. From http://www.trans.ci.portland.or.us; written approximately $1997 \mathrm{~b}$. 
Price, N.T., and Hunter-Zaworski, K.M. Evaluation of photo radar for the City of Portland, Oregon. Paper presented at Transportation Research Board 77th Annual Meeting, January 11-15 1998, Washington DC.

Proctor, S. Pedestrian safety - casualty reduction or danger reduction? Paper presented at seminar on Improving the pedestrian environment and realising the potential of walking as a means of transport, Aston University Civil Engineering Department, UK, March 18 1997. 4 pp.

Proctor, S., and Belcher, M. Pedestrian safety - how safe is it to walk? Paper presented at seminar on Developing a Strategy for Walking, Aston University Civil Engineering Department, UK, November $251997.6 \mathrm{pp}$.

Repard, P. National City drivers learning to say "Cheese." Law Enforcement Quarterly, May/June 1993, $11-12$.

Retting, R.A., and Farmer, C.M. Use of pavement markings to reduce excessive traffic speeds on hazardous curves. Paper presented at the Transportation Research Board 77th Annual Meeting, January 1998.

Ribbens, H. Pedestrian Facilities in South Africa: Research and Practice. Transportation Research Record No. 1538, Pedestrian and Bicycle Research, 1996, pp. 10-18.

Roberts, I., Norton, R., Jackson, R., and Hassall, I. Effect of environmental factors on risk of injury of child pedestrians by motor vehicles: a case-control study. $B M J, 1995,310: 91-94$.

Sammer, G. General $30 \mathrm{~km} / \mathrm{h}$ speed limit in the city. The results of a model project in the City of Graz, Austria. Paper presented at Transportation Research Board 76th Annual Meeting, January 1997, Washington DC.

Sarkar, S., Bach, B., Burden, D., Anderson, A., and Mitra, S. Useful guidelines for traffic calming handbook. (San Diego State U.) Paper presented at Transportation Research Board 77th Annual Meeting, January 11-15 1998, Washington DC. DRAFT only.

Sarkar, S., Nederveen, A.A.J., and Pols, A. Renewed commitment to traffic calming for pedestrian safety. Transportation Research Record \# 1578, Pedestrian and Bicycle Research 1997, pp. 11-19, 1997.

Savage, J.P. Jr., and MacDonald, R.D. A toolbox approach to residential traffic management. ITE Journal, June 1996, 66(6), 24-30.

Sayer, I.A., and Parry, D.I. Speed control using chicanes - a trial at TRL. Crowthorne, Berkshire, UK: TRL, Project Report 102, 1994.

Sayer, I.A., Parry, D.I., and Barker, J.K. Traffic calming - an assessment of selected on-road chicane schemes. Crowthorne, Berkshire, UK: TRL, Report 313, 1998.

Schlabbach, K. Traffic calming in Europe. ITE Journal, 67(7), July 1997, pp. 38-40.

Schoon, C.C., and van Minnen, J. The safety of roundabouts in The Netherlands. Summary article based on Schoon, CC and van Minnen, J. Accidents on roundabouts: II. Second study into the road hazard 
presented by roundabouts, particularly with regard to cyclists and moped riders. Leidschendam, The Netherlands: SWOV Institute for Road Safety Research, Report R-93-16, 1993 (in Dutch).

Seattle, City of, Engineering Department, Transportation Division. Neighborhood traffic control program - citizen requested traffic circle (city funded). Division Operating Instructions, Org. No. 3620, Policy No. 23, April 22, 1986 (Interim).

Seattle Engineering Department, Community and Transportation Services. Phinney Ridge traffic control project. May 1993, 13 pp.

Shah, B.V., Barnwell, B.G., and Bieler, G.S. SUDAAN - Software for Analysis of Correlated Data. User's Manual, Release 6.40. Research Triangle Park, NC: Research Triangle Institute, 1995.

Skene, M., Chartier, G., Erickson, D., Mack, G., and Drdul, R. Developing a Canadian guide to traffic calming. ITE Journal, 67(7), July 1997, pp. 34-37.

Snyder, M.B., and Knoblauch, R.L. The Identification of Precipitating Factors and Possible Countermeasures, Volume I and Volume II - Appendices. Silver Spring, Maryland: Operations Research, Inc. U.S. Department of Transportation Report No. FH-11-7312, January, 1971.

Streff, F.M., and Molnar, L.J. Developing policies for automated speed enforcement: a survey of Michigan opinions. Accident Analysis and Prevention, 1995, 27(4), 611-616.

Summala, H., Näätänen, R., and Roine, M. Exceptional condition of police enforcement: driving speeds during the police strike. Accident Analysis and Prevention, 12 (3), pp. 179-184, 1980.

Szplett, D., and Sale, L. Some challenges in developing neotraditional neighborhood designs. ITE Journal, 67(7), 42-46, 1997.

Tan, C.H., and Zegeer, C.V. European practices and innovations for pedestrian crossings. ITE Journal, 65(11), 24-31, 1995.

Teed, N., and Lund, A.K. The effect of laser speed-measuring devices on speed limit law enforcement in Charleston, South Carolina. Accident Analysis and Prevention, 25(4), 459-463, 1993.

Teed, N., Lund, A.K., and Knoblauch, R. The duration of speed reductions attributable to radar detectors. Accident Analysis and Prevention, 25(2), 131-137, 1993.

Traffic Advisory Unit (TAU), Department of Transport. Speed control humps. Traffic Advisory Leaflet 2/90, November 1990.

Traffic Advisory Unit (TAU), Department of Transport. $20 \mathrm{mph}$ speed limit zones. Traffic Advisory Leaflet 7/91, May 1991.

Traffic Advisory Unit (TAU), Department of Transport. $20 \mathrm{mph}$ speed limit zone signs. Traffic Advisory Leaflet 2/93, May 1993.

Traffic Advisory Unit (TAU), Department of Transport. Traffic calming regulations. Traffic Advisory Leaflet 7/93, August 1993. 
Traffic Advisory Unit (TAU), Department of Transport. Rumble devices. Traffic Advisory Leaflet 11/93, November 1993.

Traffic Advisory Unit (TAU), Department of Transport. Overrun areas. Traffic Advisory Leaflet 12/93, November 1993.

Traffic Advisory Unit (TAU), Department of Transport. Gateways. Traffic Advisory Leaflet 13/93, December 1993.

Traffic Advisory Unit (TAU), Department of Transport. Entry treatments. Traffic Advisory Leaflet 2/94, August 1994.

Traffic Advisory Unit (TAU), Department of Transport. Speed cushions. Traffic Advisory Leaflet 4/94, October 1994.

Traffic Advisory Unit (TAU), Department of Transport. "Thumps" thermoplastic road humps. Traffic Advisory Leaflet 7/94, October 1994.

Traffic Advisory Unit (TAU), Department of Transport. Horizontal deflections. Traffic Advisory Leaflet 9/94, December 1994.

Traffic Advisory Unit (TAU), Department of Transport. Traffic islands for speed control. Traffic Advisory Leaflet 7/95, November 1995.

Traffic Advisory Unit (TAU), Department of Transport. $75 \mathrm{~mm}$ high road humps. Traffic Advisory Leaflet 2/96, April 1996.

Traffic Advisory Unit (TAU), Department of Transport. Highways (road humps) regulations 1996. Traffic Advisory Leaflet 7/96, June 1996.

Traffic Advisory Unit (TAU), Department of Environment, Transport, and the Regions (DETR). Chicane schemes. Traffic Advisory Leaflet 12/97, December 1997.

Traffic Advisory Unit (TAU), Department of Environment, Transport, and the Regions (DETR). Speed cushion schemes. Traffic Advisory Leaflet 1/98, February 1998.

Transportation Research Board. 55: A decade of experience. Special Report 204, National Research Council, 1984.

Vaa, T. Increased police enforcement: effects on speed. Accident Analysis and Prevention, 1997, 29(3), 373-385.

Vaa, T., Christensen, P., and Ragnøy, A. Politiets fartskontroller: Virkning på fart og subjectiv oppdagelsesrisiko ved ulike overvåkingsnivåer. TØI rapport no. 301/1995. Transportøkonomisk institutt (TØI), Oslo (in Norwegian with English abstract).

Van Loesbroek, W.A.J.M. Traffic safety and environmental quality: The Dutch experience. Paper presented at Transportation Research Board 76th Annual Meeting, January 1997, Washington DC.

Verra, O. Welcome to emission control; Athens' solution to traffic pollution. Traffic Technology International, Annual Review '98, 1998, 68-70. 
Von Borstel, E. Controlling neighborhood traffic. APWA Reporter, November 1985, 14-15, 32.

Wallwork, M.J., and Burden, D. Traffic calming devices. Walkable Communities, Inc. Slides to support group presentations, 1998.

Walter, C.E. Suburban residential traffic calming. ITE Journal, September 1995, 65(9), 44-48.

Walz, F.H., Hoefliger, M., and Fehlmann, W. Speed Limit Reduction from 60 to $50 \mathrm{Km} / \mathrm{H}$ and Pedestrian Injuries. Proceedings of the Twenty-Seventh Stapp Car Crash Conference, October 17-19, 1983 San Diego, California. SAE Technical Paper 831625. 1983. pp. 311-318.

Wazana, A., Krueger, P., Raina, P., and Chambers, L. A review of risk factors for child pedestrian injuries: are they modifiable? Injury Prevention, 1997(3), 295-304.

Webster, D.C. The grounding of vehicles on road humps. Simpson Drewett and Co. Ltd., 70 Sheen Road, Richmond, Surrey, UK: Traffic Engineering + Control, July/August 1993a, 3 pp.

Webster, D.C. Road humps for controlling vehicle speeds. Crowthorne, Berkshire, UK: TRL, Project Report 18, 1993 b.

Webster, D.C. Speeds at 'thumps' and low height road humps. Crowthorne, Berkshire, UK: TRL, Project Report 101, 1994.

Webster, D.C. Traffic calming - vehicle-activated speed limit reminder signs. Crowthorne, Berkshire, UK: TRL, Report 177, 1995.

Webster, D.C. Traffic calming - public attitude studies: A literature review. Crowthorne, Berkshire, UK: TRL, Report 311, 1998.

Webster, D.C., and Layfield, R.E. Traffic calming - road hump schemes using $75 \mathrm{~mm}$ high humps. Crowthorne, Berkshire, UK: TRL, Report 186, 1996.

Wellar, B. Using the walking security index (WSI) to evaluate traffic calming needs, initiatives, and outcomes: A progress report. Paper presented at the 76th Annual Meeting, Transportation Research Board, Washington DC, January 12-16 1997a.

Wellar, B. Walking security index variables: initial specification. Interim Report 5, RMOC Project No. 912-33-409, 57 pp., November 1997b.

Wellar, B. Walking Security Index. Final Report. RMOC Project No. 912-33409, 191 pp., July 1998.

West, J., Lowe, A. Integration of transportation and land use planning through residential street design. ITE Journal, 67(8), August 1997, pp. 48, 51.

Wheeler, A.H., Abbott, P.G., Godfrey, N.S., Lawrence, D.J., and Phillips, S.M. Traffic calming on major roads: The A49 trunk road at Craven Arms, Shropshire. Crowthorne, Berkshire, UK: TRL, Report $212,1996$.

Wheeler, A.H., Abbott, P.G., Godfrey, N.S., Phillips, S.M., and Stait, R. Traffic calming on major roads: The A47 trunk road at Thorney, Cambridgeshire. Crowthorne, Berkshire, UK: TRL, Report 238, 1997. 
Wheeler, A.H., Taylor, M., and Payne, A. The effectiveness of village 'gateways' in Devon and Gloucestershire. Crowthorne, Berkshire, UK: TRL, Project Report 35, 1993.

Windle, R., and Hodge, A.R. Public attitude survey - the New Forest traffic calming programme. Crowthorne, Berkshire, UK: TRL, Project Report 14, 1993.

Windle, R., and Mackie, A.M. Survey on public acceptability of traffic calming schemes. Crowthorne, Berkshire, UK: TRL, Contractor Report 298, 1992.

Zaidel, D., Hakkert, A.S., and Pistiner, A.H. The use of road humps for moderating speeds on urban streets. Accident Analysis and Prevention, 24(1), pp. 45-56, 1992.

Zegeer, C.V.. Technical council report summary: A proposed recommended practice: Design and safety of pedestrian facilities, by ITE Technical Council Committee 5A-5. ITE Journal, March 1995, 65(3), 14.

Zegeer, C.V., Cynecki, M., Fegan, J., Lagerwey, P., Tan, C., and Works, R. Summary report on FHWA study tour for pedestrian and bicyclist safety in England, Germany, and the Netherlands. FHWA International Technology Scanning Program, Report No. FHWA-PL-95-006, October 1994, 101 pp.

Zein, S.R., Geddes, E., Hemsing, S., and Johnson, M. Safety benefits of traffic calming. Transportation Research Record No. 1578, Pedestrian and Bicycle Research, pp. 3-10, 1997. 
DOT HS 809021

October 1999 